
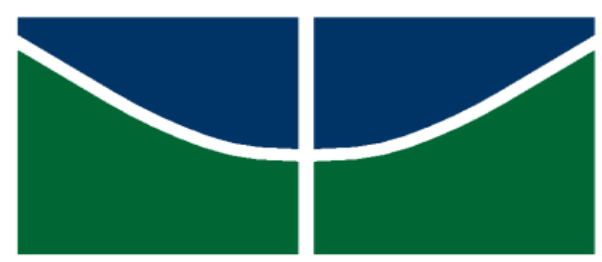

Universidade de Brasília

Instituto de Química-IQ

Programa de Pós-Graduação em Tecnologia Química e Biológica

Ana Paula Alvares

\title{
SÍNTESE E ANÁLISE FOTOFÍSICA DE HÍBRIDOS DE CUMARINAS-CHALCONAS
}

Dissertação de Mestrado

Prof. Dr. Wender Alves da Silva

BRASÍLIA-DF 
SÍNTESE E ANÁLISE FOTOFÍSICA DE HÍBRIDOS DE CUMARINASCHALCONAS.

Dissertação apresentada à Universidade de Brasília, como parte das exigências do Programa de Pós-Graduação em Tecnologia Química e Biológica, para obtenção do título de Mestre.

Orientador Prof. Dr. Wender Alves da Silva

BRASÍLIA - DF 
"Desistir ... eu já pensei seriamente nisso, mas nunca me levei realmente a sério; é que tem mais chão nos meus olhos do que cansaço nas minhas pernas, mais esperanças nos meus passos do que tristezas nos meus ombros, mais estrada no meu coração do que medo na minha cabeça" 


\section{AGRADECIMENTOS}

Primeiramente a Deus, que sempre me mostrou em todos os momentos que a fé, a coragem e Sua presença em minha vida são necessárias para que todos os meus desafios fossem superados.

Aos meus pais, Pelaio Alvares Junior e Nylza Buzatto Alvares, que me criaram e me ensinaram que caráter e respeito são os alicerces de todas as relações. A minha irmã Simone Gabriela Alvares e meu sobrinho Guilherme Alvares Lopes que souberam administrar minhas faltas e ausência em suas vidas.

Ao meu orientador Prof. Dr. Wender Alves da Silva agradeço pela orientação, disponibilidade, paciência e por me dar a oportunidade de fazer parte do seu grupo, do seu projeto e de sua vida. A todos os professores que de alguma forma fizeram parte desses anos do meu mestrado, compartilhando seus conhecimentos, mas principalmente aos professores Dr. Angelo Henrique de Lira Machado, Dr ${ }^{\mathrm{a}}$. Angélica de Fátima Silva Barreto e Dr. Rafael Oliveira Rocha.

Aos meus colegas do grupo LaPSCA e em especial ao meu querido "filho" Mathur Benedetti que me auxiliou desde do início do meu mestrado e minha querida amiga Lennine Rodrigues de Melo, que sempre reservava um tempo para me ajudar e ouvir minhas loucuras, com muito riso e choro.

Aos colegas dos laboratórios LaQMOS e LaQuiMet, principalmente a Gisele Souza pela ajuda inestimável e paciência. E aos novos e velhos amigos, especialmente Nathália Almeida, que fazem parte da minha vida e entendem de verdade minhas loucuras e minhas conquistas. 


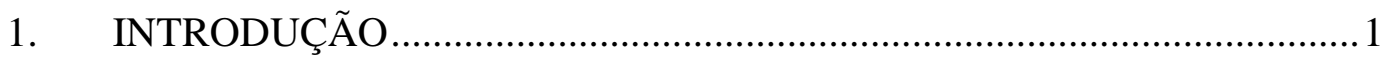

1.1 CUMARINAS …………………………………………………...

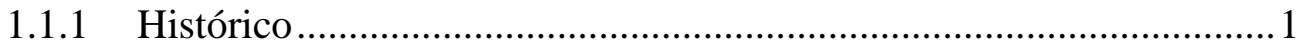

1.1.2 Síntese das cumarinas e mecanismos de reação....................................2

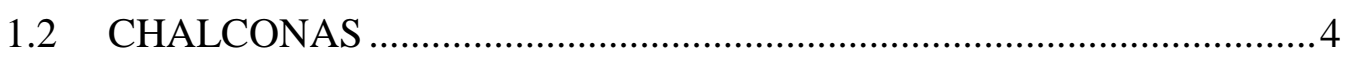

1.3 HIBRIDIZAÇÃO MOLECULAR ........................................................

1.4 ESTUDOS FOTOFÍSICOS: FLUORESCÊNCIA ……………………....10

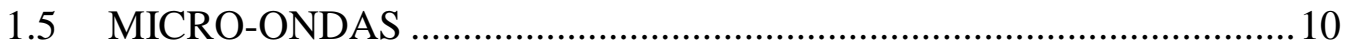

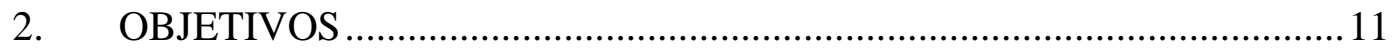

2.1 OBJETIVOS GERAIS ........................................................................

2.2 OBJETIVOS ESPECÍFICOS ………………………….......................11

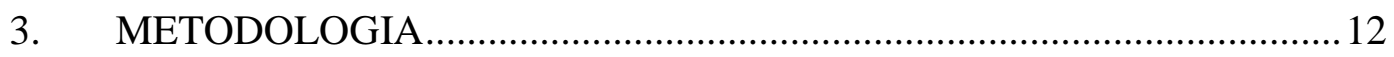

3.1 SÍNTESE DAS CUMARINAS ……………………………………....12

3.2 SÍNTESE DE HÍBRIDOS DE CUMARINAS-CHALCONAS ................12

4. RESULTADOS E DISCUSSÕES .............................................................

4.1 SÍNTESE DAS CUMARINAS …………………………………..... 13

4.2 IDENTIFICAÇÃO ESTRUTUTAL DAS CUMARINAS ……………....13

4.3 SÍNTESE DOS HÍBRIDOS DE CUMARINAS-CHALCONAS ............17

4.3.1 Obtenção dos híbridos de cumarinas-chalconas .................................19

4.4 IDENTIFICAÇÃO ESTRUTURAL DOS HÍBRIDOS DAS

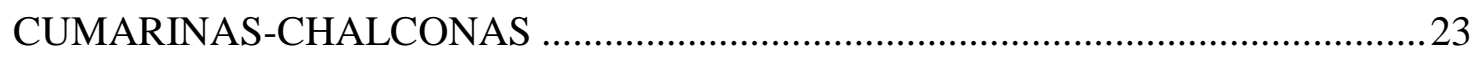

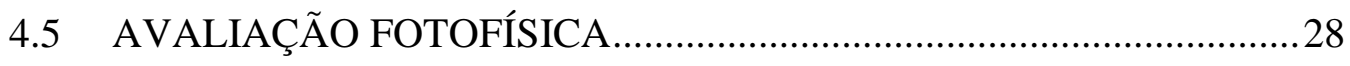

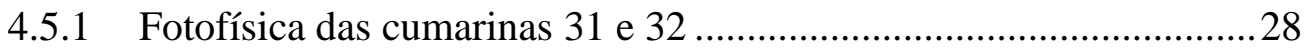

4.5.2 Fotofísica dos híbridos de cumarinas-chalconas 51 B-57 B ...............30

4.5.3 Gráficos de Lippert-Mataga para cumarinas e seus híbridos ..............32

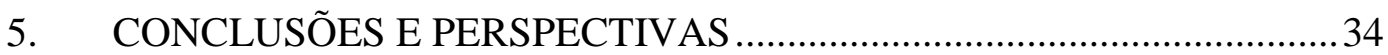

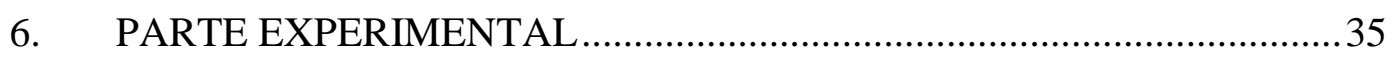

6.1 REAGENTES, SOLVENTES E EQUIPAMENTOS ...................................35

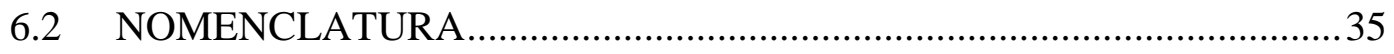

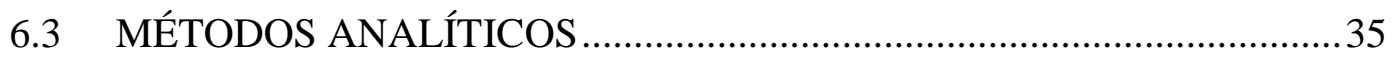

6.3.1 Ressonância Magnética Nuclear (RMN) …………………………....35

6.3.2 Espectrofotômetro: estudo fotofísico e rendimento quântico ............36

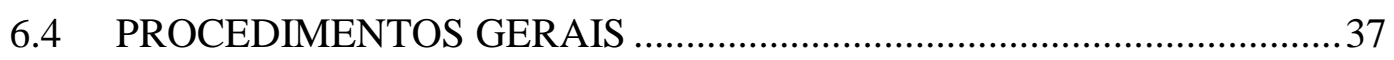


6.4.1 Procedimento geral para síntese das cumarinas 31 e 32

6.4.2 Procedimento e dados espectroscópicos das cumarinas 31 e 32 ........38

6.4.3 Procedimento geral para síntese dos híbridos de cumarinaschalconas: condição A

6.4.4 Procedimento e dados espectroscópicos do híbrido de cumarinachalcona: condição A

6.4.5 Procedimento geral para síntese dos híbridos de cumarinaschalconas: condição B 40

6.4.6 Procedimento e dados espectroscópicos dos híbridos de cumarinaschalconas: condição $\mathrm{B}$ .40

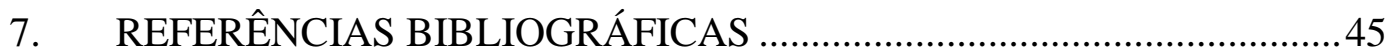

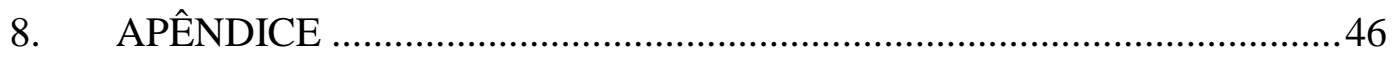

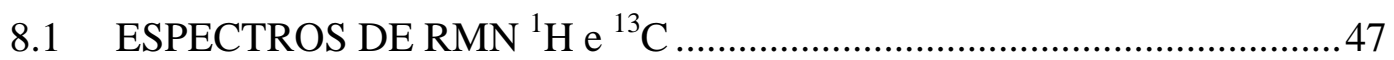

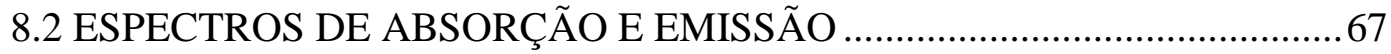

8.2.1 Espectros das cumarinas 31 e 32 ..................................................67

8.2.2 Espectros dos híbridos de cumarinas-chalconas 51 B-57 B.............69

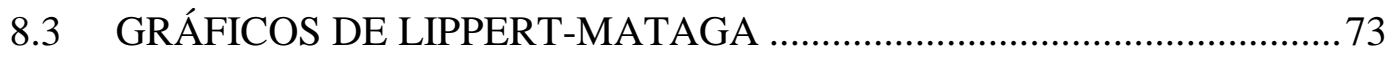

8.3.1 Gráficos das cumarinas 31 e 32 ................................................ 73

8.3.2 Gráficos dos híbridos de cumarinas-chalconas 51 B-57 B .............. 75 


\section{LISTA DE FIGURAS}

Figura 1. Flor de trevo (Melilotus Officinalis) e estrutura básica da cumarina 2-H-

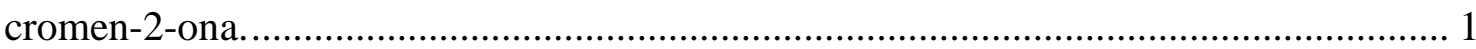

Figura 2. Estrutura básica da chalcona 1,3- diaril-2-propen-1-ona. …............................ 4

Figura 3. Esquema geral de uma chalcona CLA adaptado da referência 13................... 5

Figura 4. Diagrama de Jablonski, adaptado da referência 23....................................... 9

Figura 5. Representação esquemática de um deslocamento de Stokes em um espectro de

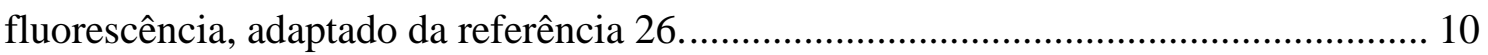

Figura 6. (A) Espectro de $\mathrm{RMN}$ de ${ }^{1} \mathrm{H}\left(600 \mathrm{MHz}, \mathrm{CDCl}_{3}\right)$ da cumarina 32 e (B)

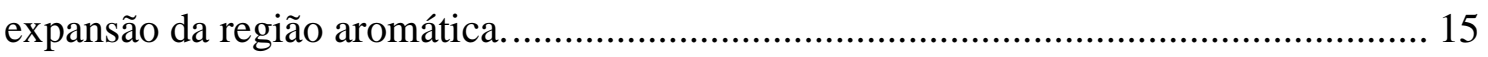

Figura 7. Espectro de $\mathrm{RMN}{ }^{13} \mathrm{C}\left(150 \mathrm{MHz}, \mathrm{CDCl}_{3}\right)$, da estrutura da cumarina $32 \ldots \ldots . .16$

Figura 8. Espectro de RMN de ${ }^{1} \mathrm{H}\left(600 \mathrm{MHz}, \mathrm{CDCl}_{3}\right)$ do híbrido $51 \mathrm{~B}$........................ 22

Figura 9. Espectro de RMN de ${ }^{13} \mathrm{C}\left(150 \mathrm{MHz}, \mathrm{CDCl}_{3}\right)$ do híbrido $51 \mathrm{~B}$...................... 23

Figura 10. (A) Espectro de RMN de ${ }^{1} \mathrm{H}\left(300 \mathrm{MHz}, \mathrm{CDCl}_{3}\right)$ do híbrido $56 \mathrm{~B}$ e (B)

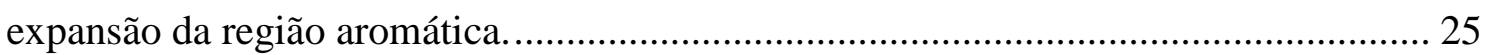

Figura 11. Espectro de $\mathrm{RMN}$ de ${ }^{13} \mathrm{C}\left(75 \mathrm{MHz}, \mathrm{CDCl}_{3}\right)$ do híbrido $56 \mathrm{~B}$........................ 27

Figura 12. Espectro de absorção (esquerda) e emissão (direita) para a cumarina 31... 28

Figura 13. Espectro de absorção (esquerda) e emissão (direita) para o híbrido 51 B. ... 30

Figura 14. Gráfico de Lippert-Mataga, da cumarina 31 (esquerda) e do híbrido 57 B

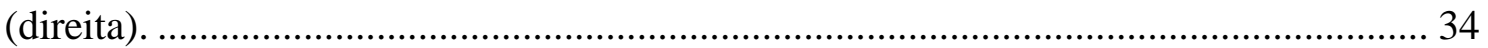




\section{LISTA DE TABELAS}

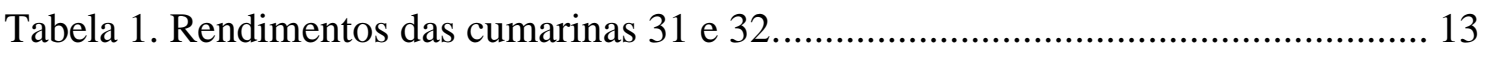

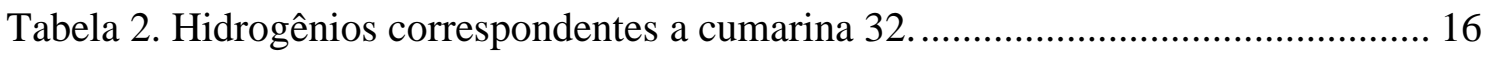

Tabela 3. Carbonos correspondentes a cumarina 32 ................................................ 17

Tabela 4. Híbridos de cumarinas-chalconas e seus respectivos rendimentos: condição A. 18

Tabela 5. Híbridos de cumarinas-chalconas e seus respectivos rendimentos: condição B.

Tabela 6. Híbrido de cumarina-chalcona sintetizado pela condição A e B.................... 21

Tabela 7. Hidrogênios correspondentes ao híbrido 51 B. .............................................. 23

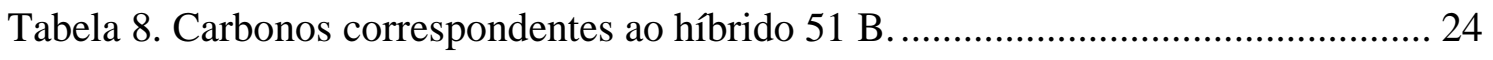

Tabela 9. Hidrogênios correspondentes ao híbrido 56 B. ........................................... 26

Tabela 10. Carbonos correspondentes ao híbrido 56 B. .............................................. 27

Tabela 11. Dados fotofísicos de comprimento de onda de absorção e emissão, deslocamento de Stokes e rendimento quântico das cumarinas 31 e 32. ....................... 29

Tabela 12. Dados fotofísicos de comprimento de onda de absorção e emissão, deslocamento de Stokes e rendimento quântico dos híbridos 51B-57B........................ 31

Tabela 13. Parâmetro de polarização de Reichardt utilizados nas aquisições dos gráficos de Lippert-Mataga, adaptado da referência 32 .......................................................... 32

Tabela 14. Dados extraídos dos gráficos de Lippert-Mataga: equação de reta e fator de

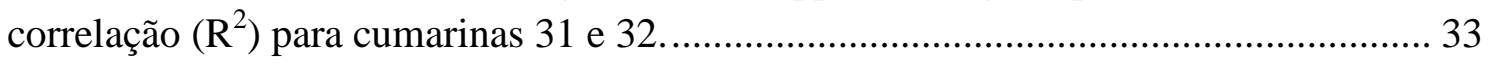

Tabela 15. Dados extraídos dos gráficos de Lippert-Mataga: equação de reta e fator de correlação $\left(\mathrm{R}^{2}\right)$ para os híbridos $51 \mathrm{~B}-57 \mathrm{~B}$. 


\section{LISTA DE ESQUEMAS}

Esquema 1. Reação de Perkin para síntese da cumarina. ................................................ 2

Esquema 2. Reação de Knoevenagel para síntese da cumarina. ....................................... 3

Esquema 3. Reação para síntese da cumarina 3-acetil-2H-cromen-2-ona. ....................... 3

Esquema 4. Mecanismo da reação de condensação de Knoevenagel para obtenção da

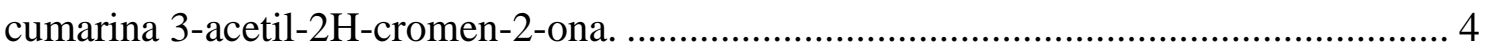

Esquema 5. Reação geral da síntese da 3-aril-1-(3-cumarina)propen-1-ona (2a-2k),

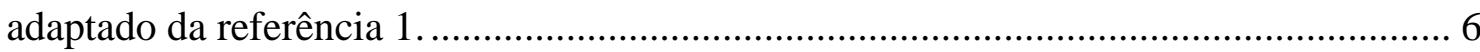

Esquema 6. Reação de síntese das cumarinas-chalconas (3a-3f), adaptado da referência 21.

Esquema 7. Esquema geral da reação de condensação aldólica de Claisen-Schmidt para o composto 3 - ((2E) -3- (2-hidroxifenil) prop-2-enol)) - 4- hidroxi-2 (H) -cromen-2ona, adaptado da referência 14 .

Esquema 8. Mecanismo da reação de condensação aldólica de Claisen-Schmidt, onde B é a base conjugada e HB é um ácido, adaptado da referência 10.................................. 8

Esquema 9. Reação de síntese dos híbridos de cumarinas-chalconas, onde (A) é a cetocumarina e (B) é o híbrido de cumarina-chalcona....................................................... 12

Esquema 10. Reação de síntese das cumarinas. ........................................................... 12

Esquema 11. (A) Síntese de híbridos de cumarinas-chalconas. Condições: $\mathrm{T}=80^{\circ} \mathrm{C} \mathrm{e}$ refluxo. (B) Síntese de híbridos de cumarinas-chalconas. Condições: $\mathrm{T}=80^{\circ} \mathrm{C}$ e micro-

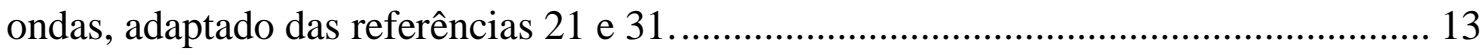

Esquema 12. Síntese dos híbridos de cumarinas-chalconas. Condições: $\mathrm{T}=80^{\circ} \mathrm{C}$ e refluxo, adaptado da referência 21 .

Esquema 13. Síntese de híbridos de cumarinas-chalconas. Condições: $\mathrm{T}=80^{\circ} \mathrm{C}$ e microondas, adaptado da referência 28 


\section{LISTA DE ACRÔNIMOS}

\begin{tabular}{|c|c|}
\hline $\mathrm{CCD}$ & Cromatografia em camada delgada \\
\hline CLA & $\begin{array}{l}\text { Chalcones Library Amide - Biblioteca de Chalconas } \\
\text { Amidas }\end{array}$ \\
\hline$D-\pi-A$ & Doador-conjugação $\pi$-aceptor \\
\hline HOMO & $\begin{array}{l}\text { Highest Occupied Molecular Orbital - Orbital } \\
\text { Molecular Ocupado mais Alto }\end{array}$ \\
\hline LUMO & $\begin{array}{l}\text { Lowest Unoccupied Molecular Orbital- Orbital } \\
\text { Não-Ocupado mais Alto }\end{array}$ \\
\hline $\mathrm{Hz}$ & Hertz \\
\hline TCI & Transferência de Carga Intramolecular \\
\hline Ppm & Parte por milhão \\
\hline $\mathrm{R}^{2}$ & Fator de correlação \\
\hline RMN & Ressonância Magnética Nuclear \\
\hline $\mathrm{RMN}{ }^{1} \mathrm{H}$ & Ressonância magnética nuclear de hidrogênio \\
\hline $\mathrm{RMN}{ }^{13} \mathrm{C}$ & Ressonância magnética nuclear de carbono \\
\hline$S_{0}$ & Estado singleto fundamental \\
\hline$S_{1}$ & Primeiro estado singleto excitado \\
\hline $\mathrm{S}_{2}$ & Segundo estado singleto excitado \\
\hline $\mathrm{T}_{1}$ & Primeiro estado tripleto excitado \\
\hline UV-Vis & Espectroscopia no ultravioleta visível \\
\hline$\Lambda$ & Comprimento de onda \\
\hline$\Delta$ & Deslocamento químico \\
\hline$\Phi$ & Rendimento quântico \\
\hline $\mathbf{J}$ & Constante de acoplamento \\
\hline
\end{tabular}




\section{RESUMO}

O desenvolvimento de novas rotas sintéticas para a obtenção de derivados de cumarinas é de fundamental importância para ciência, tendo em vista a vasta aplicação destes compostos no cotidiano, que vai desde a utilização em fármacos e perfumes até a mais alta tecnologia como, por exemplo em sondas fluorescentes. Diante desses aspectos, esse trabalho buscou sintetizar e realizar estudos fotofísicos de dois grupos de híbridos de cumarinas-chalconas, do qual o primeiro partiu da cumarina 3-acetil-2H-cromen-2ona e resultou na síntese de cinco moléculas e o segundo grupo partiu da cumarina 3acetil-7-dietilamino-2H-cromen-2-ona e originou duas moléculas. As estruturas dos compostos sintetizados foram devidamente caracterizadas através de análises realizadas por ressonância magnética nuclear (RMN) e as avaliações das propriedades fotofísicas foram realizadas utilizando técnicas de espectrofotometria (absorção) e espectrofluorimetria (emissão). Posteriormente, outros parâmetros como: deslocamento de Stokes, de Lipert-Mataga e rendimentos quânticos também foram calculados. Esses parâmetros foram determinados para mostrar as interações entre as moléculas dos solventes e dos fluoróforos sintetizados. 


\begin{abstract}
The development of new synthetic routes for obtaining coumarin derivatives is of fundamental importance for science, based on the wide application of these compounds in daily life, ranging from the use in drugs and perfumes to the highest technology such as fluorescent probes. Given these aspects, this study aimed to synthesize and perform photophysical studies of two groups of coumarins-chalcones hybrid, which the first group started from the coumarin-3-acetyl-2H-chromen-2-one and resulted in the synthesis of five molecules and the second group initiated from coumarin 3diethylamino-7-acetyl-2H-chromen-2-one and produced two molecules. The structures of the synthesized compounds were properly characterized by nuclear magnetic resonance (NMR) analysis and the evaluation of their photophysical properties was performed using spectrophotometry (absorption) and spectrofluorimetry (emission) methods. Subsequently, other parameters such as the Stokes shift, Lipert Mataga and quantum yields were also calculated. These parameters were determined to show the interactions between the solvents molecules and the synthesized fluorophores molecules.
\end{abstract}




\section{INTRODUÇÃO}

As cumarinas são compostos que têm uma papel especial na natureza e chamam a atenção da comunidade científica pois apresentam interessantes atividades biológicas e farmacológicas. Os derivados de cumarinas têm sido relatados por apresentarem atividades anticoagulantes, antibacterianas, anti-inflamatórias, antioxidantes e anticancerígenos. $^{1,2,3}$

As chalconas são cetonas $\alpha, \beta$-insaturadas, o que as tornam biologicamente ativas. Dependendo do padrão de substituição nos anéis aromáticos, uma grande variedade de atividades farmacológicas podem ser identificadas, e isso é facilmente evidenciado pelo grande número de publicações e foco de estudo em inúmeros grupos de pesquisa. ${ }^{1}$

Uma importante ferramenta sintética é a hibridização molecular entre compostos biologicamente ativos ou com unidades farmacofóricas pré-estabelecidas para produzirem novas moléculas com efeito farmacológico desejado. Diante das possibilidades de uso e aplicações das cumarinas e das chalconas, estudos são constantemente realizados para utilizar esses compostos para tal finalidade. ${ }^{4}$

\subsection{CUMARINAS}

\subsubsection{Histórico}

Em 1820, ocorreu o primeiro relato que uma cumarina foi isolada de flores de trevo (Melilotus Officinalis) e de sementes de cumaru, por Vogel. ${ }^{4}$
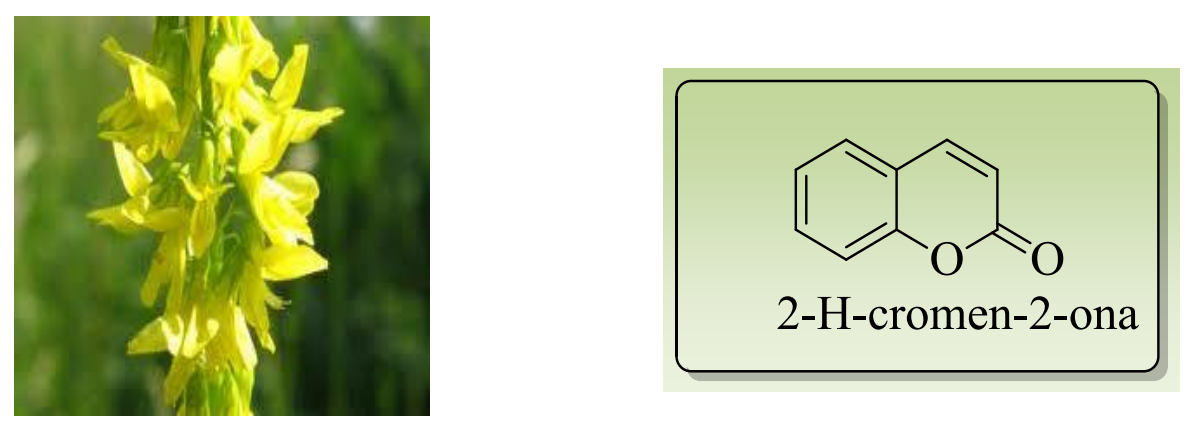

Figura 1. Flor de trevo (Melilotus Officinalis) e estrutura básica da cumarina 2-H-cromen-2ona.

A cumarina é um princípio ativo natural que pode ser encontrado em diversas frutas e plantas. Mais de 1400 cumarinas foram identificadas em fontes naturais; como: vegetais, fungos e bactérias. Elas são encontradas principalmente nas famílias Asteraceae, Fabaceae, Lamiaceae, Moraceae, Poaceae Thymeleaceae, Umbelliferae 
Apiaceae e Rutaceae. E sua concentração é maior em raízes, sementes e frutos e em geral, seu aroma é similar ao da baunilha. ${ }^{4}$

Cumarinas são lactonas do ácido $o$-hidroxi-cinâmico e constituem uma classe de metabólicos secundários. ${ }^{1}$

As cumarinas apresentam propriedades anti-inflamatórias, anticoagulantes, antibióticas, antioxidantes, imunomodulatórias, antiviral, antimicrobianas e broncodilatadoras. Deste modo, são aplicadas na medicina no tratamento de doenças como: câncer, queimaduras, linfoedemas e doenças reumáticas. As cumarinas também são utilizadas na indústria de alimentos como: corantes, essências e em bebidas alcoólicas e na indústria de cosméticos, como fixador de perfumes e em pastas de dentes. ${ }^{4}$

A classe das cumarinas possui diversas aplicações tecnológicas e tem despertado o interesse de muitos pesquisadores na área de novos materiais como: corantes, pigmentos, branqueadores ópticos, lasers, dispositivos de armazenamento de dados ópticos, corantes sensibilizadores de células solares, entre outros. ${ }^{5}$

\subsubsection{Síntese das cumarinas e mecanismos de reação}

Existem diferentes métodos de síntese para obtenção das cumarinas e sua escolha dependerá do padrão de substituição desejado. Algumas metodologias são baseadas nas seguintes reações: Perkin ${ }^{6}$, Reformastsky $^{7}$, Knoevenagel $^{8}$, Pechmann $^{9}$, Wittig $^{10}$

Destas, se destacam duas metodologias, a primeira envolve a reação de Perkin ${ }^{6}$, a qual consiste na formação de cumarinas por condensação aldólica. A reação ocorre adicionando o salicilaldeído e anidrido acético na presença de um sal alcalino (Esquema $1)$.<smiles>O=C(O)c1ccccc1O</smiles>

Salicilaldeído

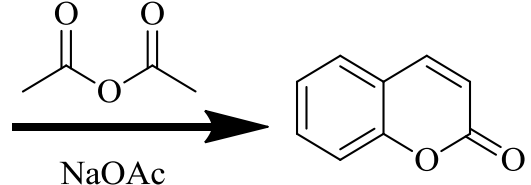

2-H-cromen-2-ona

Esquema 1. Reação de Perkin para síntese da cumarina. 
A segunda metodologia para a síntese de cumarinas se dá pela condensação de Knoevenagel. Normalmente a reação é catalisada por bases fracas ou por combinações adequadas de aminas e ácidos carboxílicos ou ainda ácidos de Lewis ${ }^{8}$ (Esquema 2).

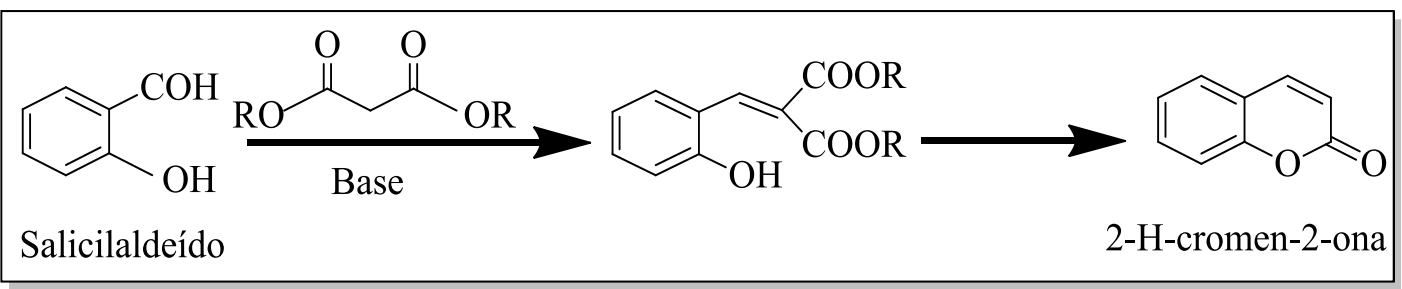

Esquema 2. Reação de Knoevenagel para síntese da cumarina.

No caso específico desse projeto, a síntese de cumarinas com substituição acetil na posição 3 se dá satisfatoriamente através da condensação de Knoevenagel, conforme Esquema 3.

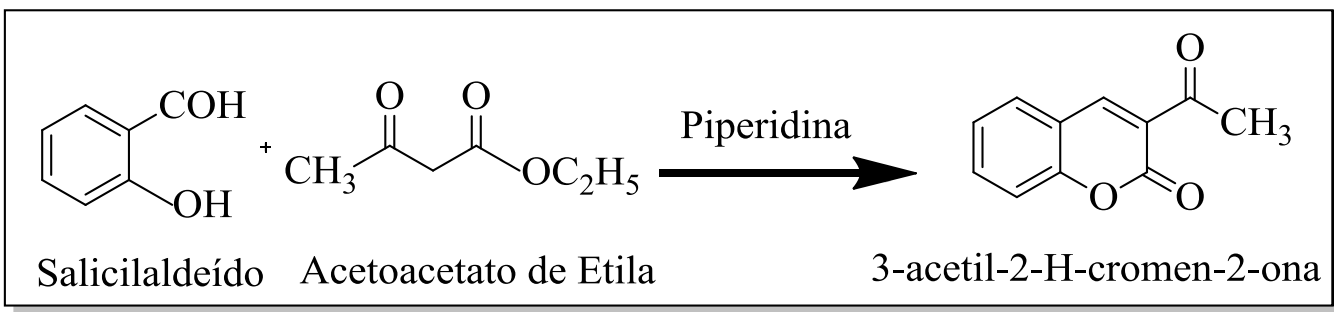

Esquema 3. Reação para síntese da cumarina 3-acetil-2H-cromen-2-ona.

O mecanismo da reação de condensação de Knoevenagel $^{8}$ em meio básico é conhecido, como representado no Esquema 4. Envolve primeiramente a formação do íon imínio entre o salicilaldeído e a amina secundária (piperidina). Posteriormente o hidrogênio $\alpha$-carbonílico do acetoacetato de etila é abstraído por outra molécula de piperidina, originando um bom nucleófilo, que ataca o carbono eletrofílico do íon imínio. Em seguida, os pares de elétrons da hidroxila na posição orto adicionam na carboxila do éster, levando a formação do anel lactônico. E por último, a base que está no meio remove o hidrogênio $\alpha$-carbonílico levando à eliminação da piperidina e formação da cumarina. 


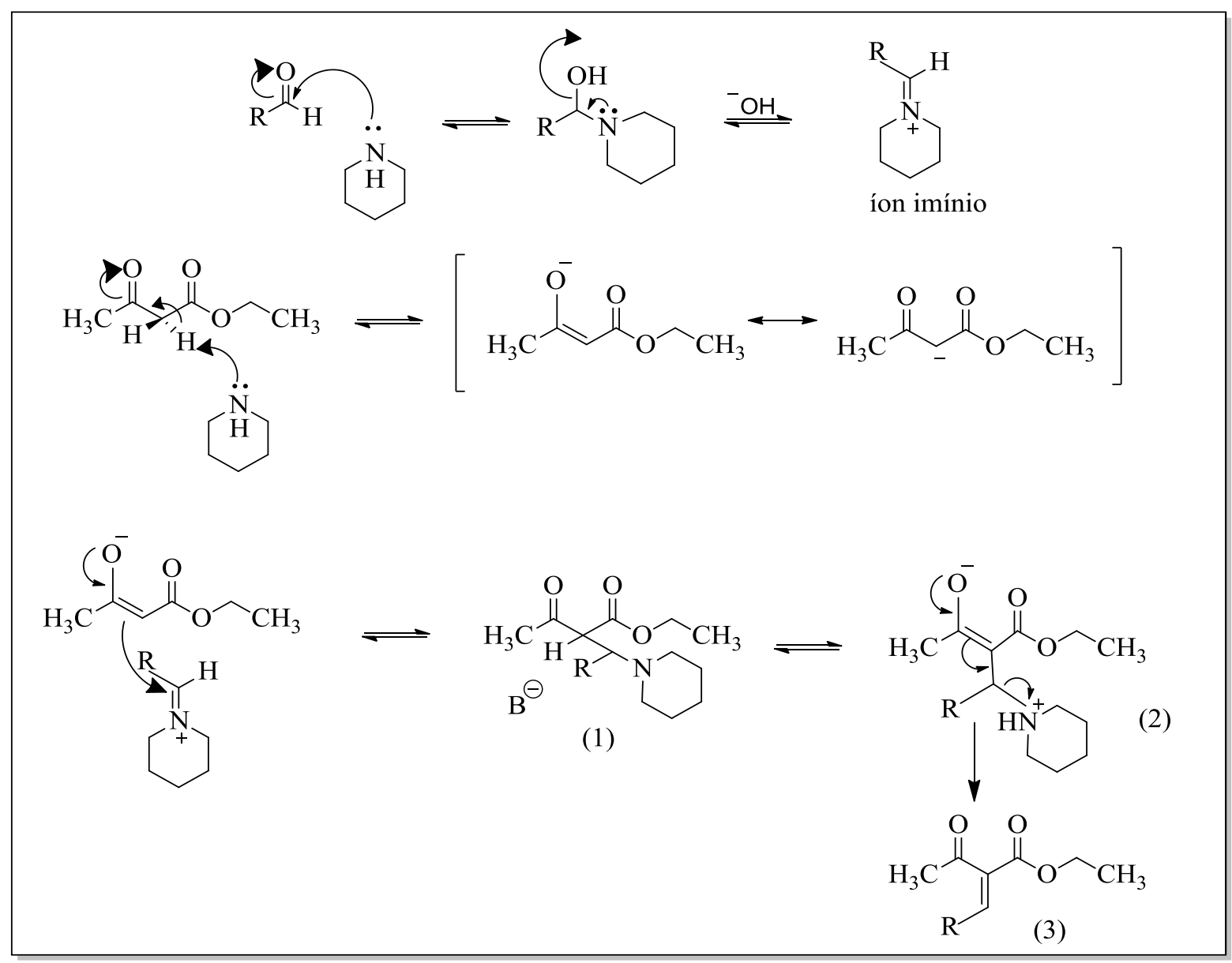

Esquema 4. Mecanismo da reação de condensação de Knoevenagel para obtenção da cumarina 3-acetil-2H-cromen-2-ona.

\subsection{CHALCONAS}

Chalconas são cetonas $\alpha, \beta$-insaturadas que apresentam o núcleo 1,3-diaril-2-propen-1ona como demonstrado na Figura 2. São compostos precursores de flavonóides e isoflavonóides na natureza, encontradas largamente nos vegetais, principalmente nas pétalas das flores e são conhecidas por possuírem várias atividades biológicas. ${ }^{11,12}$<smiles>O=C(/C=C/c1ccccc1)c1ccccc1</smiles>

\section{1,3- diaril-2-propen-1-ona}

Figura 2. Estrutura básica da chalcona 1,3- diaril-2-propen-1-ona. 
Além de suas aplicações medicinais, as propriedades fotofísicas e fotoquímicas das chalconas têm despertado um grande interesse científico, porque a compreensão de seus mecanismos e tais propriedades ainda é desafiador. Muitos derivados de chalconas exibem atraentes propriedades fotofísicas, como por exemplo: altos rendimentos quânticos, estabilização em processos de transferência de carga no estado excitado sendo assim aplicadas em diferentes áreas da ciência como biologia (marcadores celulares) ou desenvolvimento de novos materiais (fotônica). ${ }^{13,14,15}$

Moléculas que apresentam o fenômeno push-pull ou D- $\pi$-A possuem sistemas conjugados, onde as substituições nesses sistemas são formadas por grupos doadores de elétrons (D) e grupos aceptores de elétrons (A) que estão conectadas através da conjugação $\pi$. Esse tipo de fenômeno, somado a influência da transferência intramolecular de carga, elucida a fluorescência das chalconas e seus derivados. ${ }^{14,16,17}$

A estrutura básica da chalcona conduz, naturalmente, à ideia de uma arquitetura de doador-aceptor-doador. Dessa maneira, é de se esperar uma eficiente transferência intramolecular de carga, particularmente com grupos doadores de elétrons, ligados aos anéis aromáticos. ${ }^{14,15}$

Para elucidar a importância do fenômeno push-pull, destaca-se o trabalho de Lee e colaboradores que propuseram um novo acervo de chalconas amidas (CLA). A ideia foi sintetizar novas chalconas, com substituições no anel aromático com grupos amida e amina. Esses grupos por serem doadores de elétrons, aumentariam a intensidade de fluorescência da molécula conforme mostrado na Figura $3{ }^{13}$

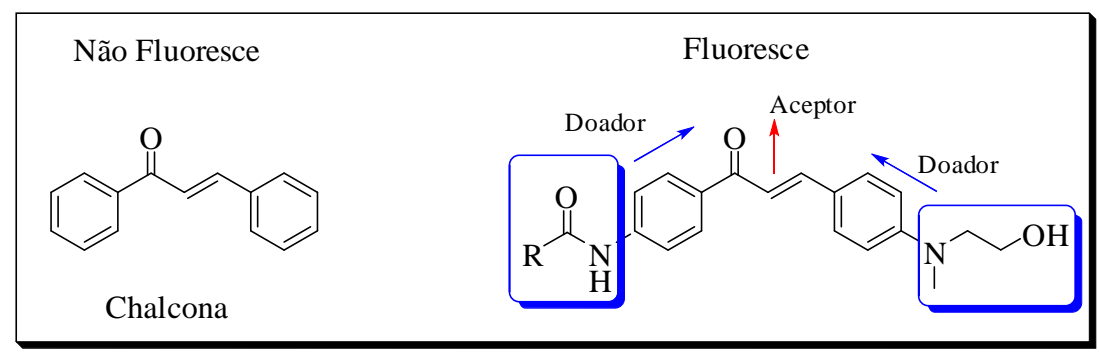

Figura 3. Esquema geral de uma chalcona CLA adaptado da referência 13.

\subsection{HIBRIDIZAÇÃO MOLECULAR}

A resistência de organismos patogênicos aos fármacos atuais tem estimulado o desenvolvimento de novas drogas e se tornou um desafio para químicos orgânicos e 
farmacêuticos. Uma estratégia que vem sendo utilizada para ajudar a resolver esse problema é a hibridização molecular. ${ }^{18,19}$

O processo de hibridização molecular busca reunir em um mesmo composto, por meio de ligações covalentes, diferentes grupos farmacofóricos com a finalidade de potencializar suas atividades. ${ }^{18,19,20}$

Diante desse contexto, destaca-se o trabalho de Mahajan e colaboradores, ${ }^{1}$ que em 2011, desenvolveram um estudo de hibridização molecular, onde combinaram duas moléculas potentes, uma cumarina e uma chalcona. A ideia desse trabalho foi sintetizar híbridos de cumarinas-chalconas e utilizá-los contra micróbios patogênicos. Esse artigo também relata essas sínteses sendo realizadas por micro-ondas, o qual, nas últimas décadas, tem sido prática comum nos laboratórios de química e biologia. Estudos relatam que o uso do micro-ondas é um método de ativação eficiente e não poluente. ${ }^{1}$

O método geral utilizado para realizar a síntese desses híbridos de cumarinaschalconas, foi a condensação de Knoevenagel, conforme apresentado no Esquema 5. Essas reações quando sintetizadas por refluxo convencional apresentaram rendimentos entre 41 e $70 \%$ e o intervalo de tempo de reação foi de 4 a 12 horas e quando sintetizadas utilizando micro-ondas apresentaram rendimentos entre 45 e $78 \%$ e o intervalo de tempo de reação foi de 20 a 145 min.

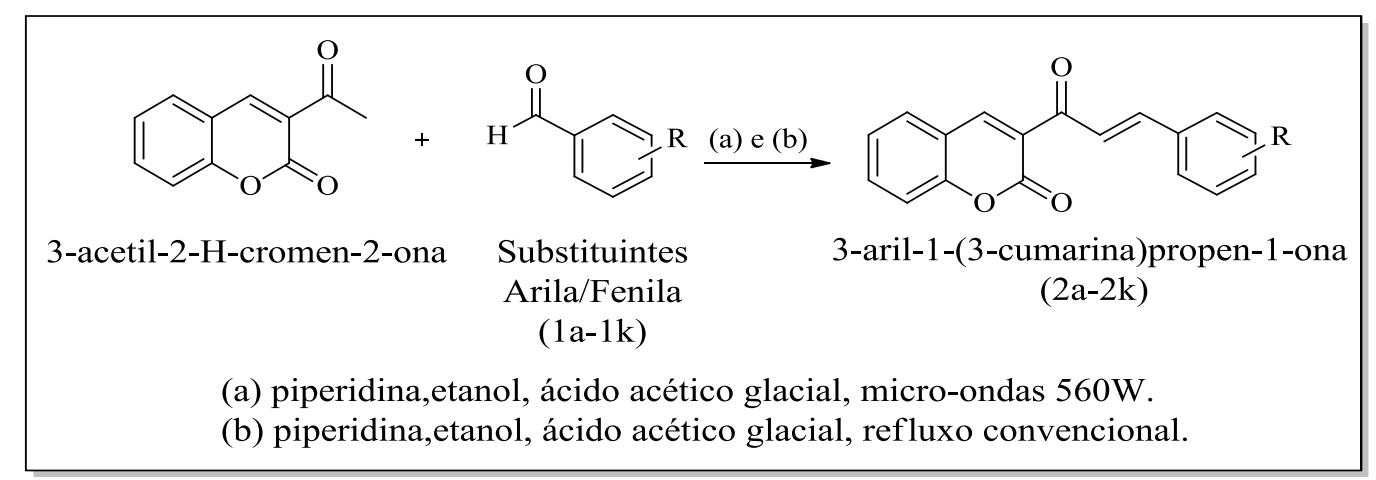

Esquema 5. Reação geral da síntese da 3-aril-1-(3-cumarina)propen-1-ona (2a-2k), adaptado da referência 1 .

Outro trabalho relevante é de Jagtap e colaboradores. A proposta desse trabalho foi preparar derivados heteroaromáticos, com especial interesse em cumarinas fluorescentes. A ideia surgiu quando identificaram um derivado de cumarina, com a estrutura 1,4-dietil-1,2,3,4-tetrahidroquinoxalina, o qual apresentava boa fluorescência, um efeito batocrômico pronunciado e boa estabilidade térmica. ${ }^{21}$ 
Para estender o estudo de compostos altamente fluorescentes, combinaram um dos derivados a 8-acetil-1,4-dietil-1, 2, 3, 4-tetra-hidro-7H-pirano [2,3-g] quinoxalina-7ona com vários tipos de aldeídos aromáticos (2a-2f), para sintetizar derivados de cumarinas-chalconas (3a-3f) através de reações de condensação aldólica clássica como mostrado no Esquema $6 .^{21}$

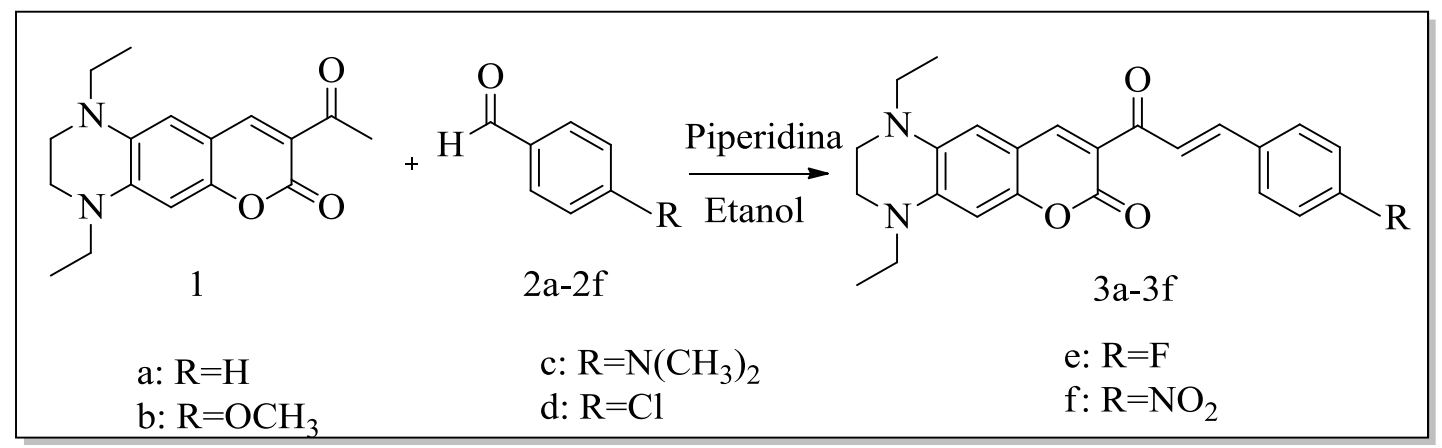

Esquema 6. Reação de síntese das cumarinas-chalconas (3a-3f), adaptado da referência 21.

Para obter as cumarinas-chalconas (3a-3f), uma mistura de 8-acetil-1,4-dietil1,2, 3,4-tetra-hidro-7H-pirano [2,3-g] quinoxalina-7-ona e um aldeído aromático foram aquecidos sob refluxo em etanol absoluto e uma quantidade catalítica de piperidina. ${ }^{21}$

Por fim, cito o trabalho de Ghouili e colaboradores ${ }^{14}$, no qual foi sintetizado o seguinte híbrido: 3 - ((2E) -3- (2-hidroxifenil) prop-2-enol)) - 4- hidroxi-2 (H) -cromen2-ona, através de reação de condensação aldólica de Claisen-Schmidt. Foi utilizada uma mistura da cumarina 3-acetil-hidroxicumarina com o aldeído aromático 2hidroxibenzaldeído, o solvente usado foi o clorofórmio e a piperidina como catalisador, conforme o Esquema 7.

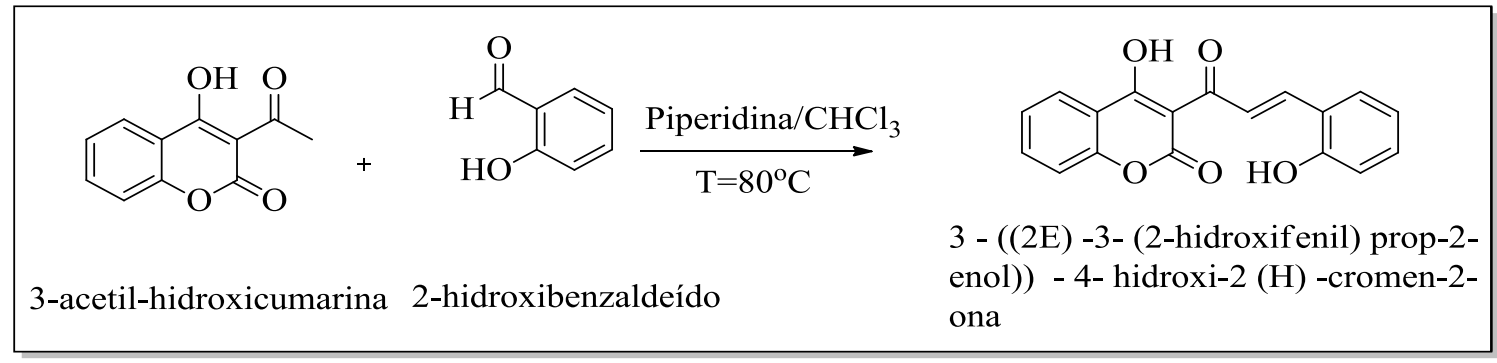

Esquema 7. Esquema geral da reação de condensação aldólica de Claisen-Schmidt para o composto 3 - ((2E) -3- (2-hidroxifenil) prop-2-enol)) - 4- hidroxi-2 (H) -cromen-2-ona, adaptado da referência 14.

O mecanismo da reação de condensação aldólica de Claisen Schmidt em meio básico é conhecido, como descrito no Esquema 8. Primeiramente, a base (B') 
desprotona o hidrogênio $\alpha$-carbonílico da cetona (1) formando o íon enolato (2), que será o nucleófilo da reação. O qual, ao ter a carbonila regenerada ataca o aldeído formando o composto 3 que está em equilíbrio com sua forma aldólica 4 . A base presente no meio retira o hidrogênio ácido no composto $\mathbf{5}$, formando a espécie indicada em 6 que, por mecanismo $\mathrm{E}_{1} \mathrm{CB}$, forma o composto $\alpha, \beta$-insaturado (7). ${ }^{10}$

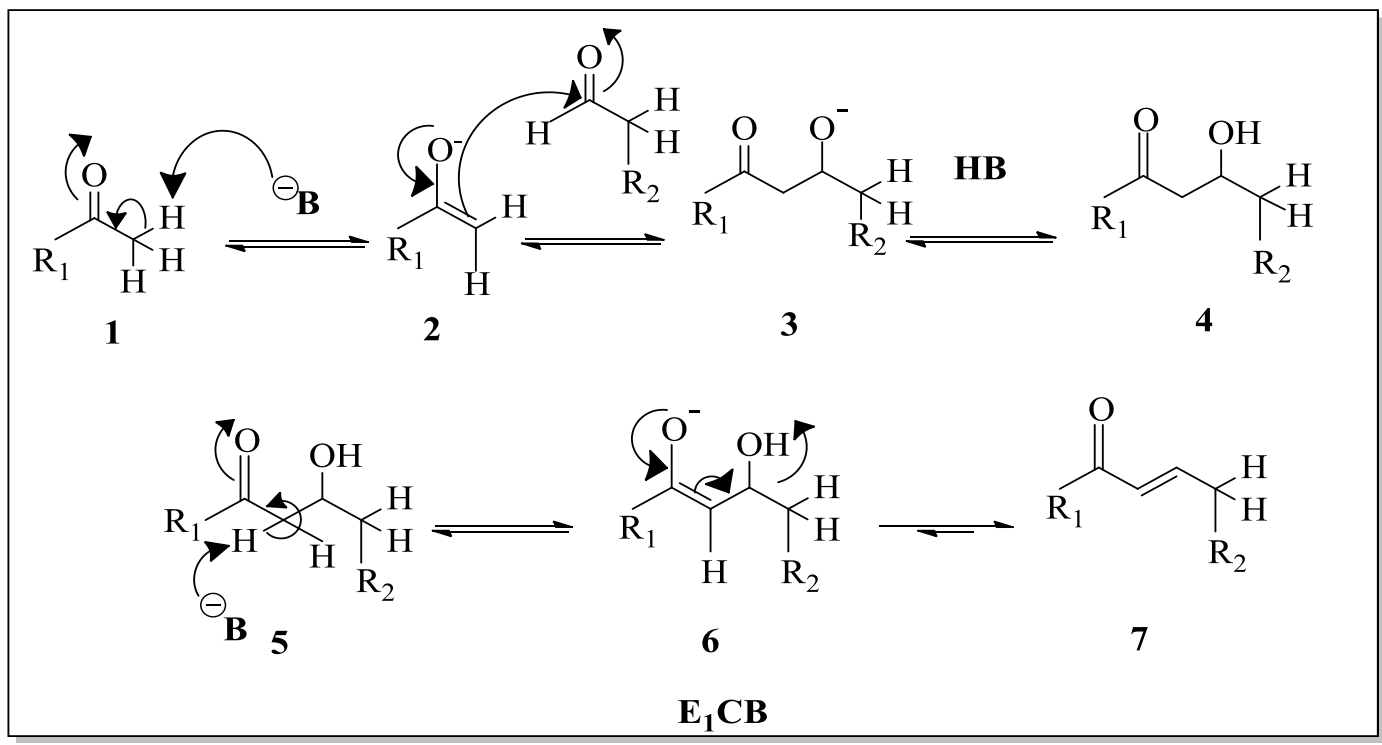

Esquema 8. Mecanismo da reação de condensação aldólica de Claisen-Schmidt, onde B é a base conjugada e HB é um ácido, adaptado da referência 10.

\subsection{ESTUDOS FOTOFÍSICOS: FLUORESCÊNCIA}

Os processos radiativos são geralmente classificados como fenômenos de luminescência, que ocorrem a partir de estados eletronicamente excitados. A fluorescência é um processo de fotoluminescência, no qual os átomos ou moléculas são excitados pela absorção de um feixe de radiação eletromagnética. A velocidade de fluorescência é tipicamente da ordem de $10^{8} \mathrm{~s}^{-1} .^{22}$

A espécie que foi excitada relaxa para um estado fundamental e fornece seu excesso de energia na forma de fótons. A Figura 4 mostra o diagrama de Jablonski, onde $S_{0}, S_{1}, S_{2}, T_{1}$ são respectivamente: estado fundamental simpleto, primeiro estado singleto excitado, segundo estado singleto excitado e o primeiro estado tripleto excitado. A transição $S_{1 \rightarrow S_{0}}$ é o fenômeno de fluorescência. ${ }^{22,23,24}$ 


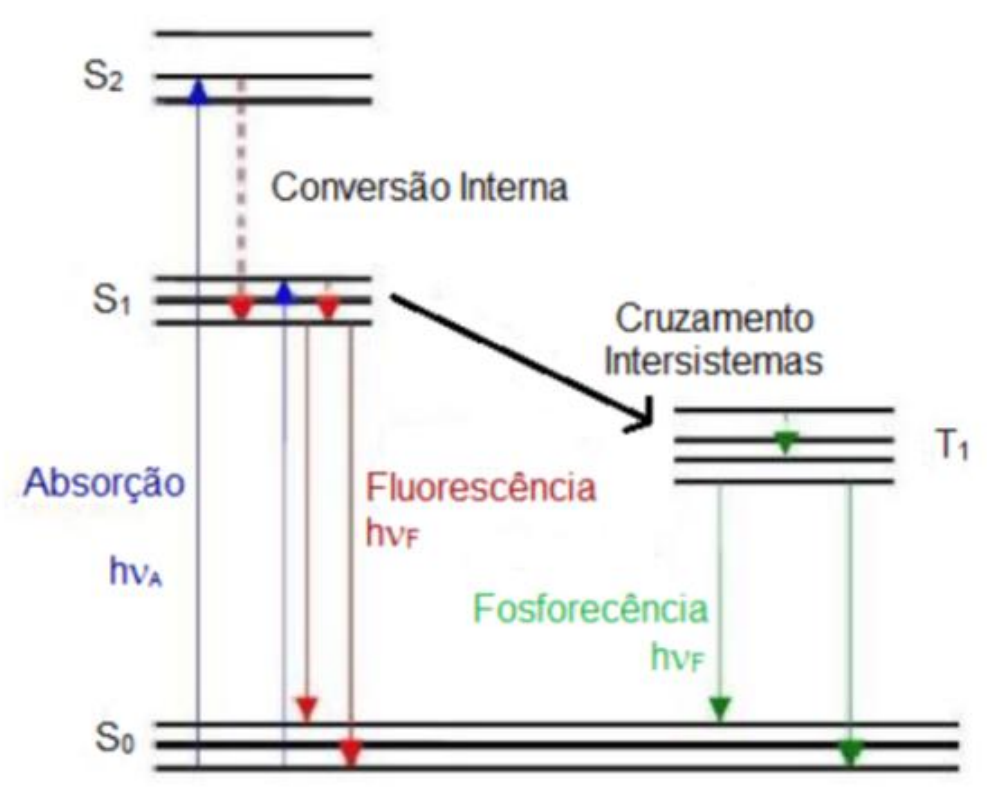

Figura 4. Diagrama de Jablonski, adaptado da referência 23.

As transições não-radiativas envolvem a conversão de um estado eletrônico mais energético para o estado fundamental, sem emissão de radiação eletromagnética. Apesar de todas as transições que não geram emissão de luz serem não-radiativas, incluindo a perda de energia por interações particulares com o solvente, o termo não radiativo é usado preferencialmente para indicar processos intramoleculares. ${ }^{22,25}$

Existem dois tipos de relaxação não radiativa, a primeira é a relaxação vibracional que é observada nos níveis vibracionais e ocorre durante as colisões entre as moléculas excitadas e as moléculas dos solventes, e a segunda é a conversão interna que ocorre entre o nível vibracional mais baixo do estado eletrônico excitado e o nível vibracional superior de outro estado eletrônico. ${ }^{22}$

É importante destacar que existem outros parâmetros que devem ser avaliados para se ter certeza da eficiência da fluorescência de um determinado composto. Para o cálculo dessa eficiência normalmente se usa o deslocamento de Stokes e o rendimento quântico.

O deslocamento de Stokes é definido como a diferença entre os comprimentos de onda em que se encontram os picos de absorção e emissão. Normalmente o pico de emissão é uma imagem espelhada ao pico de absorção, ou seja, tem perfis semelhantes e intensidade de absorção da mesma grandeza, com modificações relevantes apenas no comprimento de onda (Figura 5). Isso ocorre porque os níveis vibracionais no estado fundamental são parecidos aos do estado excitado. ${ }^{22,26}$ 


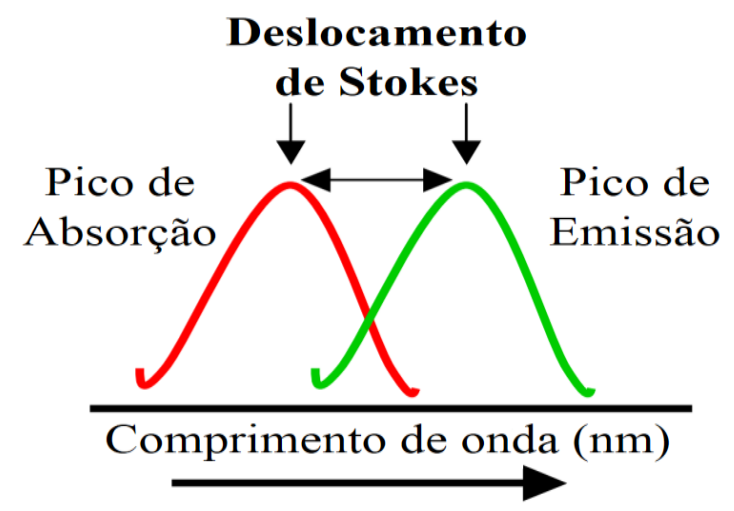

Figura 5. Representação esquemática de um deslocamento de Stokes em um espectro de fluorescência, adaptado da referência 26.

Outro parâmetro utilizado é o rendimento quântico $(Q)$ que é definido em função do caminho de relaxação preferencial. Pode-se definir o rendimento quântico como sendo a razão entre os fótons emitidos $(f E)$ e os fótons absorvidos $(f A)$, ou seja, é a razão entre o número de moléculas que fluorescem e o número total de moléculas excitadas. $^{22}$

$$
(Q)=(f E) /(f A)
$$

\subsection{MICRO-ONDAS:}

Uma micro-onda é uma forma de energia eletromagnética. A energia de micro-onda consiste em um campo elétrico e um campo magnético, embora apenas o campo elétrico transfira energia para aquecer a substância. A interação do campo magnético normalmente não ocorre em sínteses químicas. ${ }^{27}$

$\mathrm{O}$ aquecimento por micro-ondas ocorre através da interação das micro-ondas diretamente com as moléculas que estão presentes na reação, levando a um aumento rápido da temperatura. Quando ocorre a excitação das moléculas, o efeito de absorção de microondas é puramente cinético. ${ }^{27}$

$\mathrm{Na}$ área de química orgânica a utilização de equipamento de micro-ondas para a realização dessas sínteses tem como intuito melhorar o tempo reacional e os seus rendimentos, outra vantagem seria a possibilidade dessas reações serem feitas sem solventes, gerando um menor desperdício de reagentes, menor decomposição térmica e maior seletividade. ${ }^{28,29}$ 


\section{OBJETIVOS}

\section{$2.1 \quad$ OBJETIVOS GERAIS}

Este trabalho teve como objetivos a síntese e a avaliação das propriedades fotofísicas dos híbridos de cumarinas-chalconas.

\subsection{OBJETIVOS ESPECÍFICOS}

- Síntese e caracterização das ceto-cumarinas.

- Síntese e caracterização dos híbridos de cumarinas-chalconas derivadas das ceto-cumarinas.

- Avaliação dos parâmetros fotofísicos das ceto-cumarinas e de seus híbridos. 


\section{METODOLOGIA}

Para sintetizar os híbridos de cumarinas-chalconas, as ceto-cumarinas foram produzidas através de reação de condensação do tipo Knoevenage ${ }^{10}$ e posteriormente, foram combinadas com aldeídos aromáticos, conforme representado no Esquema 9.

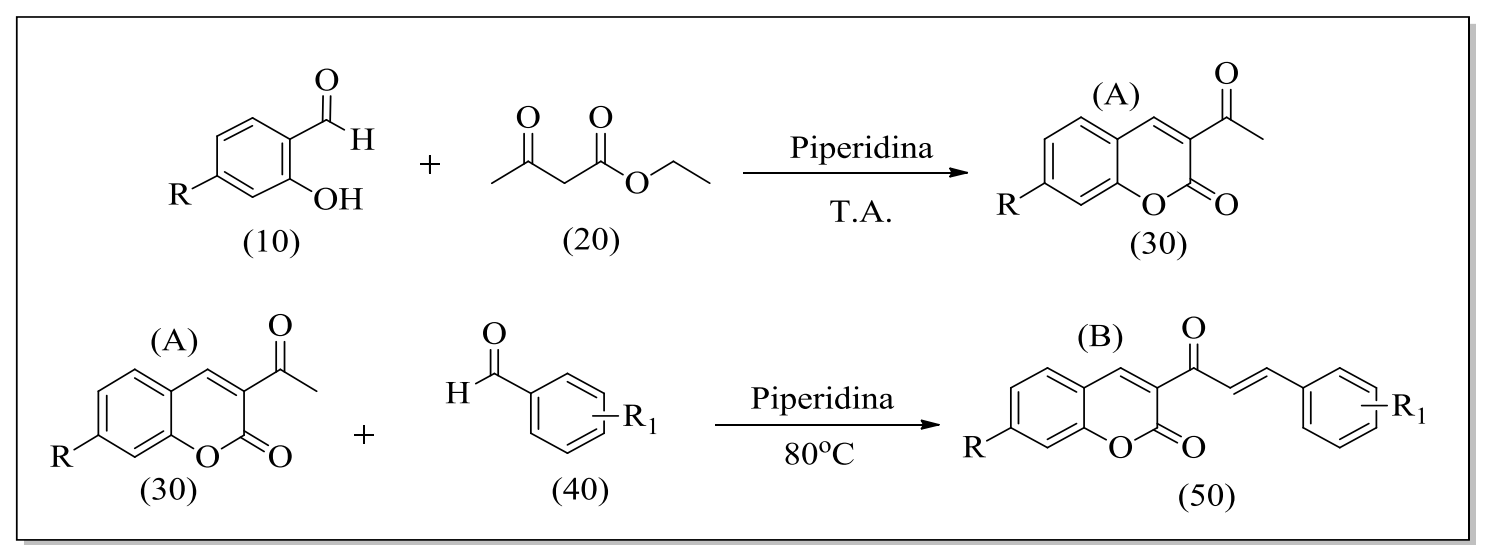

Esquema 9. Reação de síntese dos híbridos de cumarinas-chalconas, onde (A) é a cetocumarina e (B) é o híbrido de cumarina-chalcona.

\subsection{SÍNTESE DAS CUMARINAS}

As cumarinas foram sintetizadas através de reação de condensação aldólica do tipo Knoevenagel $^{10}$ e seguiram a metodologia descrita por Khode e colaboradores ${ }^{30}$. Onde o aldeído aromático reagiu com acetoacetato de etila formando os compostos desejados, conforme mostrado no Esquema 10.

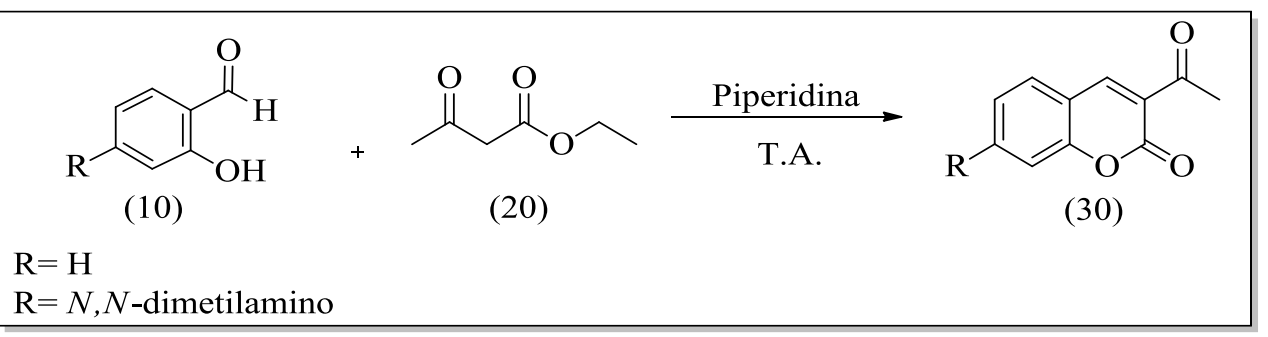

Esquema 10. Reação de síntese das cumarinas.

\subsection{SÍNTESE DE HÍBRIDOS DE CUMARINAS-CHALCONAS}

As sínteses dos híbridos de cumarinas-chalconas, quando em método convencional de refluxo, seguiram a metodologia descrita por Jagtap e colaboradores $^{21}$; e quando utilizaram o método de micro-ondas seguiram a metodologia Ajani e Nwinyi ${ }^{28}$. Essas 
reações ocorreram via mecanismo de condensação aldólica do tipo Claisen Schmidt ${ }^{10}$ (Esquema 11).

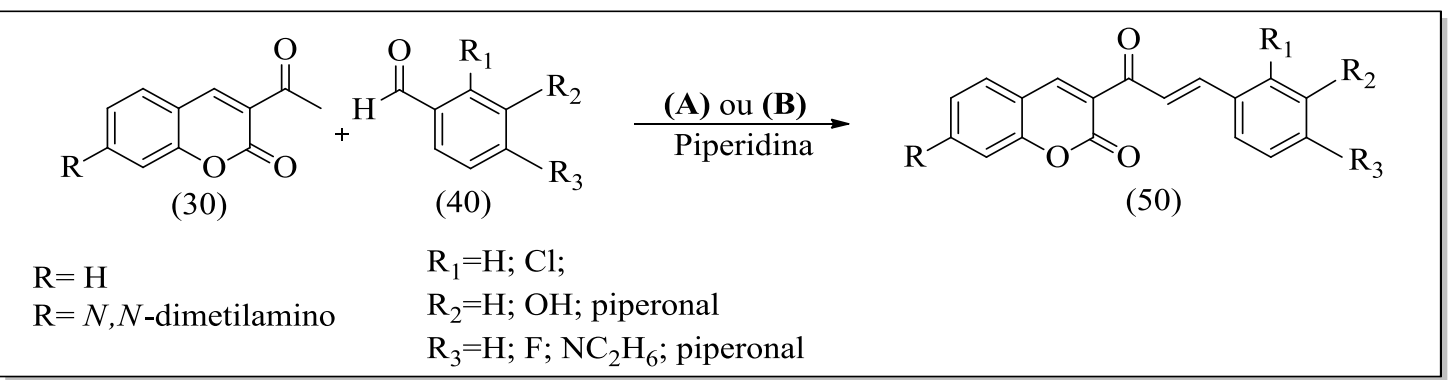

Esquema 11. (A) Síntese de híbridos de cumarinas-chalconas. Condições: $\mathrm{T}=80^{\circ} \mathrm{C}$ e refluxo. (B) Síntese de híbridos de cumarinas-chalconas. Condições: $\mathrm{T}=80^{\circ} \mathrm{C}$ e micro-ondas, adaptado das referências 21 e 31 .

\section{RESULTADOS E DISCUSSÕES}

\subsection{SÍNTESE DAS CUMARINAS}

Seguindo a metodologia apresentada por Khode e colaboradores ${ }^{30}$, a reação de condensação ocorreu entre o aldeído aromático e o acetoacetato de etila, utilizando a piperidina como catalisador. $\mathrm{O}$ sistema reacional foi mantido em temperatura ambiente durante duas horas. Os compostos obtidos foram purificados por recristalização e caracterizados por RMN ${ }^{1} \mathrm{H}$. Adotando esse método, foram sintetizadas duas cumarinas, a 3-acetil-2-H-cromen-2-ona (31) e a 3-acetil-7-dietilamino-2-H-cromen-2-ona (32), como mostrado na Tabela 1.

Tabela 1. Rendimentos das cumarinas 31 e 32 .

\begin{tabular}{l|c|c}
\hline Composto & Estrutura & Rendimento (\%) \\
\hline 31 & &
\end{tabular}

\subsection{IDENTIFICAÇÃO ESTRUTURAL DAS CUMARINAS}


Foram sintetizadas as cumarinas 31 e 32 , sendo a 32 a escolhida para exemplificar a análise espectral (Figura 6). A cumarina 31 foi analisada, seguindo a mesma sistemática e seus dados espectrais estão listados na parte experimental (item 6.4.1, página 37).

A principal evidência da formação da cumarina 32 é um simpleto deslocado em 8,43 ppm, integrando um hidrogênio, referente à posição H-a. Observa-se, também, três sinais na região aromática, cada um integrando para um hidrogênio, sendo em H-b um dupleto em 7,40 ppm (d, $J=9,0 \mathrm{~Hz}, 1 \mathrm{H})$, em H-c um duplo dupleto em 6,62 ppm (dd, $J$ $=9,0 \mathrm{~Hz}$ e $J=2,6 \mathrm{~Hz}, 1 \mathrm{H})$ e em $\mathrm{H}$-d um dupleto em $6,47 \mathrm{ppm}(\mathrm{d}, J=2,6 \mathrm{~Hz}, 1 \mathrm{H})$. Além disso, observa-se um quarteto em 3,46 ppm (q, $J=7,3 \mathrm{~Hz}, 4 \mathrm{H})$ e um tripleto em 1,24 ppm (t, $J=7,0 \mathrm{~Hz}, 6 \mathrm{H})$, referentes aos hidrogênios etílicos e um simpleto em 2,68 ppm $(\mathrm{s}, 3 \mathrm{H})$, referentes aos hidrogênios metílicos, vizinhos à carbonila. Os dados acima podem ser melhor observados na Tabela 2 . 


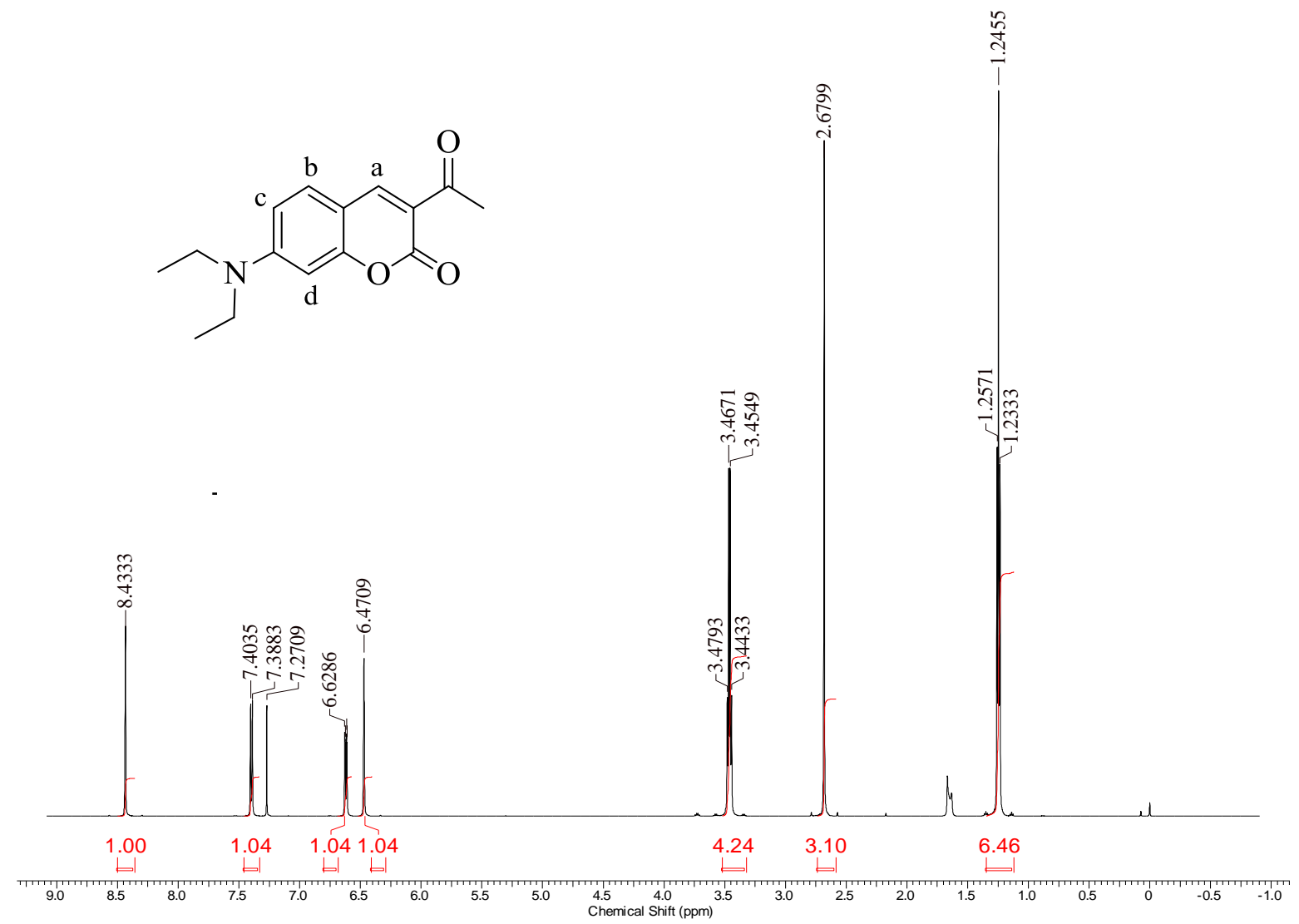

(A)

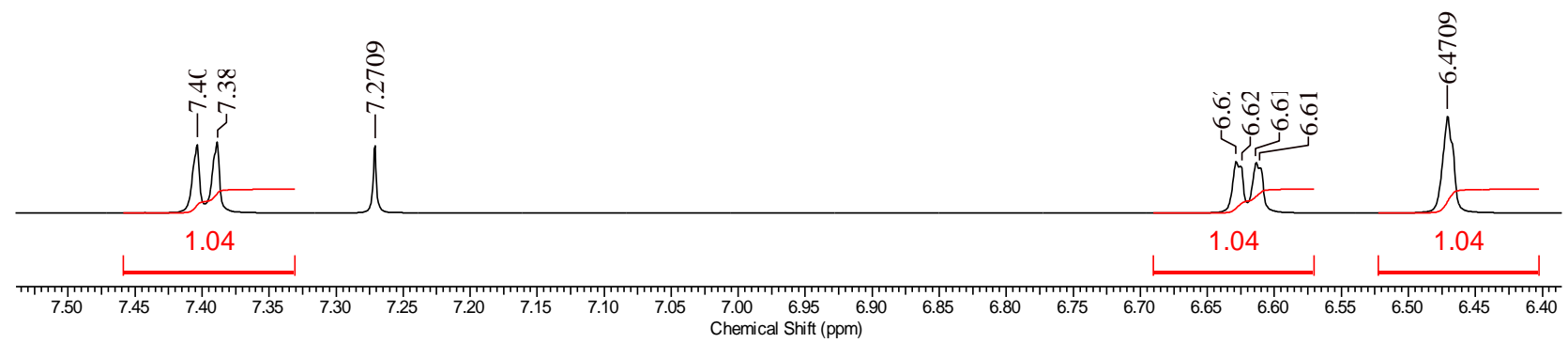

(B)

Figura 6. (A) Espectro de $\mathrm{RMN}$ de ${ }^{1} \mathrm{H}\left(600 \mathrm{MHz}, \mathrm{CDCl}_{3}\right)$ da cumarina 32 e (B) expansão da região aromática. 
Tabela 2. Hidrogênios correspondentes a cumarina 32.

\begin{tabular}{ccccc}
\hline $\boldsymbol{\delta}(\mathbf{p p m})$ & Integração & Multiplicidade & $\begin{array}{c}\text { Hidrogênios } \\
\text { correspondentes }\end{array}$ & $\boldsymbol{J}(\mathbf{H z})$ \\
\hline 8,43 & 1 & simpleto & H-a & - \\
7,40 & 1 & dupleto & H-b & 9,0 \\
6,62 & 1 & duplo dupleto & H-c & 9,0 \\
6,50 & 1 & dupleto & H-d & 2,6 \\
3,46 & 4 & quarteto & - & 7,3 \\
2,67 & 3 & simpleto & - & - \\
1,24 & 6 & tripleto & - & 7,0 \\
\hline
\end{tabular}

No espectro de RMN ${ }^{13} \mathrm{C}$ da cumarina 32 (Figura 7), observam-se 13 sinais. Sendo os sinais em 195,8 ppm e 160,9 ppm referentes aos carbonos carbonílicos C-b e C-c, respectivamente, já os picos em 45,2 ppm (C-d) e 12,5 ppm (C-e) são dos grupos etila, o pico em 30,6 ppm (C-a) é referente ao grupo metila e os demais são característicos dos carbonos aromáticos. Os dados espectrais completos estão listados na Tabela 3.<smiles>[CH]CN([CH])c1ccc2cc(C(=O)O)c(=O)oc2c1</smiles>
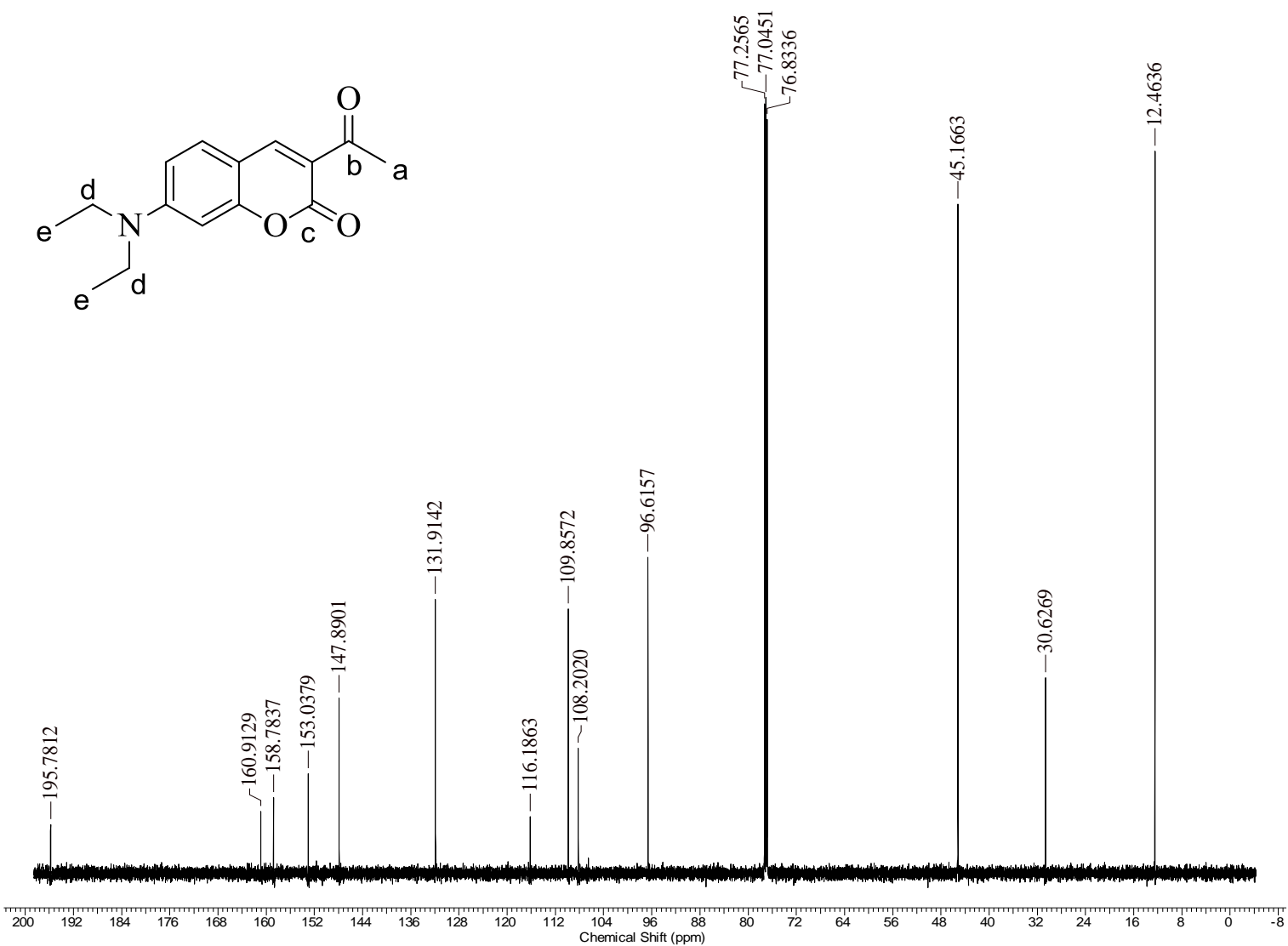

Figura 7. Espectro de $\mathrm{RMN}{ }^{13} \mathrm{C}\left(150 \mathrm{MHz}, \mathrm{CDCl}_{3}\right)$, da estrutura da cumarina 32. 
Tabela 3. Carbonos correspondentes a cumarina 32.

\begin{tabular}{cc}
\hline $\boldsymbol{\delta}(\mathbf{p p m})$ & Carbonos Correspondentes \\
\hline 195,8 & $\mathrm{C}-\mathrm{b}$ \\
160,9 & $\mathrm{C}-\mathrm{c}$ \\
158,8 & aromático \\
153,0 & aromático \\
147,9 & aromático \\
131,9 & aromático \\
116,2 & aromático \\
109,9 & aromático \\
108,2 & aromático \\
96,6 & aromático \\
45,2 & $\mathrm{C}-\mathrm{d}\left(\mathrm{CH}_{2}\right)$ \\
30,6 & $\mathrm{C}-\mathrm{a}\left(\mathrm{CH}_{3}\right)$ \\
12,5 & $\mathrm{C}-\mathrm{e}\left(\mathrm{CH}_{3}\right)$ \\
\hline
\end{tabular}

\subsection{SÍNTESE DOS HÍBRIDOS DAS CUMARINAS-CHALCONAS}

\subsubsection{Obtenção dos híbridos de cumarinas-chaloconas}

\section{Condicão A:}

Seguindo a metodologia apresentada por Jagtap e colaboradores ${ }^{21}$, que realizaram as sínteses usando o mecanismo de condensação aldólica, as reações foram feitas sob condições de refluxo durante $12 \mathrm{~h}$ em etanol. Os aldeídos aromáticos foram adicionados a ceto-cumarina e a piperidina foi usada como catalisador (Esquema12).

As estruturas de todos os compostos com seus respectivos rendimentos estão representadas na Tabela 4.

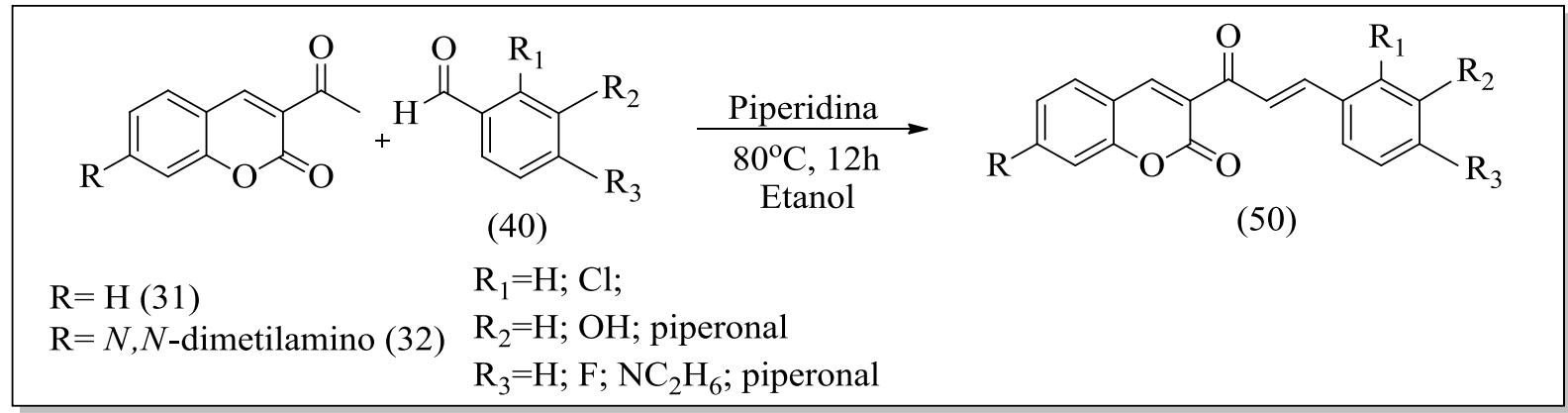

Esquema 12. Síntese dos híbridos de cumarinas-chalconas. Condições: $\mathrm{T}=80^{\circ} \mathrm{C}$ e refluxo, adaptado da referência 21. 
Tabela 4. Híbridos de cumarinas-chalconas e seus respectivos rendimentos: condição A.

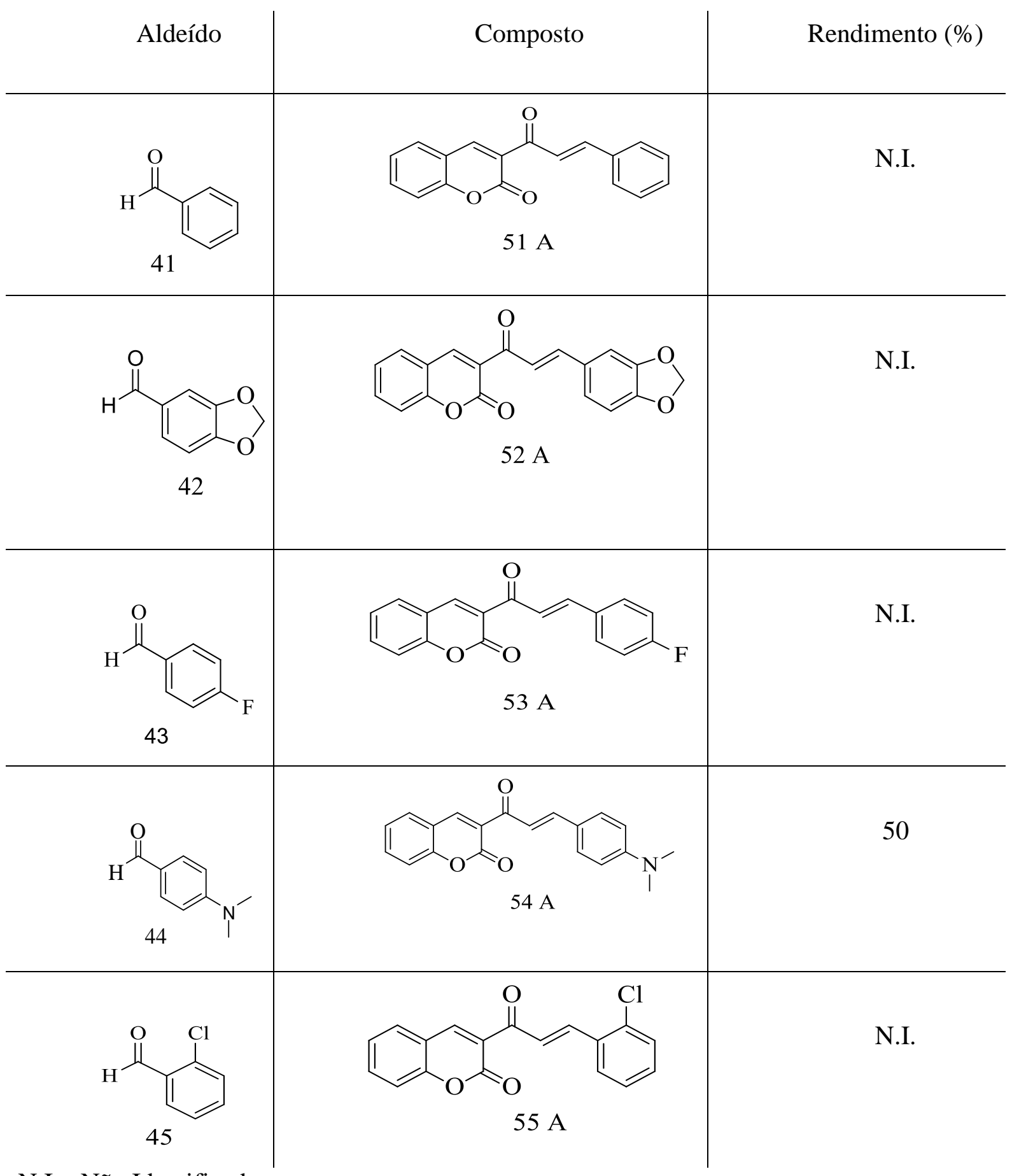

N.I.= Não Identificado

Observando-se os dados apresentados na Tabela 4, pode-se concluir que o método utililizado não foi satisfatório, pois houve apenas a formação de um dos híbridos, o 54 A. Diante desse resultado, decidiu-se utilizar a condição $B$, na qual foi aplicado o método de micro-ondas. 


\section{Condição B:}

Seguindo a metodologia apresentada por Ajani e Nwinyi ${ }^{31}$, foram realizadas as reações entre os aldeídos aromáticos e as ceto-cumarinas, utilizando piperidina como catalisador (Esquema 13). As reações foram feitas em micro-ondas, durante um período de 7 a 45 min gerando rendimentos que variaram de 9 a $68 \%$, como demonstrado na Tabela 6 .

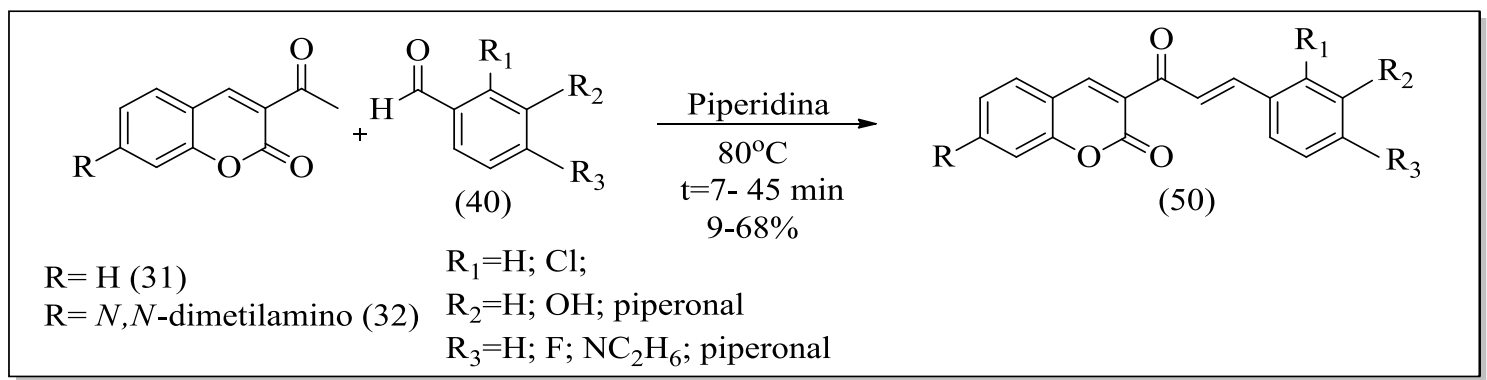

Esquema 13. Síntese de híbridos de cumarinas-chalconas. Condições: $\mathrm{T}=80^{\circ} \mathrm{C}$ e micro-ondas, adaptado da referência 28. 
Tabela 5. Híbridos de cumarinas-chalconas e seus respectivos rendimentos: condição B.

\begin{tabular}{l|l|l} 
Tempo (min) \\
\hline
\end{tabular}

Observando-se os dados apresentados na Tabela 5, pode-se concluir que o método utilizado foi satisfatório, pois houve a formação de sete híbridos. A condição B apresentou as seguintes vantagens: as reações foram feitas sem solventes, o que eliminou a necessidade de reciclar, descartar e manipular um solvente orgânico; o tempo de reação foi reduzido; apresentou a formação dos produtos desejados. 
Na Tabela 6, utilizando o composto 54 como exemplo de molécula que foi sintetizada pela condição A e B, foi possível constatar que a condição B melhorou o rendimento e diminuiu significativamente o tempo de reação.

Tabela 6. Híbrido de cumarina-chalcona sintetizado pela condição A e B.

\begin{tabular}{|l|c|c|c|c|c|}
\hline \multirow{2}{*}{ Composto } & \multirow{2}{*}{ Aldeído } & \multicolumn{2}{|c|}{ Tempo de Reação } & \multicolumn{2}{c|}{ Rendimento (\%) } \\
\cline { 3 - 7 } & & $\mathbf{A}(\mathbf{h})$ & $\mathbf{B}(\mathbf{m i n})$ & $\mathbf{A}$ & $\mathbf{B}$ \\
\hline
\end{tabular}

\subsection{IDENTIFICAÇÃO ESTRUTURAL DOS HÍBRIDOS DAS CUMARINAS- CHALCONAS}

Foram sintetizados sete híbridos 51 B-57 B, sendo os compostos 51 B e 56 B escolhidos para exemplificar a identificação estrutural. Os demais compostos foram analisados seguindo a mesma sistemática e seus dados espectrais estão listados na parte experimental (no item 6.4.4, página 39).

$\mathrm{O}$ espectro de $\mathrm{RMN}{ }^{1} \mathrm{H}$ do composto $51 \mathrm{~B}$ (Figura 8) mostra dois dupletos centrados em 7,95 ppm (d, $J=15,4 \mathrm{~Hz}, 1 \mathrm{H}, \mathrm{H}-\mathrm{c})$ e 7,88 ppm (d, $J=15,4 \mathrm{~Hz}, 1 \mathrm{H}, \mathrm{H}-\mathrm{b})$, referentes aos hidrogênios da ligação dupla, característicos de sistemas olefínicos trans. Observa-se um simpleto, relativo ao H-a em 8,59 ppm, integrando um hidrogênio. Além disso, verificam-se três sinais referentes aos hidrogênios aromáticos: um tripleto em 7,36 ppm (t, $J=7,0 \mathrm{~Hz}, 1 \mathrm{H})$, dois multipletos, sendo um observado entre 7,69-7,65 ppm $(\mathrm{m}, 4 \mathrm{H})$ e o outro entre $7,42-7,40 \mathrm{ppm}(\mathrm{m}, 4 \mathrm{H})$. Os dados acima podem ser melhor observados na Tabela 7. 
<smiles>O=C(C=Cc1ccccc1)c1cc2ccccc2oc1=O</smiles>
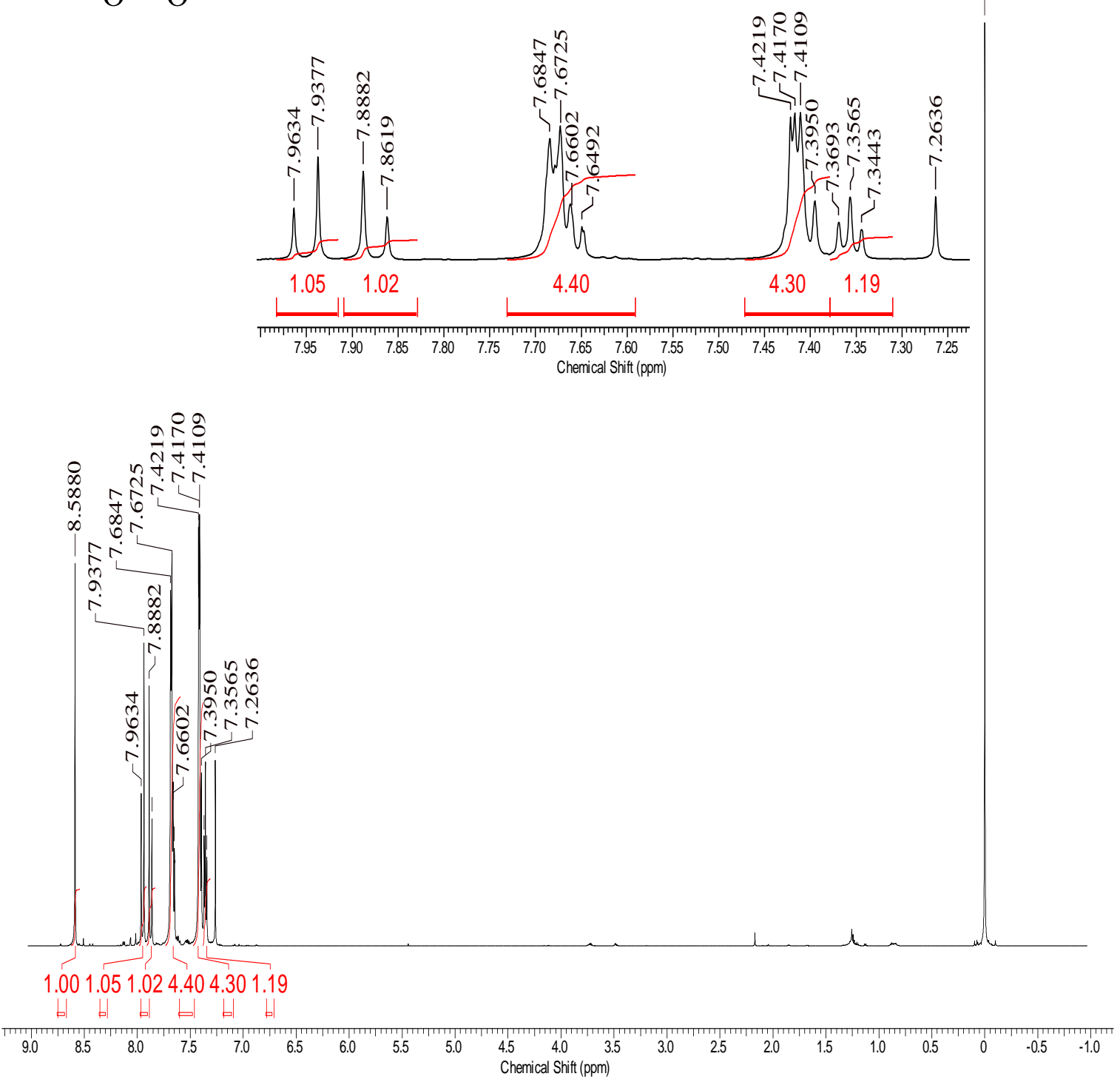

Figura 8. Espectro de $\mathrm{RMN}$ de ${ }^{1} \mathrm{H}\left(600 \mathrm{MHz}, \mathrm{CDCl}_{3}\right)$ do híbrido $51 \mathrm{~B}$. 
Tabela 7. Hidrogênios correspondentes ao híbrido $51 \mathrm{~B}$.

\begin{tabular}{ccccc}
\hline $\boldsymbol{\delta}(\mathbf{p p m})$ & Integração & Multiplicidade & $\begin{array}{c}\text { Hidrogênios } \\
\text { correspondentes }\end{array}$ & $\boldsymbol{J}(\mathbf{H z})$ \\
\hline 8,59 & 1 & simpleto & H-a & - \\
7,88 & 1 & dupleto & H-c & 15,4 \\
7,82 & 1 & dupleto & H-b & 15,4 \\
$7,69-7,65$ & 4 & multipleto & - & - \\
$7,42-7,40$ & 4 & multipleto & - & - \\
7,36 & 1 & tripleto & - & 7,0 \\
\hline
\end{tabular}

No espectro de RMN ${ }^{13} \mathrm{C}$ do composto 51 B (Figura 9) observam-se 15 sinais, sendo os sinais em 186,5 ppm e 159,3 referentes aos carbonos carbonílicos C-a e C-b, respectivamente. Os outros dados espectrais estão listados na Tabela 8.

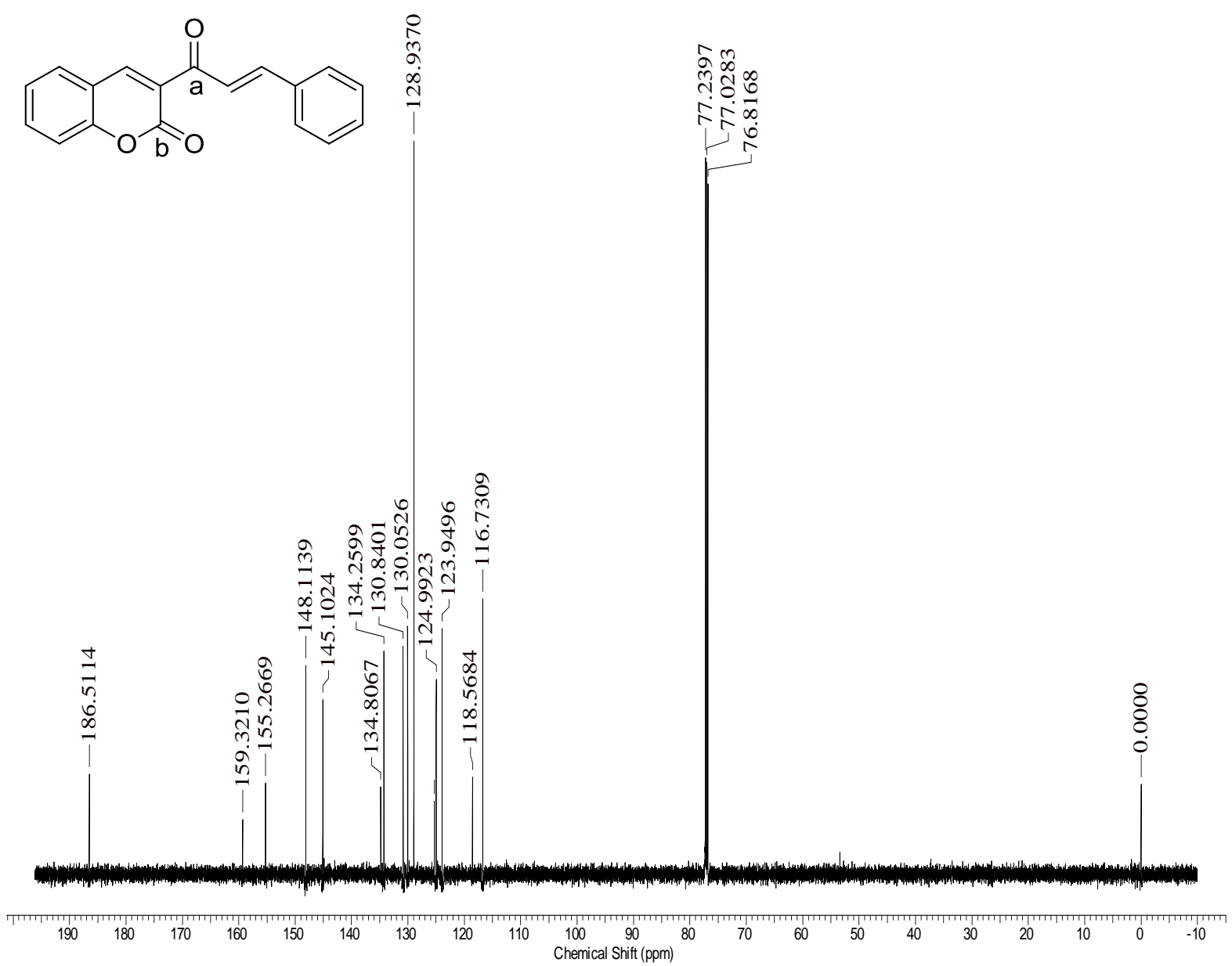

Figura 9. Espectro de $\mathrm{RMN} \mathrm{de}{ }^{13} \mathrm{C}\left(150 \mathrm{MHz}, \mathrm{CDCl}_{3}\right)$ do híbrido $51 \mathrm{~B}$. 
Tabela 8. Carbonos correspondentes ao híbrido 51 B.

\begin{tabular}{cc}
\hline $\boldsymbol{\delta}(\mathbf{p p m})$ & Carbonos Correspondentes \\
\hline 186,5 & $\mathrm{C}-\mathrm{a}$ \\
159,3 & $\mathrm{C}-\mathrm{b}$ \\
155,3 & aromático \\
148,1 & aromático \\
145,1 & aromático \\
134,8 & aromático \\
134,3 & aromático \\
130,8 & aromático \\
130,1 & aromático \\
128,9 & aromático \\
124,9 & aromático \\
123,9 & aromático \\
118,6 & aromático \\
116,7 & aromático \\
\hline
\end{tabular}

$\mathrm{O}$ espectro de $\mathrm{RMN}{ }^{1} \mathrm{H}$ do composto $56 \mathrm{~B}$ (Figura 10) mostra dois dupletos centrados em 7,97 ppm (d, $J=15,5 \mathrm{~Hz}, 1 \mathrm{H}, \mathrm{H}-\mathrm{c})$ e 7,84 ppm (d, $J=15,5 \mathrm{~Hz}, 1 \mathrm{H}, \mathrm{H}-\mathrm{b})$, referentes aos hidrogênios da ligação dupla, característicos de sistemas olefínicos trans. Observa-se um simpleto, relativo ao H-a em 8,54 ppm, integrando um hidrogênio.

Verificaram-se, também, cinco sinais referentes aos hidrogênios aromáticos: primeiramente um dupleto em 7,59 ppm $(\mathrm{d}, J=9,0 \mathrm{~Hz}, 2 \mathrm{H})$ e mais dois dupletos, sendo um em 7,41 ppm (d, $J=9,0 \mathrm{~Hz}, 1 \mathrm{H})$ e o outro em 6,68 ppm (d, $J=9,0 \mathrm{~Hz}, 2 \mathrm{H})$. Depois um duplo dupleto em $6,61 \mathrm{ppm}(\mathrm{dd}, J=9,0 \mathrm{~Hz}$ e $J=2,3 \mathrm{~Hz}, 1 \mathrm{H})$ e mais um dupleto em $6,49 \mathrm{ppm}(\mathrm{d}, J=2,3 \mathrm{~Hz}, 1 \mathrm{H})$. Além disso, pode-se verificar um quarteto em 3,45 ppm (q, $J=7,0 \mathrm{~Hz}, 4 \mathrm{H})$, um simpleto em 3,0 ppm (s, 6H,) e um tripleto em 1,24 ppm (t, $J=$ 7,0 Hz, 6H). Os dados acima podem ser melhor observados na Tabela 9. 


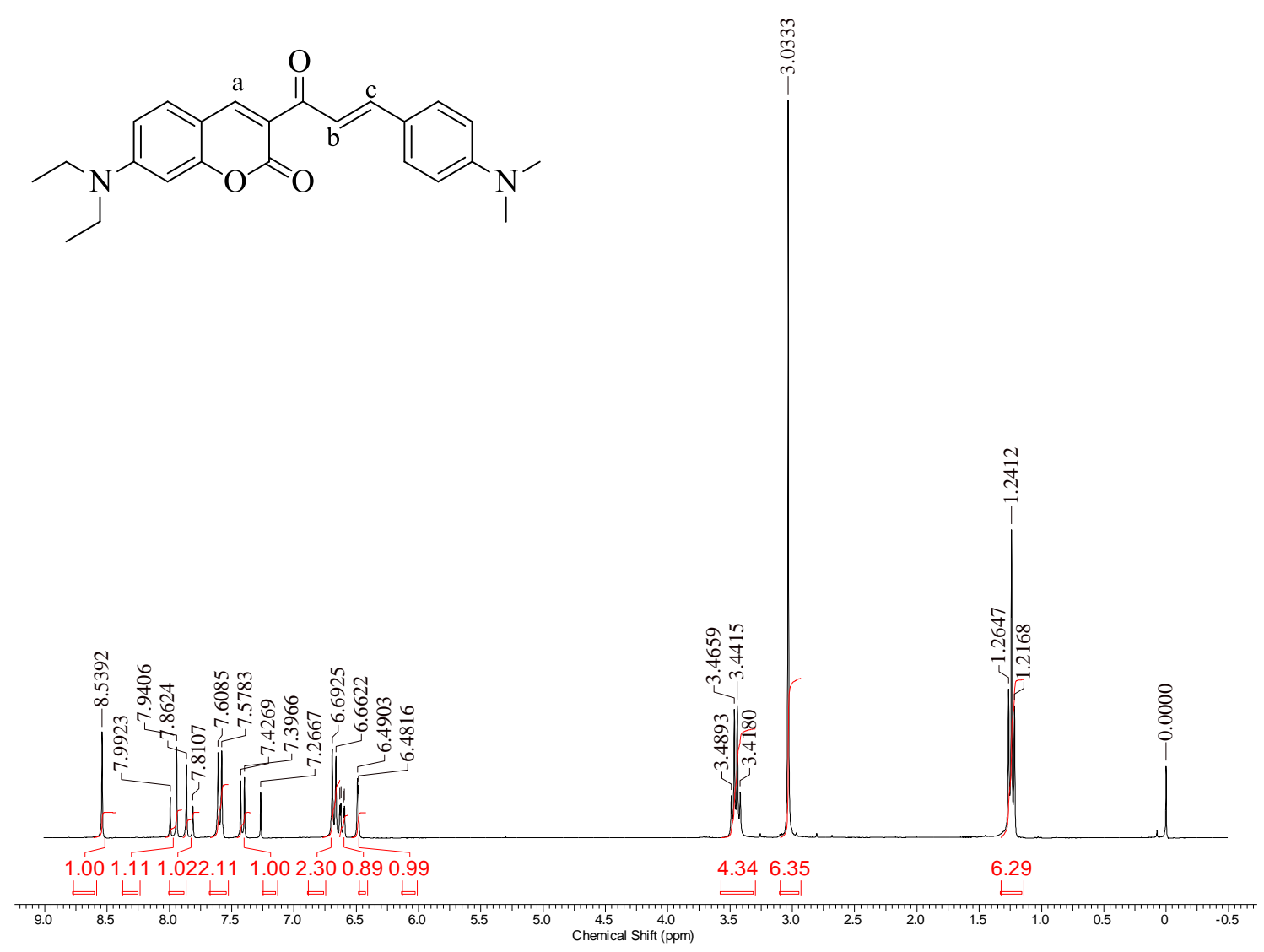

(A)

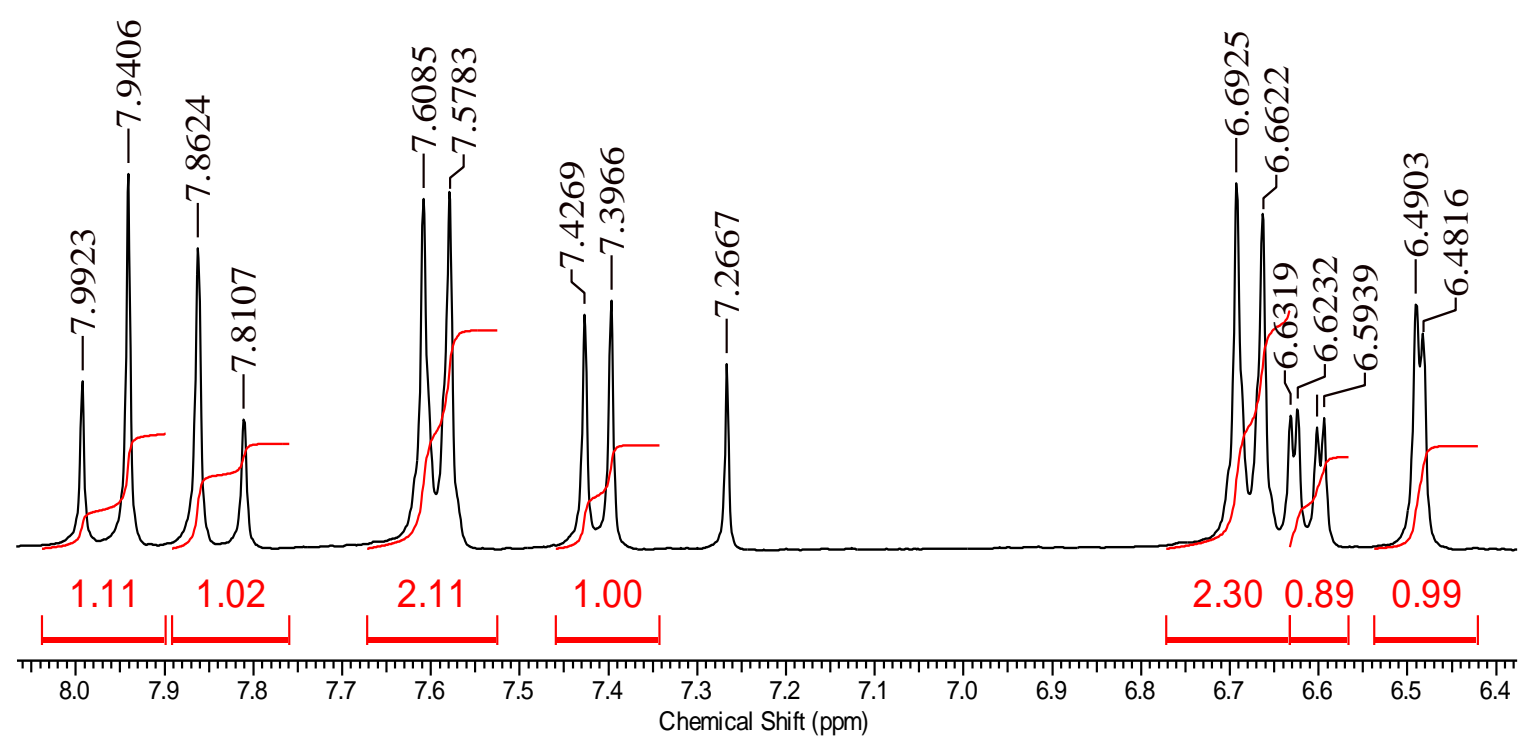

(B)

Figura 10. (A) Espectro de RMN de ${ }^{1} \mathrm{H}\left(300 \mathrm{MHz}, \mathrm{CDCl}_{3}\right)$ do híbrido $56 \mathrm{~B}$ e (B) expansão da região aromática. 
Tabela 9. Hidrogênios correspondentes ao híbrido 56 B.

\begin{tabular}{ccccc}
\hline $\boldsymbol{\delta}(\mathbf{p p m})$ & Integração & Multiplicidade & $\begin{array}{c}\text { Hidrogênios } \\
\text { correspondentes }\end{array}$ & $\boldsymbol{J}(\mathbf{H z})$ \\
\hline 8,54 & 1 & simpleto & H-a & - \\
7,97 & 1 & dupleto & H-c & 15,5 \\
7,82 & 1 & dupleto & H-b & 15,5 \\
7,59 & 2 & dupleto & - & 9,0 \\
7,41 & 1 & dupleto & - & 9,0 \\
6,68 & 2 & dupleto & - & 9,0 \\
6,61 & 1 & duplo dupleto & - & 9,$0 ; 2,3$ \\
6,49 & 1 & dupleto & - & 2,3 \\
3,45 & 4 & quarteto & - & 7,0 \\
3,0 & 6 & simpleto & - & - \\
1,24 & 6 & tripleto & - & 7,0 \\
\hline
\end{tabular}

No espectro de RMN ${ }^{13} \mathrm{C}$ do composto 56 B (Figura 11), observam-se 19 sinais. Sendo os sinais em 186,2 ppm e 161,0 ppm referentes aos carbonos carbonílicos C-b e C-c, respectivamente. Os outros dados espectrais estão listados na Tabela 10. 
<smiles>CCN(CC)c1ccc2cc(C(=O)/C=C/c3ccc(N(C)C)cc3)c(=O)oc2c1</smiles>

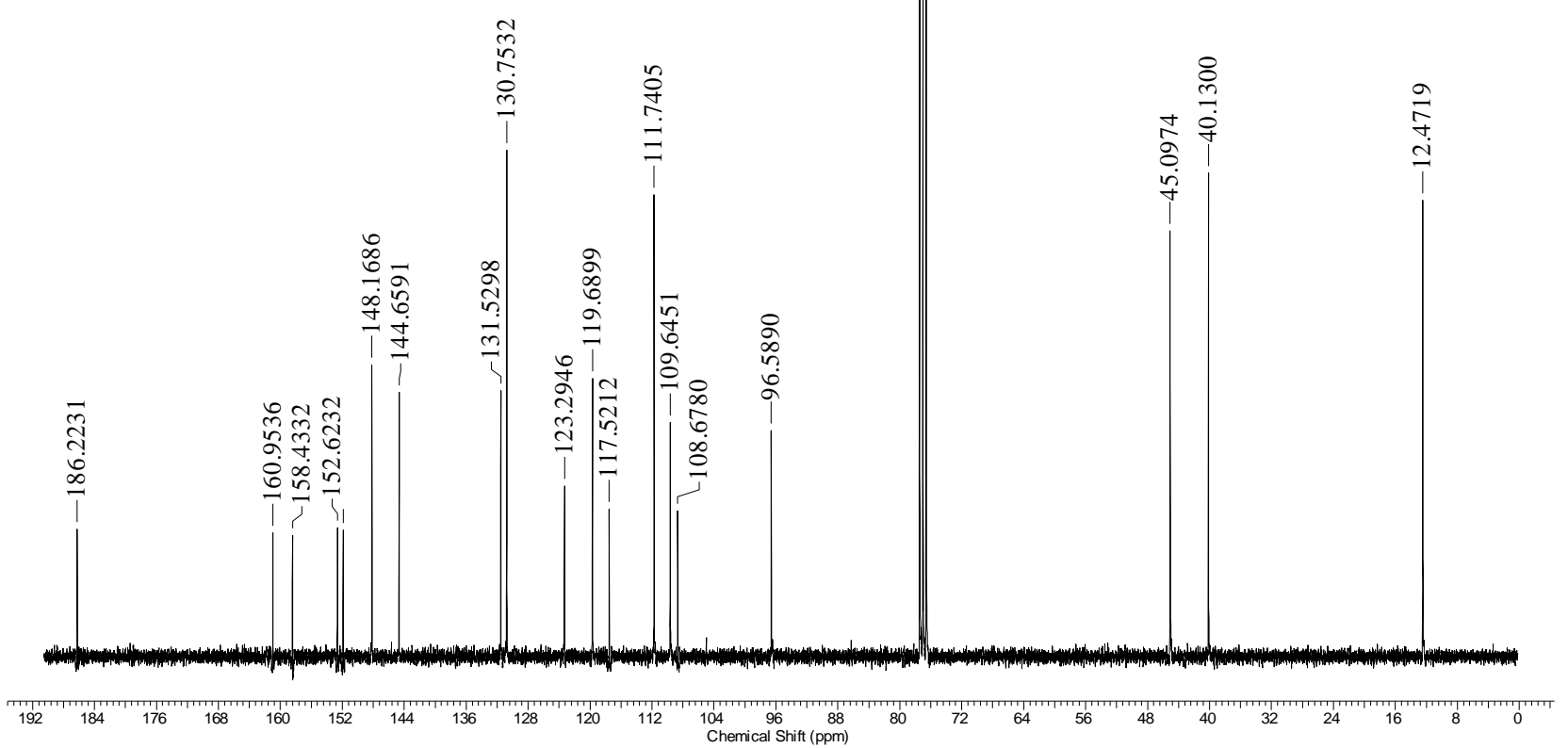

Figura 11. Espectro de $\mathrm{RMN}$ de ${ }^{13} \mathrm{C}\left(75 \mathrm{MHz}, \mathrm{CDCl}_{3}\right)$ do híbrido $56 \mathrm{~B}$.

Tabela 10. Carbonos correspondentes ao híbrido 56 B.

\begin{tabular}{cc}
\hline $\boldsymbol{\delta}(\mathbf{p p m})$ & Carbonos Correspondentes \\
\hline 186,2 & $\mathrm{C}-\mathrm{b}$ \\
161,0 & $\mathrm{C}-\mathrm{c}$ \\
158,4 & aromático \\
152,6 & aromático \\
144,7 & aromático \\
131,5 & aromático \\
130,8 & aromático \\
123,3 & aromático \\
119,7 & aromático \\
117,5 & aromático \\
111,7 & aromático \\
109,6 & aromático \\
108,7 & aromático \\
96,6 & aromático \\
45,1 & $\mathrm{C}-\mathrm{d}\left(\mathrm{CH}_{2}\right)$ \\
40,1 & $\mathrm{C}-\mathrm{a}\left(\mathrm{CH}_{3}\right)$ \\
\hline
\end{tabular}




\subsection{AVALIAÇÃO FOTOFÍSICA}

\subsubsection{Fotofísica das cumarinas 31 e 32}

Para a avaliação fotofísica das cumarinas foram realizadas análises de espectrofotometria (absorção) e espectrofluorimetria (emissão) em sete diferentes solventes: acetato de etila, acetonitrila, dimetilsulfóxido, diclorometano, etanol, metanol e tolueno.

Nessa etapa do estudo fotofísico, as cumarinas foram analisadas em soluções de concentrações $10 \mu \mathrm{M}$, nos respectivos solventes citados acima. Vale ressaltar que as substâncias foram testadas em água destilada, mas não apresentaram solubilidade nesse solvente, sendo esses dados espectrais desconsiderados.

As propriedades de absorção e emissão fluorescente para as cumarinas 31 e 32 nos sete solventes citados acima estão listados na Tabela 11. Como se pode observar, as bandas de absorção máxima para cumarinas 31 variaram de 336 a $347 \mathrm{~nm}$ e para 32 entre 417 a 437 nm, já as bandas de emissão, as variações para cumarina 31 foram entre 471 a 546 nm e para 32 entre 450 a 488 nm. Para elucidar, a Figura 12 apresenta os espectros de absorção e emissão da cumarina 31. Os espectros de absorção e emissão da cumarina 32 encontram-se no apêndice da seção 8.2, item 8.2.1, página 67.
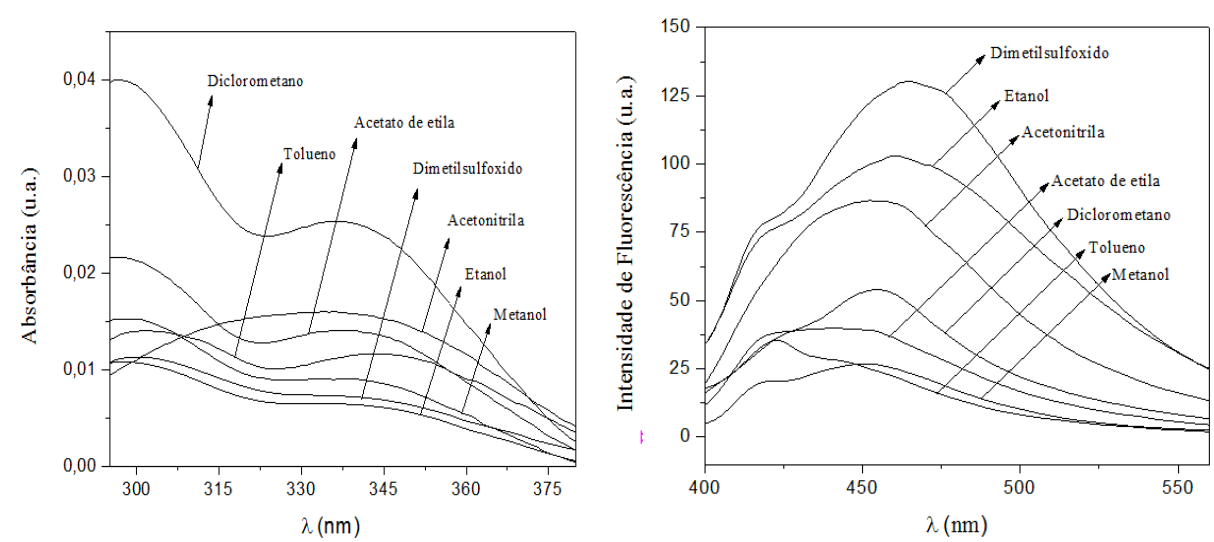

Figura 12. Espectro de absorção (esquerda) e emissão (direita) para a cumarina 31. 
Tabela 11. Dados fotofísicos de comprimento de onda de absorção e emissão, deslocamento de Stokes e rendimento quântico das cumarinas 31 e 32.

\begin{tabular}{|c|c|c|c|c|c|}
\hline Compostos & Solventes & $\begin{array}{l}\lambda_{\max } \\
(\mathbf{a b s}) \\
(\mathbf{n m})\end{array}$ & $\begin{array}{l}\lambda_{\max } \\
(\mathrm{em}) \\
(\mathbf{n m})\end{array}$ & $\begin{array}{l}\text { Deslocamento } \\
\text { de Stokes } \\
(\mathbf{n m})\end{array}$ & $\begin{array}{l}\text { Rendimento } \\
\text { Quântico }(\phi)\end{array}$ \\
\hline \multirow{7}{*}{31} & $\mathrm{AcOEt}$ & 336 & 495 & 49 & \multirow{7}{*}{0,004} \\
\hline & $\mathrm{MeCN}$ & 335 & 524 & 72 & \\
\hline & $\mathrm{CH}_{2} \mathrm{Cl}_{2}$ & 337 & 501 & 45 & \\
\hline & DMSO & 339 & 518 & 64 & \\
\hline & EtOH & 341 & 539 & 87 & \\
\hline & $\mathrm{MeOH}$ & 338 & 546 & 93 & \\
\hline & Tolueno & 347 & 471 & 18 & \\
\hline \multirow{7}{*}{32} & $\mathrm{AcOEt}$ & 425 & 464 & 39 & \multirow{7}{*}{0,05} \\
\hline & $\mathrm{MeCN}$ & 428 & 478 & 50 & \\
\hline & $\mathrm{CH}_{2} \mathrm{Cl}_{2}$ & 432 & 468 & 36 & \\
\hline & DMSO & 437 & 483 & 46 & \\
\hline & $\mathrm{EtOH}$ & 433 & 488 & 55 & \\
\hline & $\mathrm{MeOH}$ & 433 & 481 & 48 & \\
\hline & Tolueno & 417 & 450 & 33 & \\
\hline
\end{tabular}

O que se pode observar nas características de fluorescência dessas moléculas (31 e 32), foram os efeitos dos solventes. Notou-se que, quanto maior a polaridade do solvente ocorria um desvio para maior comprimento de onda, e isso pode ser confirmado pelo cálculo do deslocamento de Stokes.

O cálculo do deslocamento de Stokes foi feito pela diferença entre os comprimentos de ondas máximos observados para absorção e emissão para um mesmo solvente, esse parâmetro proporciona informações importantes sobre o estado de excitação.

No estado excitado, fluoróforos apresentam maior momento de dipolo do que no estado fundamental. E esta polarização é estabilizada também pelos momentos de dipolo das moléculas dos solventes que estão ao redor dos fluoróforos. Esse efeito de estabilização será maior em solventes de maior polaridade. ${ }^{23,31}$

Quanto maior o valor do deslocamento fica indicado que o estado excitado $\left(S_{1}\right)$ é mais estabilizado pelo solvente analisado. Em consequência dessa estabilização, maiores comprimentos de ondas são atingidos.

O que se pode notar é que as cumarinas 31 e 32 apresenta um deslocamento mais pronunciado quando solubilizadas em solventes mais polares como a acetonitrila, etanol e metanol. Esse aumento de deslocamento deve-se ao fato das moléculas de cumarina 
estarem melhor estabilizadas no seu estado excitado nesses solventes por ligações de hidrogênio ( etanol e metanol) e por ligações dipolo-dipolo (acetonitrila).

Os resultados dos cálculos do deslocamento de Stokes das cumarinas variaram entre 18 e 93 nm e estão listados na Tabela 11.

\subsubsection{Fotofísica dos híbridos de cumarinas-chalconas 51 B-57 B}

Para a avaliação fotofísica dos híbridos de cumarinas-chalconas foram realizadas análises de espectrofotometria (absorção) e espectrofluorimetria (emissão) em sete diferentes solventes: acetato de etila, acetonitrila, dimetilsulfóxido, diclorometano, etanol, metanol e tolueno.

Nessa etapa do estudo fotofísico, os híbridos foram analisados em soluções de concentrações $10 \mu \mathrm{M}$, nos respectivos solventes citados acima. Vale ressaltar que as estruturas foram testadas em água destilada, mas não apresentaram solubilidade nesse solvente, sendo esses dados espectrais desconsiderados.

Para efeito de qualitativo da classe, na Figura 13, têm-se os solvatogramas obtidos para a análise de absorção e emissão do híbrido 51 B. Os demais espectros de absorção e emissão dos outros compostos encontram-se no apêndice da seção 8.2, item 8.2.2, página 69.
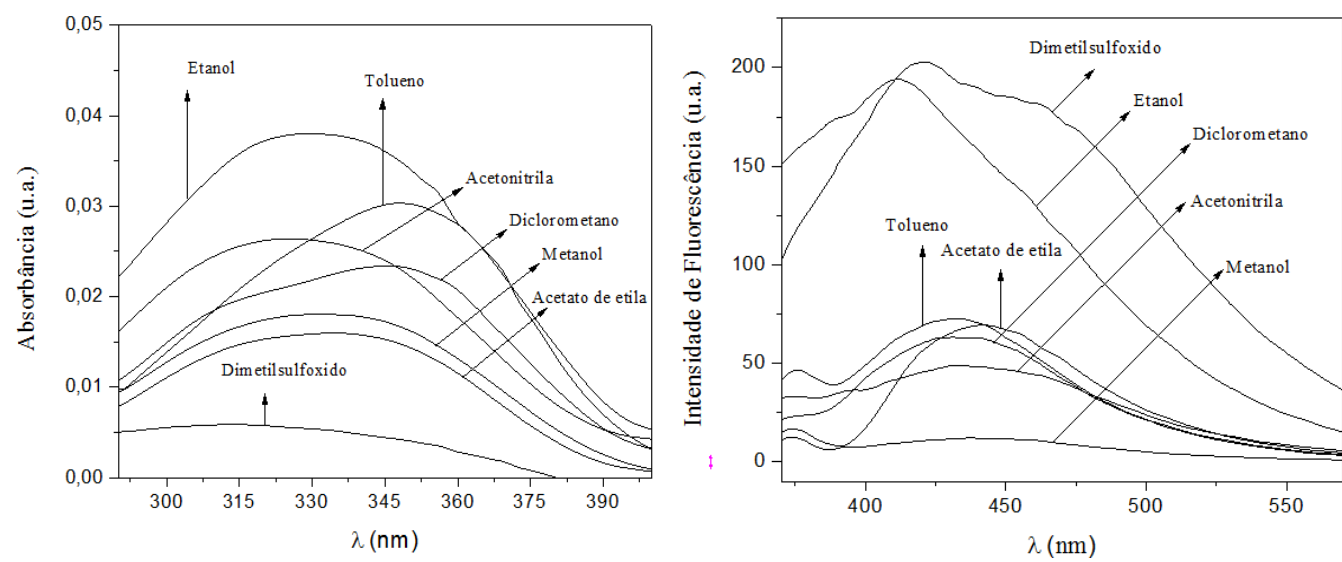

Figura 13. Espectro de absorção (esquerda) e emissão (direita) para o híbrido 51 B. 
Tabela 12. Dados fotofísicos de comprimento de onda de absorção e emissão, deslocamento de Stokes e rendimento quântico dos híbridos 51B-57B.

\begin{tabular}{|c|c|c|c|c|c|}
\hline Compostos & Solventes & $\begin{array}{l}\lambda_{\max } \\
(\mathbf{a b s}) \\
(\mathbf{n m}) \\
\end{array}$ & $\begin{array}{l}\lambda_{\max } \\
(\mathbf{e m}) \\
(\mathbf{n m}) \\
\end{array}$ & $\begin{array}{c}\text { Deslocamento } \\
\text { de Stokes } \\
(\mathrm{nm})\end{array}$ & $\begin{array}{l}\text { Rendimento } \\
\text { Quântico }(\phi)\end{array}$ \\
\hline \multirow{7}{*}{$51 \mathrm{~B}$} & $\mathrm{AcOEt}$ & 329 & 439 & 110 & \multirow{7}{*}{0,006} \\
\hline & $\mathrm{MeCN}$ & 320 & 433 & 113 & \\
\hline & $\mathrm{CH}_{2} \mathrm{Cl}_{2}$ & 333 & 434 & 101 & \\
\hline & DMSO & 313 & 421 & 108 & \\
\hline & $\mathrm{EtOH}$ & 328 & 410 & 82 & \\
\hline & $\mathrm{MeOH}$ & 329 & 439 & 110 & \\
\hline & Tolueno & 348 & 429 & 81 & \\
\hline \multirow{7}{*}{$52 \mathrm{~B}$} & $\mathrm{AcOEt}$ & 365 & 420 & 55 & \multirow{7}{*}{0,009} \\
\hline & $\mathrm{MeCN}$ & 361 & 452 & 91 & \\
\hline & $\mathrm{CH}_{2} \mathrm{Cl}_{2}$ & 376 & 455 & 79 & \\
\hline & DMSO & 359 & 465 & 106 & \\
\hline & EtOH & 369 & 460 & 91 & \\
\hline & $\mathrm{MeOH}$ & 370 & 452 & 82 & \\
\hline & Tolueno & 370 & 421 & 51 & \\
\hline \multirow{7}{*}{$53 \mathrm{~B}$} & $\mathrm{AcOEt}$ & 345 & 439 & 94 & \multirow{7}{*}{0,029} \\
\hline & $\mathrm{MeCN}$ & 334 & 456 & 122 & \\
\hline & $\mathrm{CH}_{2} \mathrm{Cl}_{2}$ & 344 & 440 & 96 & \\
\hline & DMSO & 342 & 447 & 105 & \\
\hline & $\mathrm{EtOH}$ & 343 & 433 & 90 & \\
\hline & $\mathrm{MeOH}$ & 328 & 450 & 122 & \\
\hline & Tolueno & 348 & 436 & 88 & \\
\hline \multirow{7}{*}{$54 \mathrm{~B}$} & AcOEt & 438 & 493 & 55 & \multirow{7}{*}{0,003} \\
\hline & $\mathrm{MeCN}$ & 425 & 495 & 70 & \\
\hline & $\mathrm{CH}_{2} \mathrm{Cl}_{2}$ & 455 & 460 & 5 & \\
\hline & DMSO & 446 & 497 & 51 & \\
\hline & $\mathrm{EtOH}$ & 445 & 495 & 50 & \\
\hline & $\mathrm{MeOH}$ & 445 & 496 & 51 & \\
\hline & Tolueno & 451 & 567 & 116 & \\
\hline \multirow{7}{*}{$55 \mathrm{~B}$} & AcOEt & 335 & 456 & 121 & \multirow{7}{*}{0,022} \\
\hline & $\mathrm{MeCN}$ & 330 & 463 & 133 & \\
\hline & $\mathrm{CH}_{2} \mathrm{Cl}_{2}$ & 336 & 448 & 112 & \\
\hline & DMSO & 336 & 453 & 117 & \\
\hline & EtOH & 337 & 426 & 89 & \\
\hline & $\mathrm{MeOH}$ & 334 & 454 & 120 & \\
\hline & Tolueno & 344 & 449 & 105 & \\
\hline \multirow{8}{*}{$56 \mathrm{~B}$} & AcOEt & 462 & 584 & 122 & \multirow{7}{*}{0,008} \\
\hline & $\mathrm{MeCN}$ & 469 & 580 & 111 & \\
\hline & $\mathrm{CH}_{2} \mathrm{Cl}_{2}$ & 472 & 552 & 80 & \\
\hline & DMSO & 486 & 580 & 94 & \\
\hline & $\mathrm{EtOH}$ & 480 & 592 & 112 & \\
\hline & $\mathrm{MeOH}$ & 481 & 580 & 99 & \\
\hline & Tolueno & 463 & 532 & 69 & \\
\hline & AcOEt & 446 & 495 & 49 & \\
\hline
\end{tabular}




\begin{tabular}{|c|c|c|c|}
\hline $\mathrm{MeCN}_{\mathrm{CH}_{2} \mathrm{Cl}_{2}}$ & 452 & 524 & 72 \\
\hline $\mathrm{DMSO}$ & 454 & 501 & 45 \\
\hline $\mathrm{EtOH}$ & 452 & 539 & 64 \\
\hline $\mathrm{MeOH}$ & 453 & 546 & 87 \\
\hline Tolueno & 453 & 471 & 18 \\
\hline
\end{tabular}

O cálculo do deslocamento de Stokes para os híbridos de cumarinas-chalconas foi feito do mesmo modo que foi descrito para as cumarinas. Os híbridos apresentaram deslocamento de Stokes bem característicos para cada solvente e para que se possa concluir que a estabilidade possa ser consequência da ação de processos intramoleculares, gráficos de deslocamento de Stokes versus polaridade de Reichardt $\left(E_{t}^{n}\right)$ foram traçados.

\subsubsection{Gráficos de Lippert- Mataga para as cumarinas e seus híbridos}

Apenas com os cálculos de deslocamento de Stokes, não é possível concluir que a estabilidade das cumarinas e de seus híbridos possa ser devido ao processo de transferência de carga intramolecular (TCI).

Para se avaliar a influência do TCI no estado excitado, foram traçados gráficos de Lippert-Mataga, onde o deslocamento de Stokes está no eixo y e no eixo x utiliza-se um parâmetro conhecido como polaridade de Reichardt $\left(E_{t}^{n}\right)^{32}$, Tabela 13.

Tabela 13. Parâmetro de polarização de Reichardt utilizados nas aquisições dos gráficos de Lippert-Mataga, adaptado da referência 32.

\begin{tabular}{ll}
\hline Solvente & $\boldsymbol{E}_{\boldsymbol{t}}^{\boldsymbol{n}}$ \\
\hline Acetato de etila & 0,228 \\
Acetonitrila & 0,460 \\
Diclorometano & 0,309 \\
DMSO & 0,444 \\
Etanol & 0,654 \\
Metanol & 0,762 \\
Tolueno & 0,099 \\
\hline
\end{tabular}

Esse tipo de gráfico prevê efeitos físico-químicos entre os solventes e os compostos excitados e mede sua sensibilidade em relação à polaridade do solvente. ${ }^{36}$ 
Quanto maior for a inclinação da reta, maior será influência do solvente na estabilização do estado excitado dos fluoróforos. A inclinação da reta é proporcional à diferença dos momentos do estado excitado e fundamental, a Figura 14, mostra os gráficos para a cumarina 31 e para o híbrido $57 \mathrm{~B}$.

Os gráficos de Lippert-Mataga foram construídos para se avaliar a contribuição do processo TCI dos fluoróforos. Quanto maior for o valor do coeficiente de inclinação, maior será a inclinação da reta. A influência do processo TCI será medida pelo valor de $\mathrm{R}^{2}$, valores acima de 0,7 indicam uma maior estabilização por TCI, como mostrado nas Tabelas 14 e 15 .

Tabela 14. Dados extraídos dos gráficos de Lippert-Mataga: equação de reta e fator de correlação $\left(\mathrm{R}^{2}\right)$ para cumarinas 31 e 32 .

\begin{tabular}{ccc}
\hline Cumarinas & Equação & $\mathbf{R}^{\mathbf{2}}$ \\
\hline $\mathbf{3 1}$ & $\mathrm{y}=7983,81+4728,51 \mathrm{x}$ & 0,80 \\
$\mathbf{3 2}$ & $\mathrm{y}=1669,14+1137,94 \mathrm{x}$ & 0,60 \\
\hline
\end{tabular}

Tabela 15. Dados extraídos dos gráficos de Lippert-Mataga: equação de reta e fator de correlação $\left(\mathrm{R}^{2}\right)$ para os híbridos $51 \mathrm{~B}-57 \mathrm{~B}$.

\begin{tabular}{ccc}
\hline Híbridos & Equação & $\mathbf{R}^{2}$ \\
\hline 51B & $\mathrm{y}=6560,34+1411,60 \mathrm{x}$ & 0,082 \\
$\mathbf{5 2 B}$ & $\mathrm{y}=3544,18+2997,69 \mathrm{x}$ & 0,30 \\
$\mathbf{5 3 B}$ & $\mathrm{y}=5674,41+2649,55 \mathrm{x}$ & 0,28 \\
$\mathbf{5 4 B}$ & $\mathrm{y}=3154,60-1539,67 \mathrm{x}$ & 0,11 \\
$\mathbf{5 5 B}$ & $\mathrm{y}=7470,92+124,38 \mathrm{x}$ & 0,20 \\
56B & $\mathrm{y}=3338,09+653,68 \mathrm{x}$ & 0,12 \\
$\mathbf{5 7 B}$ & $\mathrm{y}=839,19+4144,44 \mathrm{x}$ & 0,90 \\
\hline
\end{tabular}

A inclinação da reta é proporcional à diferença dos momentos do estado excitado e fundamental, a Figura 14 mostra os gráficos para a cumarina 31 e para o híbrido $57 \mathrm{~B}$.

Pode-se observar que para as moléculas em estudo, apenas a cumarina 31 e o híbrido $57 \mathrm{~B}$ apresentaram eficiência no processo TCI, cujos $\mathrm{R}^{2}$ têm valores de 0,80 e 
0,90, respectivamente. Isso indica que a geometria do composto sofre alterações no estado excitado e tem variação no momento dipolar.
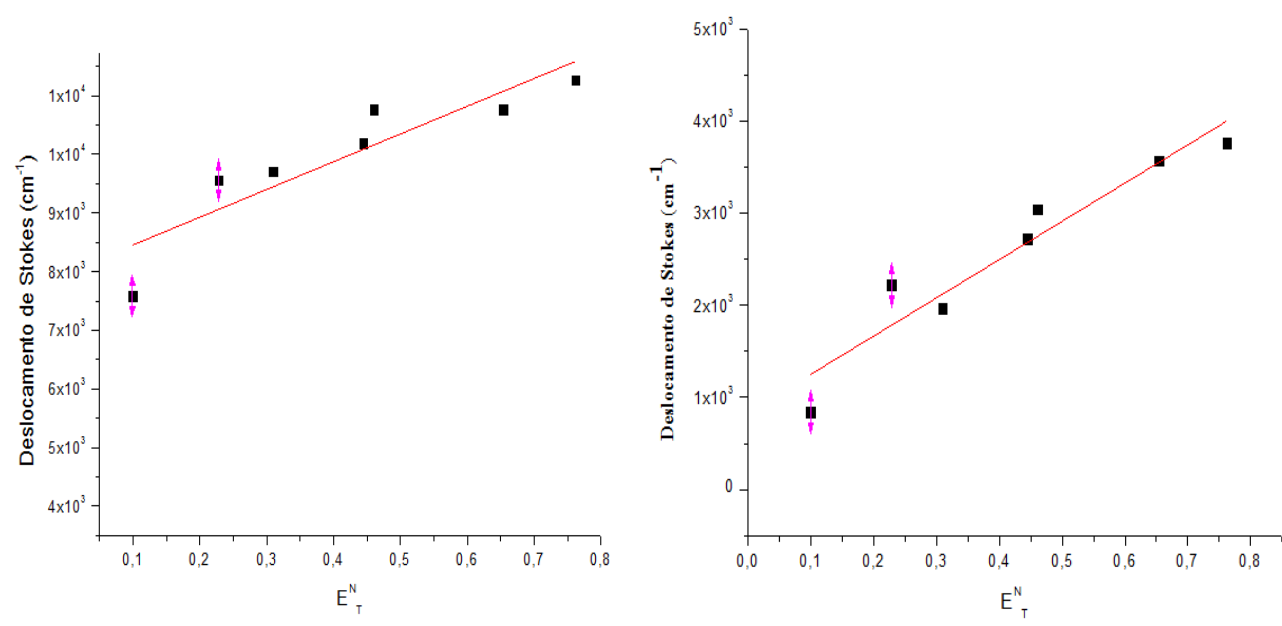

Figura 14. Gráfico de Lippert-Mataga, da cumarina 31 (esquerda) e do híbrido 57 B (direita).

\section{CONCLUSÕES E PERSPECTIVAS}

Diante da proposta desse trabalho, o objetivo desse projeto foi alcançado em termos da formação das duas cumarinas (31 e 32) e de sete híbridos derivados dessas cumarinas (51 B-57 B).

Para a síntese dos híbridos de cumarinas-chalconas, duas condições reacionais foram testadas, sendo a condição A em método convencional de refluxo e a condição B em micro-ondas. O que se pode concluir foi que a condição B se mostrou mais eficiente pois, utilizando essa condição, os sete híbridos foram sintetizados.

Nos estudos fotofísicos, os cálculos dos rendimentos quânticos e dos parâmetros extraídos dos gráficos de Lippert- Mataga (equação de reta e fator de correlação $\left(\mathrm{R}^{2}\right)$ ) nos permitiram ter uma ideia de como seriam as características das cumarinas e de seus híbridos, como fluoróforos.

Avaliando os resultados obtidos nos estudos fotofísicos das cumarinas e de seus híbridos, a perspectiva de continuidade do projeto seria a realização de estudos teóricos. Os quais possibilitam melhor compreensão das propriedades eletrônicas desses compostos e permitem a determinação dos valores energéticos dos orbitais HOMO e LUMO, além da determinação da distribuição de densidade eletrônica ao longo da estrutura de uma molécula (DFT_Density Functional Theory). 
Esses cálculos colaborariam com a possibilidade de realizar estudos com esses híbridos de cumarinas-chalconas na área de biologia, como por exemplo: marcadores biológicos.

\section{PARTE EXPERIMENTAL}

\subsection{REAGENTES, SOLVENTES E EQUIPAMENTOS}

Os solventes: acetonitrila, dimetilsulfóxido (DMSO), etanol, metanol e tolueno são comerciais e não foram destilados antes do uso. Já os solventes diclorometano e acetato de etila foram destilados, através de destilação simples sem tratamento prévio.

Os reagentes líquidos como: acetoacetato de etila, benzaldeído, 2clorobenzaldeído, 4-fluorbenzaldeído e salicilaldeído foram purificados por destilação.

Os reagentes sólidos como: 3-acetil-2H-cromen-2-ona, 3-acetil-7-dietilamino2H-cromen-2-ona, piperonal, 3-hidroxibenzaldeído e 4-dimetilaminobenzaldeído foram utilizados sem prévio tratamento.

Os equipamentos utilizados para realização das sínteses e das avaliações fotofísicas foram: balança analítica SHIMADZU 0,01 mg, espectrofotômetro: Varian Cary 50-Bio - visible Spectrophotometer, espectrofotômetro: Varian Cary Fluorescense Spectrophotometer, micro-ondas Anton Paar-Monowave 300, RMN Bruker Avance III HD $600 \mathrm{MHz}$, RMN Varian Mercury Plus 300MHz, rotaevaporador: IKA ${ }^{\circledR}$ RV10 control, pipeta automática 0,5-1,0 $\mu \mathrm{L}$ : DIGIPET e pipeta automática 1,0-5,0 $\mu \mathrm{L}$ : DIGIPET.

\subsection{NOMENCLATURA}

Os nomes dos análogos das cumarinas-chalconas foram atribuídos segundo o programa ChemDraw Ultra 12.0 que segue as regras da IUPAC.

\subsection{MÉTODOS ANALÍTICOS}

\subsubsection{Ressonância Magnética Nuclear (RMN)}

Os espectros de ressonância magnética nuclear foram obtidos em dois equipamentos, devido à sua disponibilidade na época da realização das análises. Os aparelhos usados foram: RMN Bruker Avance III HD, operando em campo magnético de $14 \mathrm{~T}$ e à frequência de ${ }^{1} \mathrm{H}$ de $600 \mathrm{MHz}$ e para o ${ }^{13} \mathrm{C}$ de $150 \mathrm{MHz}$, equipado com sonda do tipo 
Broadband Observe (BBFO) 5 mm e o RMN Varian Mercury Plus, operando em campo magnético 7,05T e à frequência de ${ }^{1} \mathrm{H}$ de $300 \mathrm{MHz}$ e para o ${ }^{13} \mathrm{C}$ de $75 \mathrm{MHz}$, equipado com sonda do tipo ATB $5 \mathrm{~mm}$.

Todas as cumarinas e seus análogos foram solubilizados em clorofórmio deuterado. Os deslocamentos químicos $(\delta)$ foram expressos em partes por milhão (ppm) tendo como referência interna o tetrametilsilano $\left(0,00 \mathrm{ppm}\right.$ para o $\left.\mathrm{RMN}{ }^{1} \mathrm{H}\right)$. Os dados espectroscópicos referentes aos espectros de RMN ${ }^{1} \mathrm{H}$ estão representados segundo a convenção: deslocamentos químicos $(\delta)$ (multiplicidade, constante de acoplamento em $\mathrm{Hz}$, número de hidrogênios). As multiplicidades dos sinais de emissão dos hidrogênios nos espectros de RMN ${ }^{1} \mathrm{H}$ foram indicadas de acordo com a convenção: s (simpleto), $\mathrm{d}$ (dupleto), dd (duplo-dupleto), t (tripleto), q (quadrupleto) e m (multipleto).

\subsubsection{Espectrofotômetro: estudo fotofísico e rendimento quântico}

As leituras de absorção e emissão foram realizadas nos seguintes equipamentos: Varian Cary 50-Bio - visible Spectrophotometer com velocidade média e leitura de branco e Varian Cary Fluorescense Spectrophotometer com leitura lenta a rápida com fenda de 5,0 a 10, respectivamente.

Para as leituras de absorção e emissão utilizou-se uma solução estoque das cumarinas e de seus análogos a concentração de $10^{-2} \mathrm{~mol} \mathrm{~L}^{-1}$ em diclorometano. Uma alíquota de $4 \mu \mathrm{L}$ era transferida para uma cubeta de quartzo por meio de uma pipeta automática (DIGIPET 0,5-1,0 $\mu \mathrm{L}$ ) e então diluída com $4 \mathrm{~mL}$ do solvente escolhido através de uma pipeta automática (DIGIPET 1,0-5,0 mL), obtendo-se uma solução com concentração de $10^{-5} \mathrm{~mol} \mathrm{~L}^{-1}$ para aquisição dos gráficos.

O estudo fotofísico foi realizado com sete solventes, e são eles: acetato de etila, acetonitrila, dimetilsulfóxido, diclorometano, etanol, metanol e tolueno. Os solventes são P.A., com exceção do acetato de etila que foi destilado.

Para definir os rendimentos quânticos usou-se o comparativo com a solução de sulfato de quinina à concentração de $10^{-5} \mathrm{~mol} \mathrm{~L}^{-1}$, essa solução foi preparada a partir do cloridrato de quinina com ácido sulfúrico $1 \mathrm{M}$.

A partir das soluções estoque das ceto-cumarinas e de seus híbridos foram feitas diluições, conforme descrito anteriormente, de forma a obterem soluções com concentração de $10^{-5} \mathrm{~mol} \mathrm{\textrm {L } ^ { - 1 }}$ em acetonitrila para cada ceto-cumarina e para cada híbrido. 
As análises foram realizadas no equipamento Varian Cary Fluorescense Spectrophotometer com fenda de 5,0 e com fonte de excitação $366 \mathrm{~nm}$ (valor de referência para o sulfato de quinina). Os dados foram coletados na forma de gráficos no próprio equipamento.

Com as curvas obtidas, as áreas absolutas foram determinadas e aplicadas na seguinte relação matemática:

$\Phi_{\mathrm{x}}=\Phi_{\mathrm{sq}}\left(\operatorname{Grad}_{\mathrm{x}} / \operatorname{Grad}_{\mathrm{sq}}\right)\left(\eta_{\mathrm{x}}{ }^{2} / \eta_{\mathrm{sq}}{ }^{2}\right)$ Eq 1

Os termos da equação são definidos da seguinte forma:

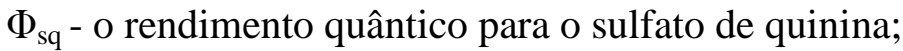

Grad - gradiente da área integrada de fluorescência;

$\eta$ - índice de refração do solvente;

$\mathrm{x}$ - cada amostra.

Importante ressaltar que o índice de refração da solução de sulfato de quinina e do solvente acetonitrila são iguais, portanto o último termo da equação se torna 1 , simplificando os cálculos.

As análises foram feitas em triplicatas e os desvios padrões dos rendimentos quânticos foram calculados para cada composto.

\subsection{PROCEDIMENTOS GERAIS}

\subsubsection{Procedimento geral para a síntese das cumarinas 31 e 32}

Em um balão de fundo redondo $(50 \mathrm{~mL})$, foram adicionados o aldeído, o acetoacetato de etila e a piperidina. O sistema foi mantido sob agitação em temperatura ambiente durante duas horas, após esse período foi adicionado ao sistema $\mathrm{HCl} 1 \mathrm{M}$. O produto precitado foi filtrado à vácuo com auxílio de água destilada e posteriormente foi purificado através de recristalização com etanol P.A.

\subsubsection{Procedimentos e dados espectroscópicos das cumarinas 31 e 32}

\section{3-acetil-2-H-cromen-2-ona (31)}<smiles>CC(=O)c1cc2ccccc2oc1=O</smiles>

Seguindo o procedimento geral para se obter a cumarina 31 utilizouse: salicilaldeído (5 mmol, 6,1 g), o acetoacetato de etila $(10 \mathrm{mmol}, 12,8 \mathrm{~mL})$ e a 
piperidina $(0,4 \mathrm{~mL})$. Obteve-se um sólido branco, massa igual 5,64 $\mathrm{g}$, rendimento de $60 \%$.

(E.1) $\mathrm{RMN}{ }^{1} \mathrm{H}\left(300 \mathrm{MHz} ; \mathrm{CDCl}_{3}\right) \delta: 8,51$ (s, 1H); 7,68-7,63 (m, 2H); 7,39-7,32 (m, $2 \mathrm{H}) ; 2,73(\mathrm{~s}, 3 \mathrm{H})$.

(E.2) $\mathrm{RMN}{ }^{13} \mathrm{C}\left(75 \mathrm{MHz} ; \mathrm{CDCl}_{3}\right) \delta: 195,5 ; 159,2 ; 155,3 ; 147,5 ; 134,4 ; 130,2 ; 125,0$; 124,$5 ; 118,2 ; 116,7 ; 30,6$.

\section{3-acetil-7-dietilamino-2-H-cromen-2-ona (32)}<smiles>CCN(CC)c1ccc2cc(C(C)=O)c(=O)oc2c1</smiles>

Seguindo o procedimento geral, para se obter a cumarina 32 utilizou-se: o $N, N$-dietil-p-salicilbenzaldeído $(0,5 \mathrm{mmol}, 0,1 \mathrm{~g})$, o acetoacetato de etila $(1 \mathrm{mmol}, 0,13 \mathrm{~mL})$ e a piperidina $(0,02 \mathrm{~mL})$. Obteve-se um sólido amarelo, massa igual $1,0 \mathrm{~g}$, rendimento de $52 \%$.

(E.3) $\mathrm{RMN}{ }^{1} \mathrm{H}\left(600 \mathrm{MHz} ; \mathrm{CDCl}_{3}\right) \delta: 8,43(\mathrm{~s}, 1 \mathrm{H}) ; 7,40(\mathrm{~d}, J=9 \mathrm{~Hz}, 1 \mathrm{H}) ; 6,62(\mathrm{dd}, J=$ $9 \mathrm{~Hz}$ e $J=2,6 \mathrm{~Hz}, 1 \mathrm{H}) ; 6,5(\mathrm{~d}, J=2,6 \mathrm{~Hz}, 1 \mathrm{H}) ; 3,46(\mathrm{q}, J=7 \mathrm{~Hz}, 4 \mathrm{H}) ; 1,24$ (t, $J=7 \mathrm{~Hz}$, $6 \mathrm{H}) ; 2,67(\mathrm{~s}, 3 \mathrm{H})$.

(E.4) $\mathrm{RMN}{ }^{13} \mathrm{C}\left(150 \mathrm{MHz} ; \mathrm{CDCl}_{3}\right) \delta: 195,8 ; 160,9 ; 158,8 ; 153,0 ; 147,9 ; 131,9 ; 116,2$; 110,$0 ; 108,2 ; 96,6 ; 45,2 ; 30,6 ; 12,5$.

\subsubsection{Procedimento geral para a síntese dos híbridos de cumarinas-chalconas: condição A}

Em um schlenck de $15 \mathrm{~mL}$ foi adicionada a ceto-cumarina, o aldeído, o etanol e a piperidina como catalisador. O sistema foi colocado sob agitação a uma temperatura de $80^{\circ} \mathrm{C}$, durante $12 \mathrm{~h}$. Concluída a reação, o solvente foi rotaevaporado, o produto foi mantido durante $6 \mathrm{~h}$ na bomba de vácuo e purificado através de coluna cromatográfica com uma mistura de acetato de etila/hexano na proporção 3:7. 


\subsubsection{Procedimento e dado espectroscópico do híbrido de cumarina-chalcona: condição A}

(E)-3-(3-(4-dimetilamino)fenil)acriloil)-2H-cromen-2-ona (54 A)

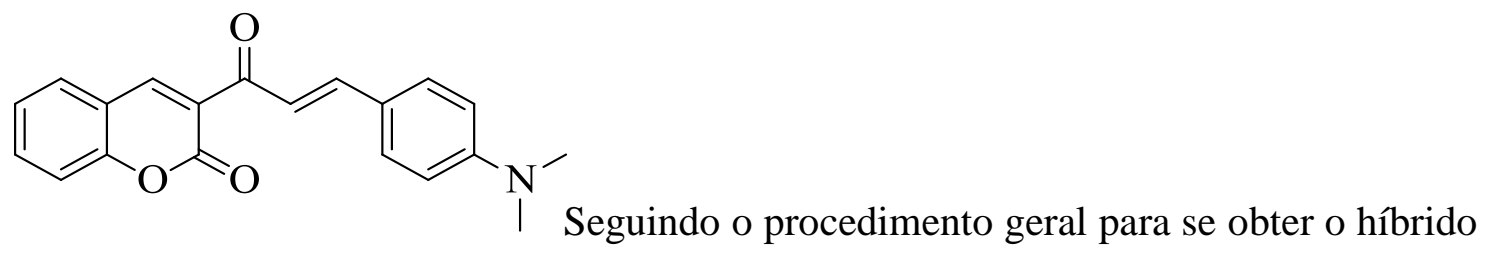

54A utilizou-se: a 3-acetil-2-H-cromen-2-ona (1 mmol, 0,188 g), o N,N-dimetilamino- $p$ benzaldeído (1 mmol, 0,149 g), o etanol $(2 \mathrm{~mL})$ e a piperidina $(0,1 \mathrm{~mL})$ como catalisador. Obteve-se um sólido laranja, massa igual 1,6 g, rendimento de 50\%.

(E.5) $\mathrm{RMN}{ }^{1} \mathrm{H}\left(600 \mathrm{MHz} ; \mathrm{CDCl}_{3}\right) \delta: 8,55(\mathrm{~s}, 1 \mathrm{H}) ; 7,87(\mathrm{~d}, J=15,7 \mathrm{~Hz}, 1 \mathrm{H}) ; 7,73(\mathrm{~d}, J=$ $15,7 \mathrm{~Hz}, 1 \mathrm{H}) ; 7,65-7,61(\mathrm{~m}, 2 \mathrm{H}) ; 7,58(\mathrm{~d}, J=9 \mathrm{~Hz}, 2 \mathrm{H}) ; 7,38(\mathrm{~d}, J=8 \mathrm{~Hz}, 1 \mathrm{H}) ; 7,33$ (t, $J$ $=8 \mathrm{~Hz}, 1 \mathrm{H}) ; 6,68(\mathrm{~d}, J=9 \mathrm{~Hz}, 2 \mathrm{H}) ; 3,05(\mathrm{~s}, 6 \mathrm{H})$.

(E.6) $\mathrm{RMN}{ }^{13} \mathrm{C}\left(150 \mathrm{MHz} ; \mathrm{CDCl}_{3}\right) \delta: 186,0 ; 160,0 ; 155,1 ; 152,3 ; 147,2 ; 146,5 ; 133,7$; 131,$1 ; 129,8 ; 126,1 ; 124,8 ; 122,7 ; 118,7 ; 116,6 ; 111,8 ; 40,1$.

\subsubsection{Procedimento geral para a síntese dos híbridos de cumarinas-chalconas: condição B}

Em um tubo selado de micro-ondas de $30 \mathrm{~mL}$ modelo $\mathrm{G} 30$ foi adicionada a cetocumarina, o aldeído e a piperidina. O tubo foi colocado no interior de um reator de M.O. (Anton Paar-Monowave 300) e submetido a irradiação por micro-ondas num intervalo de 7 a 45 min, a uma potência de $400 \mathrm{~W}$, sob uma temperatura de $80^{\circ} \mathrm{C}$. Concluída a reação o produto foi extraído com diclorometano. Posteriormente, o solvente foi rotaevaporado e o sólido obtido foi purificado através de recristalização com etanol P.A. em temperatura ambiente ou purificado através de coluna cromatográfica com uma mistura de acetato de etila/hexano na proporção de 3:7. 


\subsubsection{Procedimentos e dados espectroscópicos dos híbridos de cumarinas- chalconas: condição B}

\section{3-cinamoil-2-H-cromen-2-ona (51 B)}<smiles>O=C(/C=C/c1ccccc1)c1cc2ccccc2oc1=O</smiles>

Seguindo o procedimento geral, para se obter o híbrido 51B utilizou-se: a 3-acetil-2-H-cromen-2-ona (1 mmol, 0,188 g), o benzaldeído (1 mmol, $0,1 \mathrm{~mL})$ e a piperidina $(0,05 \mathrm{~mL})$. Tempo de reação foi de $7 \mathrm{~min}$. Obteve-se um sólido amarelo, massa igual $0,09 \mathrm{~g}$, rendimento de $31 \%$.

(E.7) $\mathrm{RMN}{ }^{1} \mathrm{H}\left(600 \mathrm{MHz} ; \mathrm{CDCl}_{3}\right) \delta: 8,59(\mathrm{~s}, 1 \mathrm{H}) ; 7,88(\mathrm{~d}, J=15,4 \mathrm{~Hz}, 1 \mathrm{H}) ; 7,82(\mathrm{~d}, J=$ $15,4 \mathrm{~Hz}, 1 \mathrm{H}) ; 7,69-7,65$ (m, 4H); 7,42-7,40 (m, 4H); 7,36 (t, $J=8 \mathrm{~Hz}, 1 \mathrm{H})$.

(E.8) $\mathrm{RMN}{ }^{13} \mathrm{C}\left(150 \mathrm{MHz} ; \mathrm{CDCl}_{3}\right) \delta: 186,5 ; 159,3 ; 155,3 ; 148,1 ; 145,1 ; 134,8 ; 134,3$; 130,$8 ; 130,1 ; 128,9 ; 125,0 ; 123,9 ; 118,6 ; 116,7$.

\section{(E)-3-(3-(benzo[d][1,3]dioxol-5-il)acriloil)-2H-cromen-2-ona (52 B)}

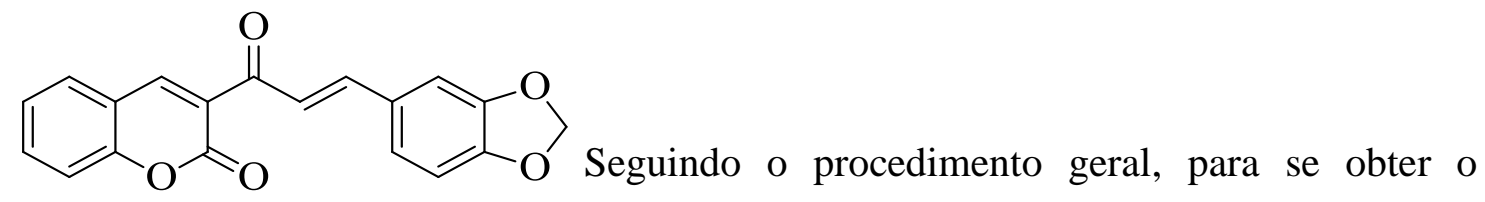
híbrido 52B utilizou-se: a 3-acetil-2-H-cromen-2-ona (1 mmol, 0,188 g), o piperonal (1 mmol, $0,150 \mathrm{~g})$ e a piperidina $(0,05 \mathrm{~mL})$. Tempo de reação foi de $15 \mathrm{~min}$. Obteve-se um sólido branco, massa igual $0,08 \mathrm{~g}$, rendimento de $25 \%$.

(E.9) $\mathrm{RMN}{ }^{1} \mathrm{H}\left(600 \mathrm{MHz} ; \mathrm{CDCl}_{3}\right) \delta: 8,58(\mathrm{~s}, 1 \mathrm{H}) ; 7,81(\mathrm{~d}, J=15,4 \mathrm{~Hz}, 1 \mathrm{H}) ; 7,78(\mathrm{~d}, J=$ $15,4 \mathrm{~Hz}, 1 \mathrm{H}) ; 7,68-7,64(\mathrm{~m}, 2 \mathrm{H}) ; 7,40(\mathrm{~d}, J=8 \mathrm{~Hz}, 1 \mathrm{H}) ; 7,35$ (t, $J=8 \mathrm{~Hz}, 1 \mathrm{H}) ; 7,21$ (d, $J$ $=1,4 \mathrm{~Hz}, 1 \mathrm{H}) ; 7,16(\mathrm{dd}, J=8 \mathrm{~Hz}$ e $J=1,4 \mathrm{~Hz}, 1 \mathrm{H}) ; 6,84(\mathrm{~d}, J=1,4 \mathrm{~Hz}, 1 \mathrm{H}) ; 6,03(\mathrm{~s}, 2 \mathrm{H})$. (E10) $\mathrm{RMN}{ }^{13} \mathrm{C}\left(150 \mathrm{MHz} ; \mathrm{CDCl}_{3}\right) \delta: 186,2 ; 159,4 ; 155,3 ; 150,3 ; 147,9 ; 145,0 ; 134,2$; 130,$0 ; 125,9 ; 125,0 ; 122,1 ; 118,6 ; 116,7 ; 108,7 ; 107,1 ; 101,7$. 
<smiles>O=C(/C=C/c1ccc(I)cc1)c1cc2ccccc2oc1=O</smiles>

Seguindo o procedimento geral, para se obter o híbrido 53B utilizou-se: a 3-acetil-2-H-cromen-2-ona (1 mmol, 0,188 g), o 4-fluorbenzaldeído $(1 \mathrm{mmol}, 0,124 \mathrm{~g})$ e a piperidina $(0,05 \mathrm{~mL})$. Tempo de reação foi de $7 \mathrm{~min}$. Obteve-se um sólido branco, massa igual 0,06g, rendimento de $22 \%$.

(E.11) $\mathrm{RMN}{ }^{1} \mathrm{H}\left(600 \mathrm{MHz} ; \mathrm{CDCl}_{3}\right) \delta: 8,59(\mathrm{~s}, 1 \mathrm{H}) ; 7,89(\mathrm{~d}, J=15,8 \mathrm{~Hz}, 1 \mathrm{H}) ; 7,83(\mathrm{~d}, J=$ $15,8 \mathrm{~Hz}, 1 \mathrm{H}) ; 7,68-7,65(\mathrm{~m}, 4 \mathrm{H}) ; 7,40(\mathrm{~d}, J=8 \mathrm{~Hz}, 1 \mathrm{H}) ; 7,36(\mathrm{t}, J=8 \mathrm{~Hz}, 1 \mathrm{H}) ; 7,10(\mathrm{~d}, J$ $=9 \mathrm{~Hz}, 2 \mathrm{H})$.

(E.12) $\mathrm{RMN}{ }^{13} \mathrm{C}\left(150 \mathrm{MHz} ; \mathrm{CDCl}_{3}\right) \delta: 186,3 ; 159,3 ; 155,3 ; 148,1 ; 145,1 ; 144,8 ; 134,8$; 134,$3 ; 130,8 ; 130,1 ; 128,9 ; 125,3 ; 125,0 ; 123,9 ; 118,6 ; 116,7 ; 53,4 ; 37,3$.

(E)-3-(3-(4-dimetilamino)fenil)acriloil)-2H-cromen-2-ona (54 B)

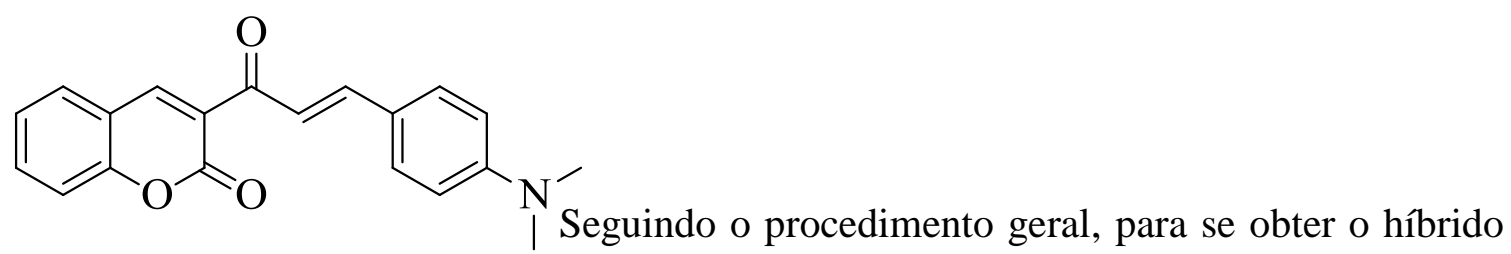
54B utilizou-se: a 3-acetil-2-H-cromen-2-ona (1 mmol, 0,188 g), o $N, N$ dimetilamino- $p$ benzaldeído ( $1 \mathrm{mmol}, 0,149 \mathrm{~g})$ e a piperidina $(0,05 \mathrm{~mL})$. Tempo de reação foi de 15 min. Obteve-se um sólido branco, massa igual $2,2 \mathrm{~g}$, rendimento de $68 \%$.

(E.13) $\mathrm{RMN}{ }^{1} \mathrm{H}\left(600 \mathrm{MHz} ; \mathrm{CDCl}_{3}\right) \delta: 8,55(\mathrm{~s}, 1 \mathrm{H}) ; 7,87(\mathrm{~d}, J=15,7 \mathrm{~Hz}, 1 \mathrm{H}) ; 7,73(\mathrm{~d}, J=$ $15,7 \mathrm{~Hz}, 1 \mathrm{H}) ; 7,65-7,61(\mathrm{~m}, 2 \mathrm{H}) ; 7,58(\mathrm{~d}, J=9 \mathrm{~Hz}, 2 \mathrm{H}) ; 7,38(\mathrm{~d}, J=8 \mathrm{~Hz}, 1 \mathrm{H}) ; 7,33$ (t, $J$ $=8 \mathrm{~Hz}, 1 \mathrm{H}) ; 6,68(\mathrm{~d}, J=9 \mathrm{~Hz}, 2 \mathrm{H}) ; 3,05(\mathrm{~s}, 6 \mathrm{H})$.

(E.14) $\mathrm{RMN}{ }^{13} \mathrm{C}\left(150 \mathrm{MHz} ; \mathrm{CDCl}_{3}\right) \delta: 186,0 ; 159,2 ; 155,1 ; 152,3 ; 147,2 ; 146,5 ; 133,7$; 131,$1 ; 129,8 ; 126,1 ; 124,8 ; 122,7 ; 118,7 ; 116,6 ; 111,8 ; 40,1$. 


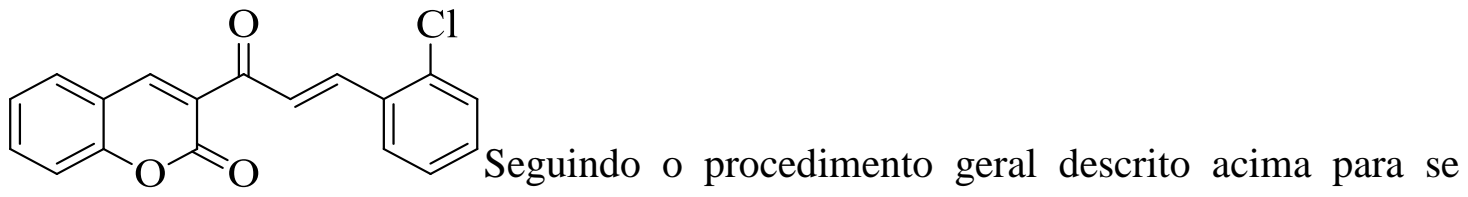
obter o híbrido 55B utilizou-se: a 3-acetil-2-H-cromen-2-ona (1 mmol, 0,188 g), o 2clorobenzaldeído ( $1 \mathrm{mmol}, 0,140 \mathrm{~g})$ e a piperidina $(0,05 \mathrm{~mL})$. Tempo de reação foi de 7 min. Obteve-se um sólido branco, massa igual 0,03g, rendimento de $9 \%$.

(E.15) $\mathrm{RMN}{ }^{1} \mathrm{H}\left(600 \mathrm{MHz} ; \mathrm{CDCl}_{3} \delta: 8,55(\mathrm{~s}, 1 \mathrm{H}) ; 7,87(\mathrm{~d}, J=15,7 \mathrm{~Hz}, 1 \mathrm{H}) ; 7,73(\mathrm{~d}, J=\right.$ $15,7 \mathrm{~Hz}, 1 \mathrm{H}) ; 7,65-7,61(\mathrm{~m}, 2 \mathrm{H}) ; 7,58(\mathrm{~d}, J=9 \mathrm{~Hz}, 2 \mathrm{H}) ; 7,38(\mathrm{~d}, J=8 \mathrm{~Hz}, 1 \mathrm{H}) ; 7,33$ (t, $J$ $=8 \mathrm{~Hz}, 1 \mathrm{H}) ; 6,68(\mathrm{~d}, J=9 \mathrm{~Hz}, 2 \mathrm{H}) ; 3,05(\mathrm{~s}, 6 \mathrm{H})$.

(E.16) $\mathrm{RMN}{ }^{13} \mathrm{C}\left(150 \mathrm{MHz} ; \mathrm{CDCl}_{3}\right) \delta: 186,0 ; 159,5 ; 155,1 ; 152,3 ; 147,2 ; 146,5 ; 133,7$; 131,$1 ; 129,8 ; 126,1 ; 124,8 ; 122,7 ; 118,7 ; 116,6 ; 111,6 ; 40,1$.

\section{(E)-7-(dietilamino)-3-(3-(4-dimetilaminol)fenil)acriloil)-2H-cromen-2-ona (56 B)}

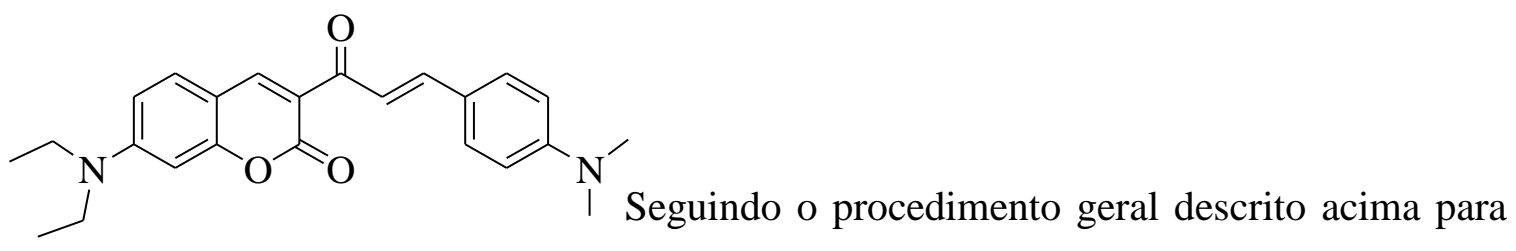
se obter o híbrido 56B utilizou-se: 3 -acetil-7-dietilamino-2-H-cromen-2-ona (0,5 mmol, 0,130 g), o 4-dimetilaminobenzaldeído (0,5 mmol, 0,075 g) e a piperidina $(0,05 \mathrm{~mL})$. Tempo de reação foi de $30 \mathrm{~min}$. Obteve-se um sólido laranja, massa igual 0,2g, rendimento de $48 \%$.

(E.17) $\mathrm{RMN}{ }^{1} \mathrm{H}\left(600 \mathrm{MHz} ; \mathrm{CDCl}_{3}\right) \delta: 8,54(\mathrm{~s}, 1 \mathrm{H}) ; 7,97(\mathrm{~d}, J=15,5 \mathrm{~Hz}, 1 \mathrm{H}) ; 7,82(\mathrm{~d}, J$ $=15,5 \mathrm{~Hz}, 1 \mathrm{H}) ; 7,59(\mathrm{~d}, J=8,8 \mathrm{~Hz}, 2 \mathrm{H}) ; 7,41(\mathrm{~d}, J=9,1 \mathrm{~Hz}, 1 \mathrm{H}) ; 6,68(\mathrm{~d}, J=9,1 \mathrm{~Hz}$, $2 \mathrm{H}) ; 6,61(\mathrm{dd}, J=9 \mathrm{~Hz}$ e $J=2,3 \mathrm{~Hz}, 1 \mathrm{H}) ; 6,49(\mathrm{~d}, J=2,3 \mathrm{~Hz}, 1 \mathrm{H}) ; 3,45(\mathrm{q}, J=7 \mathrm{~Hz}, 4 \mathrm{H})$; $3,03(\mathrm{~s}, 6 \mathrm{H}) ; 1,24(\mathrm{t}, J=7 \mathrm{~Hz}, 6 \mathrm{H})$.

(E.18) $\mathrm{RMN}{ }^{13} \mathrm{C}\left(150 \mathrm{MHz} ; \mathrm{CDCl}_{3}\right) \delta: 186,2 ; 161,0 ; 158,4 ; 152,6 ; 148,2 ; 144,7 ; 131,5$; 130,$8 ; 123,3 ; 119,7 ; 117,5 ; 111,7 ; 109,6 ; 108,7 ; 96,6 ; 45,1 ; 40,1 ; 12,5$. 
(E)-7-dietilamino-3-(3-(3-hidroxifenil)acriloil)-2H-cromen-2-ona (57 B)<smiles>CCN(CC)c1ccc2cc(C(=O)/C=C/c3cccc(O)c3)c(=O)oc2c1</smiles>

Seguindo o procedimento geral descrito acima para se obter o híbrido 57B utilizou-se: a 3-acetil-7-dietilamino-2-H-cromen-2-ona (0,5 mmol, 0,130 g), o 3-hidroxibenzaldeído (0,5 mmol, 0,06 g) e a piperidina $(0,05 \mathrm{~mL})$. Obteve-se um sólido amarelo, massa igual $0,1 \mathrm{~g}$, rendimento de $28 \%$.

(E.19) $\mathrm{RMN}{ }^{1} \mathrm{H}\left(600 \mathrm{MHz} ; \mathrm{CDCl}_{3}\right) \delta: 8,55(\mathrm{~s}, 1 \mathrm{H}) ; 8,11(\mathrm{~d}, J=15,8 \mathrm{~Hz}, 1 \mathrm{H}) ; 7,76(\mathrm{~d}, J$ $=15,8 \mathrm{~Hz}, 1 \mathrm{H}) ; 7,43(\mathrm{~d}, J=9 \mathrm{~Hz}, 2 \mathrm{H}) ; 7,25-7,19(\mathrm{~m}, 3 \mathrm{H}) ; 6,63(\mathrm{dd}, J=9 \mathrm{~Hz}$ e $J=$ 2,6Hz, 1H); 6,49 (d, $J=2,5 \mathrm{~Hz}, 1 \mathrm{H}) ; 3,47(\mathrm{q}, J=7,3 \mathrm{~Hz}, 4 \mathrm{H}) ; 1,25$ (t, $J=7 \mathrm{~Hz}, 6 \mathrm{H})$. (E.20) $\mathrm{RMN}{ }^{13} \mathrm{C}\left(150 \mathrm{MHz} ; \mathrm{CDCl}_{3}\right) \delta: 186,6 ; 161,1 ; 158,7 ; 156,2 ; 153,1 ; 148,9 ; 143,1$; 136,$9 ; 131,9 ; 130,0 ; 125,2 ; 121,7 ; 117,6 ; 114,8 ; 110,0 ; 108,7 ; 96,7 ; 45,3 ; 45,2 ; 29,7$; 12,5 . 


\section{REFERÊNCIAS BIBLIOGRÁFICAS}

[1] Naruka, S. G.; Mahajan, S. S. IJRPC, 2011, 1, 879.

[2] Martins, S. M. A.; Branco, P. C. S.; Pereira, A.M.D.L.R.. J. Braz. Chem. Soc., 2012, 23, 688.

[3] Phadtare, S. B.; Jarag, K. J.; Shankarling, G. S. Dyes Pig., 2013, 97,105.

[4] Santos,W.H.; Siqueira, M.S.; Silva-Filho, L.C. Quím. Nova, 2013, 36,1303

[5] Mohamed, F.A.; Bashandy, M.S.; Abd ElWahab, H.; Sheier, M. B.; El Molla, M.M.; Beclair; A.H. I.J.A.R., 2014, 2,248.

[6] Johnson, J.R. Org. React., 1942, 1, 210.

[7] Shriner, R. L. Org. React., 1942, 1, 15.

[8] Kadin, S. B. J. Org. Chem., 1996, 31, 620.

[9] Pechmann, V. Berichte der deutschen chemischen Gesellschaft, 1884, 17, 929.

[10] Czakó, B.; Kürti, L. Strategic Applications in Organic Synthesis, $1^{\text {a }}$ ed.; Ed. Elsevier.

[11] Lawrence, N. J.; Rennison, D.; McGown, A. T.; Ducki, S.; Gul, L. A.; Hadfield, J. A.;

Khan, K; J. Comb. Chem. 2001, 3, 421.

[12] Jayashree, B.S.; Yusuf, S.; Kumar; D.V. J. Asian Chem., 2009, 21, 5918.

[13] Lee,S.C.; Kang, N-Y.; Park, S-J.; Yun, S-W.; Chandran, Y.; Chang, Y-T. Chem. Comm., 2012

[14] Ghouili, A.; Dusek, M.; Petricek, V.; Ayed, T. B.; Hassen, R. B. J.Phys. Chem., 2014, 75, 188.

[15] Alvim, H. G. O.; Fagg, E. L.; de Oliveira, A. L.; de Oliveira, H. C. B.; Freitas, S. M.; Xavier, M.-A. E.; Soares, T. A.; Gomes, A. F.; Gozzo, F. C.; Silva, W. A.; Neto, B. A. D. Org. Biomol. Chem. 2013, 11, 4764.

[16] Setsukinai, K.; Urano, Y.; Kikuchi, K.; Higuchi, T.; Nagano, T. J. Chem. Soc., 2000, 2, 2453.

[17] Kivala, M.; Diederich, F. Acc. Chem. Res., 2009,42, 235.

[18] Barreiro, E. J.; Fraga, C.A.M. Quím. Nova, 2005,28,S 56.

[19] Oliveira, A. A., Tese de Mestrado. Universidade de Brasília, 2012, 2.

[20] Fonseca, P. S., Tese de Mestrado. Universidade de Brasília, 2012, 25.

[21] Jagtap, A. R.; Satam, V. S.; Rajule, R. N.; Kanetkar, V. R. Dyes Pig., 2011, 91,20.

[22] Skoog, D.A.; West, D.M.; Holler, F. J.; Stanley, R.C.; Fundamentos da Química Analítica, Tradução da $8^{a}$ ed.; Ed. Thomson: São Paulo, SP, 2008.

[23] Lakowicz, J. R.; Principles of Fluorescence Spectroscopy; Springer: Nova York, 2006.

[24] Beltrán, O. G.; González, C.; Pérez, E. G.; Cassels, B. K.; Santos, J. G.; Millán, D.;Mena,N.; Pavez, P.; Aliaga, M. G. J. Phys. Org. Chem, 2012, 25, 946.

[25] Lavis, L. D.; Raines, R. T.; ACS Chem. Biol. 2014, 9, 855. 
[26] Lopes, T. O., Tese de Mestrado. Universidade de Brasília, 2014,11.

[27] Hayes, B. L., Microwave Synthesis Chemistry at the Speed of Light, Ed. CEM Publishing, 2002.

[28] Yang, X.; Wu, J.; Mao, X.; Jamison, T. F.; Hatton, T. A. Chem. Comm., 2014, 50, 3245.

[29] Maitani, M.M.; Inoue, T.; Tsukushi, Y.; Hansen, N.D.J.; Mochizuki, D.; Suzuki, E.; Wada, Y. R.S.C., 2013, 49, 10841.

[30] a) Khode, S.; Maddi, V.; Aragade, P.; Palkar, M.; Ronad, P.K.; Mamledesai, S.; Thippeswamy, A. H.M.; Satyanarayana, D.; Eur. J. Med. Chem. 2009, 44, 1682. b) Tanaka, K.; Sugino, T.; Chem. Lett. 2001, 110.

[31] Ajani, O. O.; Nwinyi, O. C., J. Heterocyclic Chem. 2010, 47,179.

[32] Reichardt, C., Chem. Rev. 1994, 94, 2319.

[33] Laurent, A.D.; Houari, Y.; Carvalho, P. H. P. R.; Neto, B. A. D.; Jacquemin, D. RSC Adv. 2014, 14, 189.

[34] Reichardt, C., Solvents and Solvent Effects in Organic Chemistry Weinheim, 2003.

[35] Mataga, N.; Torihashi, Y.; Ezumi, K. Theor. Chem. Acta, 1964, 2,158.

[36] Guérin, J.; Aronica, C.; Boeuf, G.; Chauvin, J.; Moreau, J.; Lemercier, G. J.Lumin. 2011,131, 2668.

[37] Filarowski, A.; Kluba, M.; Cieslik-Boezula, K.; Koel, A.; Rochel, A.; Pandey, L.; De Borggraeve, W. M.; Vander Awweraer, M.; Catalan, J.; Boens, N. Photobiol. Sci. 2010, 9, 996. 


\section{ANEXOS}

\subsection{ESPECTROS DE RMN ${ }^{1} \mathrm{He} \mathrm{e}^{13} \mathrm{C}$}
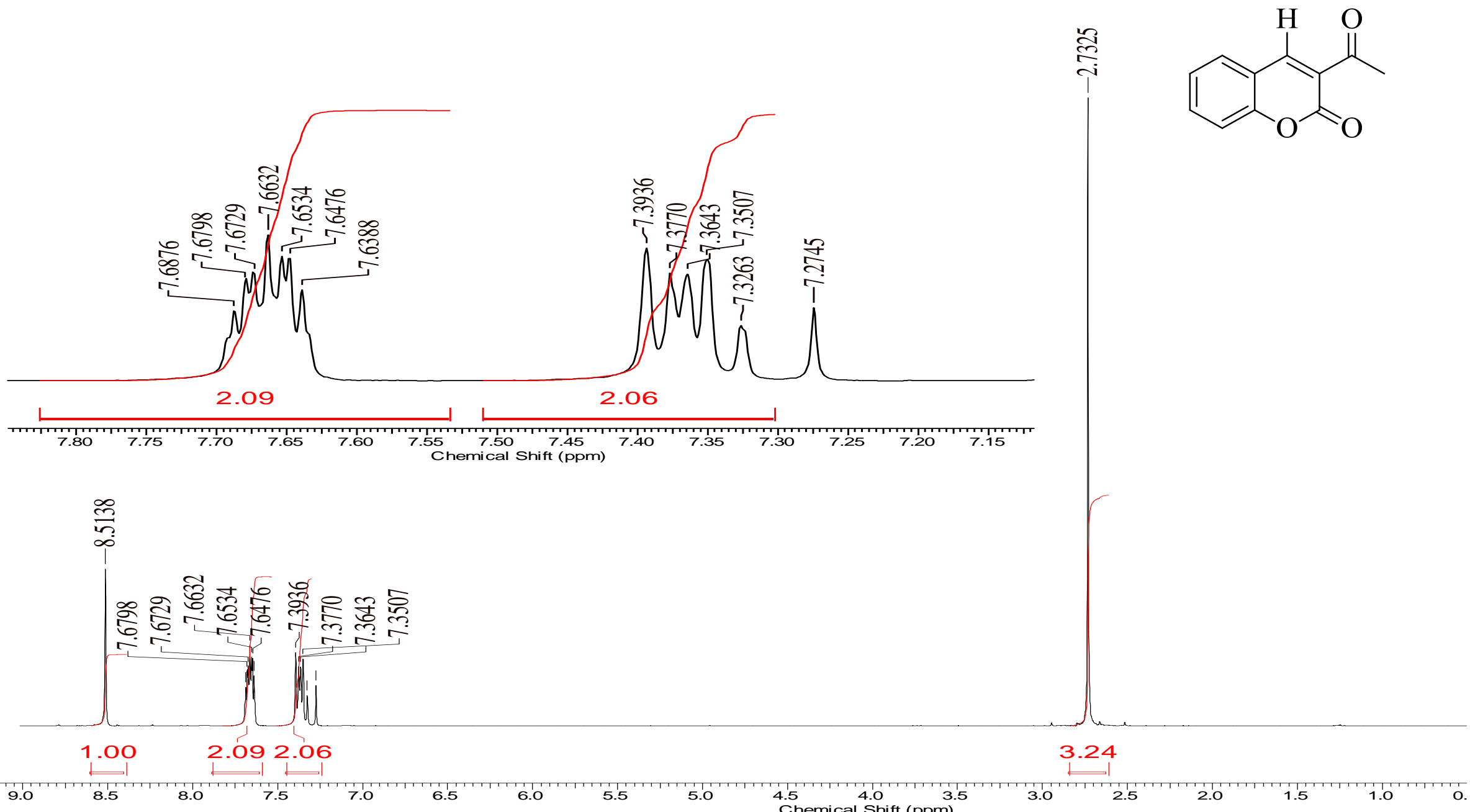

Espectro 1: Espectro de RMN ${ }^{1} \mathrm{H}\left(300 \mathrm{MHz}, \mathrm{CDCl}_{3}\right)$ da estrutura da cumarina 31. 


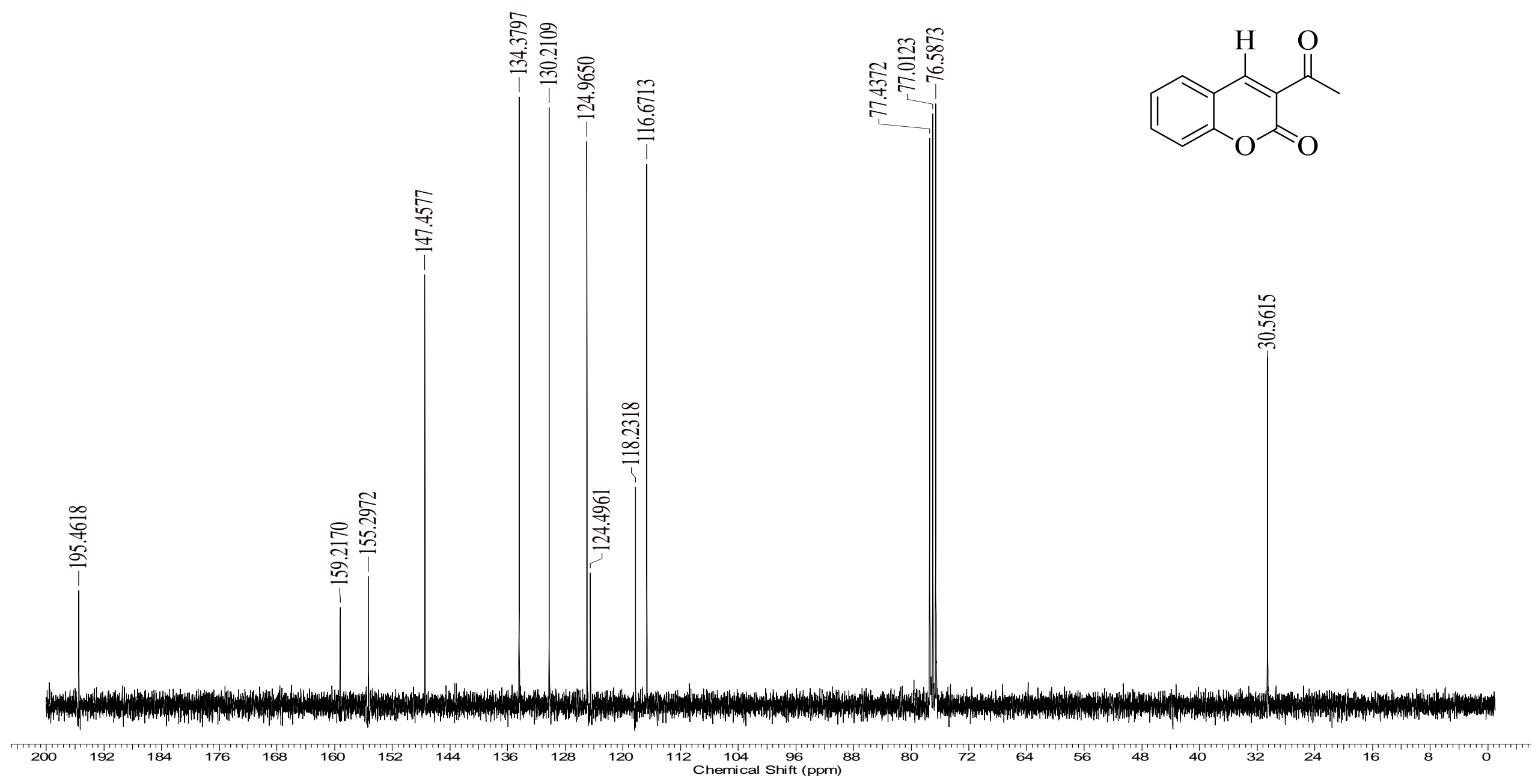

Espectro 2: Espectro de $\mathrm{RMN}{ }^{13} \mathrm{C}\left(75 \mathrm{MHz}, \mathrm{CDCl}_{3}\right)$ da estrutura da cumarina 31. 


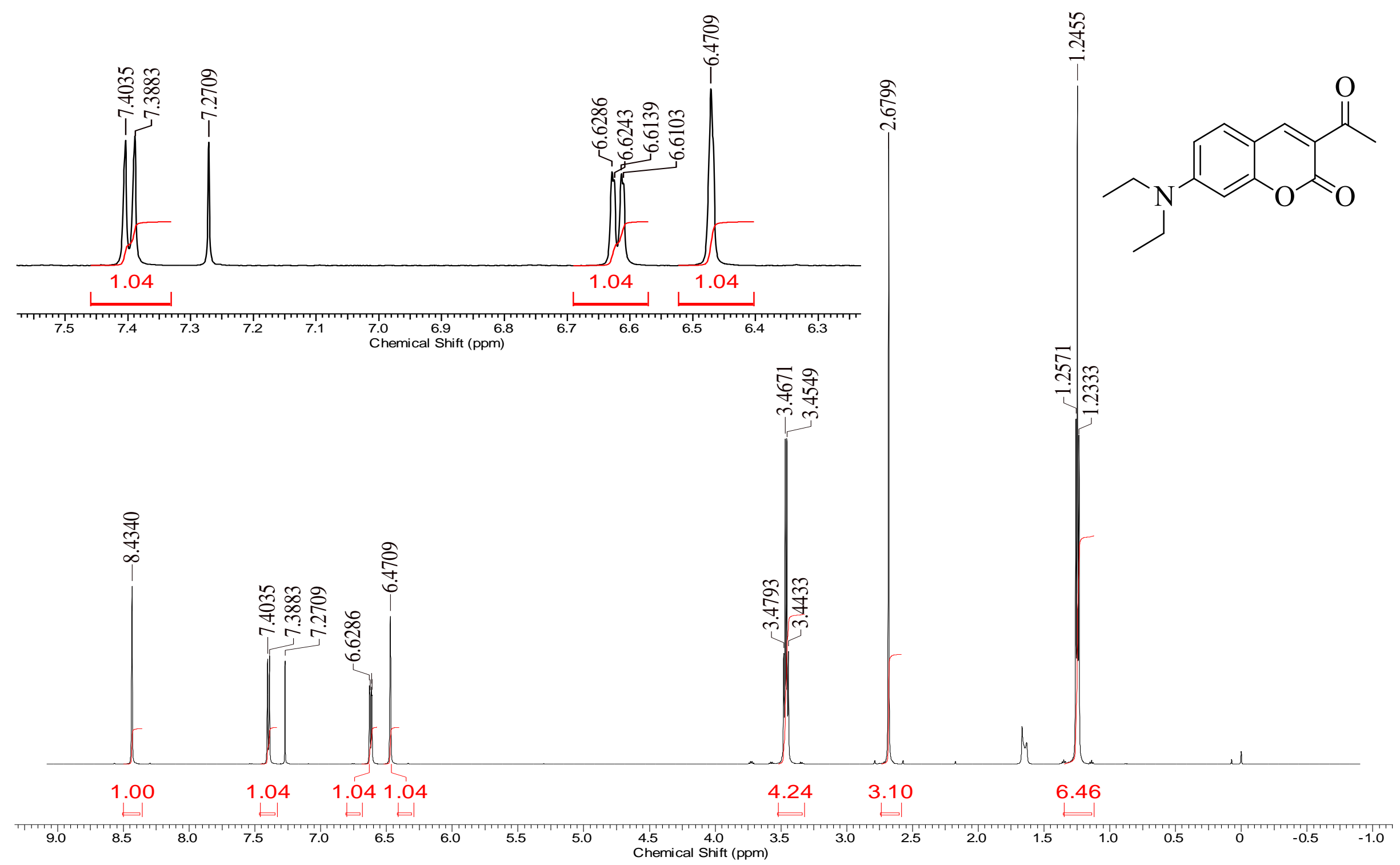

Espectro 3: Espectro de $\mathrm{RMN}{ }^{1} \mathrm{H}\left(600 \mathrm{MHz}, \mathrm{CDCl}_{3}\right)$ da estrutura da cumarina 32. 


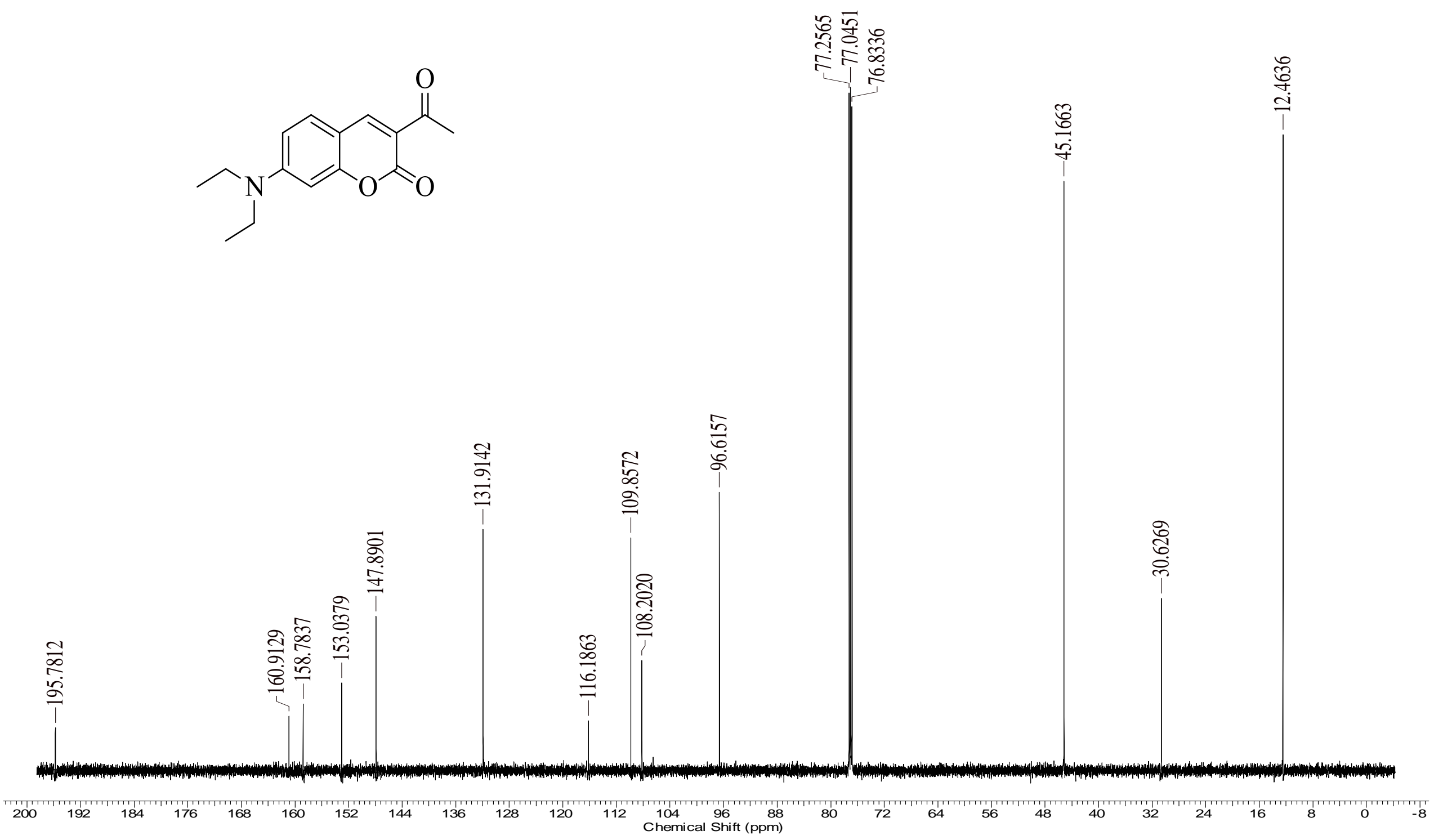

Espectro 4: Espectro de $\mathrm{RMN}{ }^{13} \mathrm{C}\left(150 \mathrm{MHz}, \mathrm{CDCl}_{3}\right)$, da estrutura da cumarina 32 


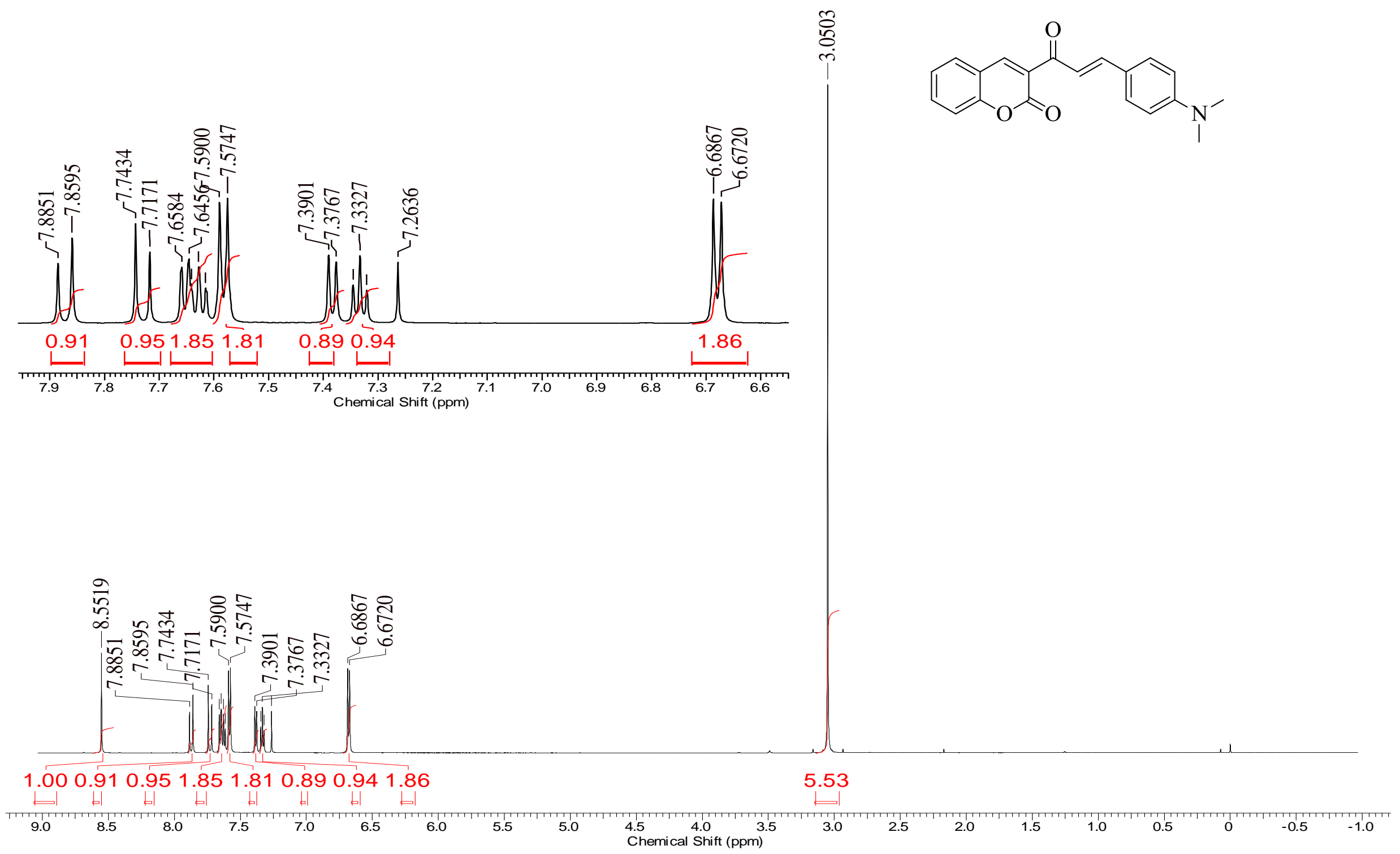

Espectro 5: Espectro de $\mathrm{RMN}{ }^{1} \mathrm{H}\left(600 \mathrm{MHz}, \mathrm{CDCl}_{3}\right)$ da estrutura do híbrido 54A. 


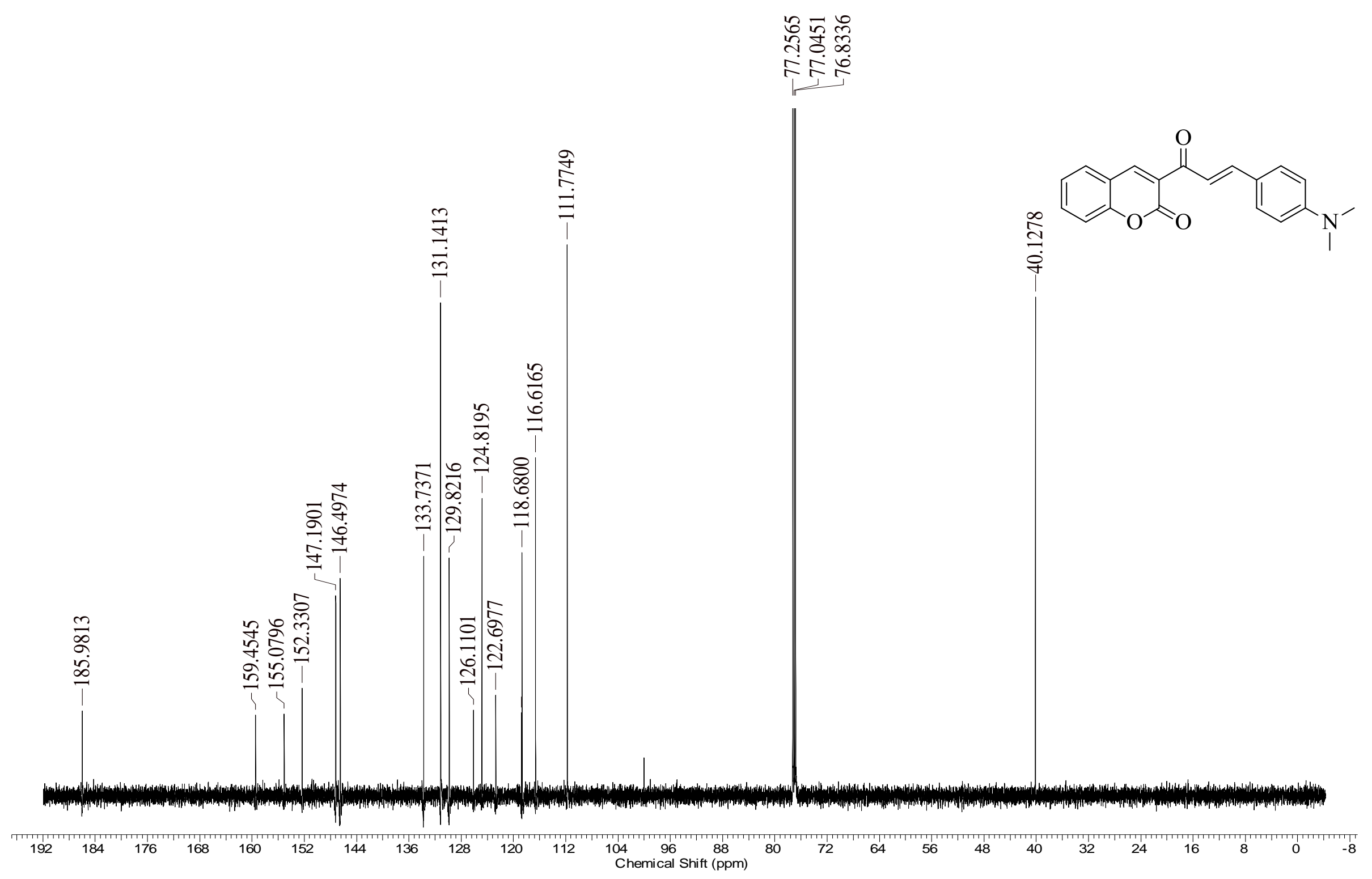

Espectro 6: Espectro de $\mathrm{RMN}{ }^{13} \mathrm{C}\left(150 \mathrm{MHz}, \mathrm{CDCl}_{3}\right)$ do híbrido 54A. 


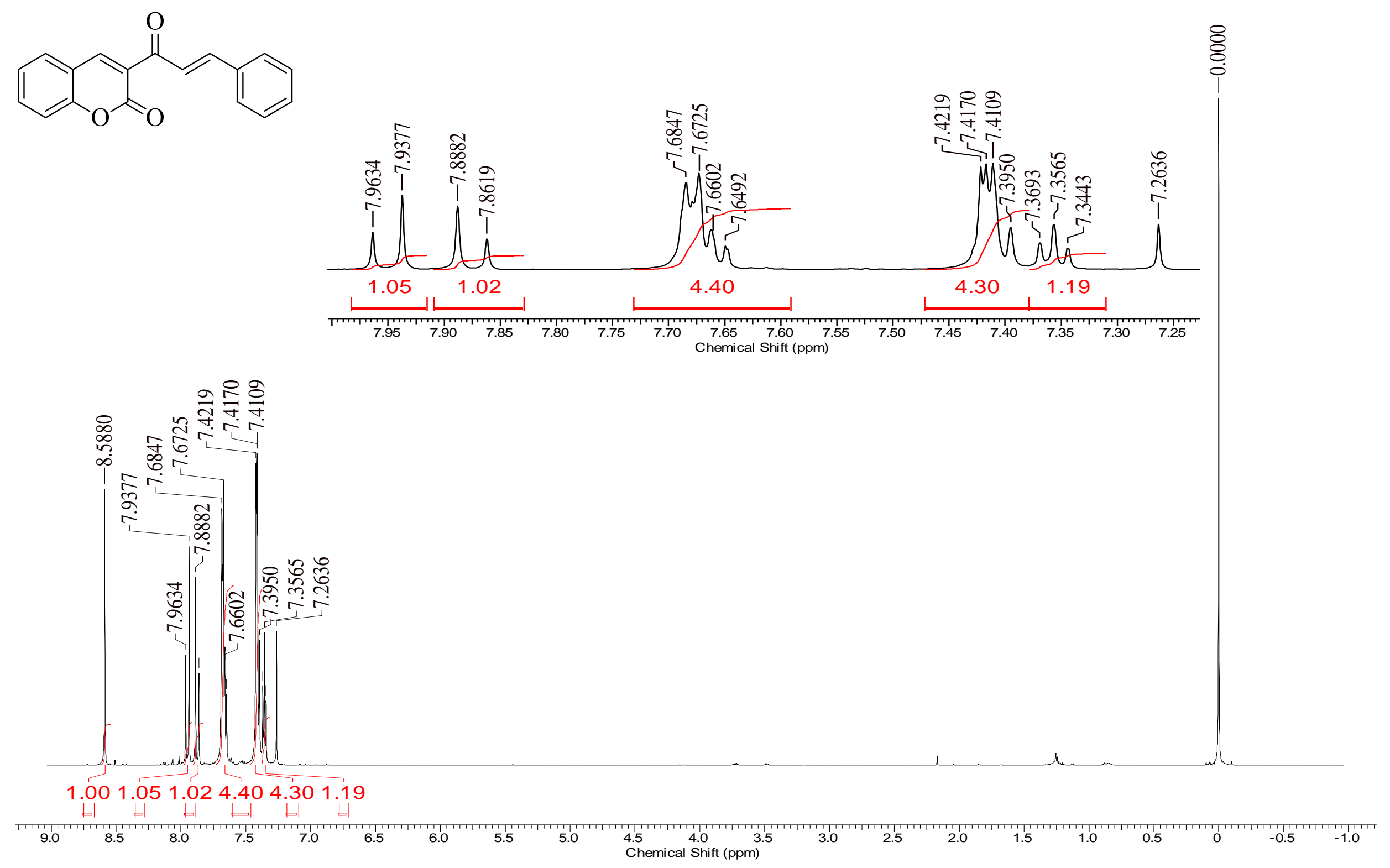

Espectro 7: Espectro de $\mathrm{RMN}{ }^{1} \mathrm{H}\left(600 \mathrm{MHz}, \mathrm{CDCl}_{3}\right)$ da estrutura do híbrido 51B 


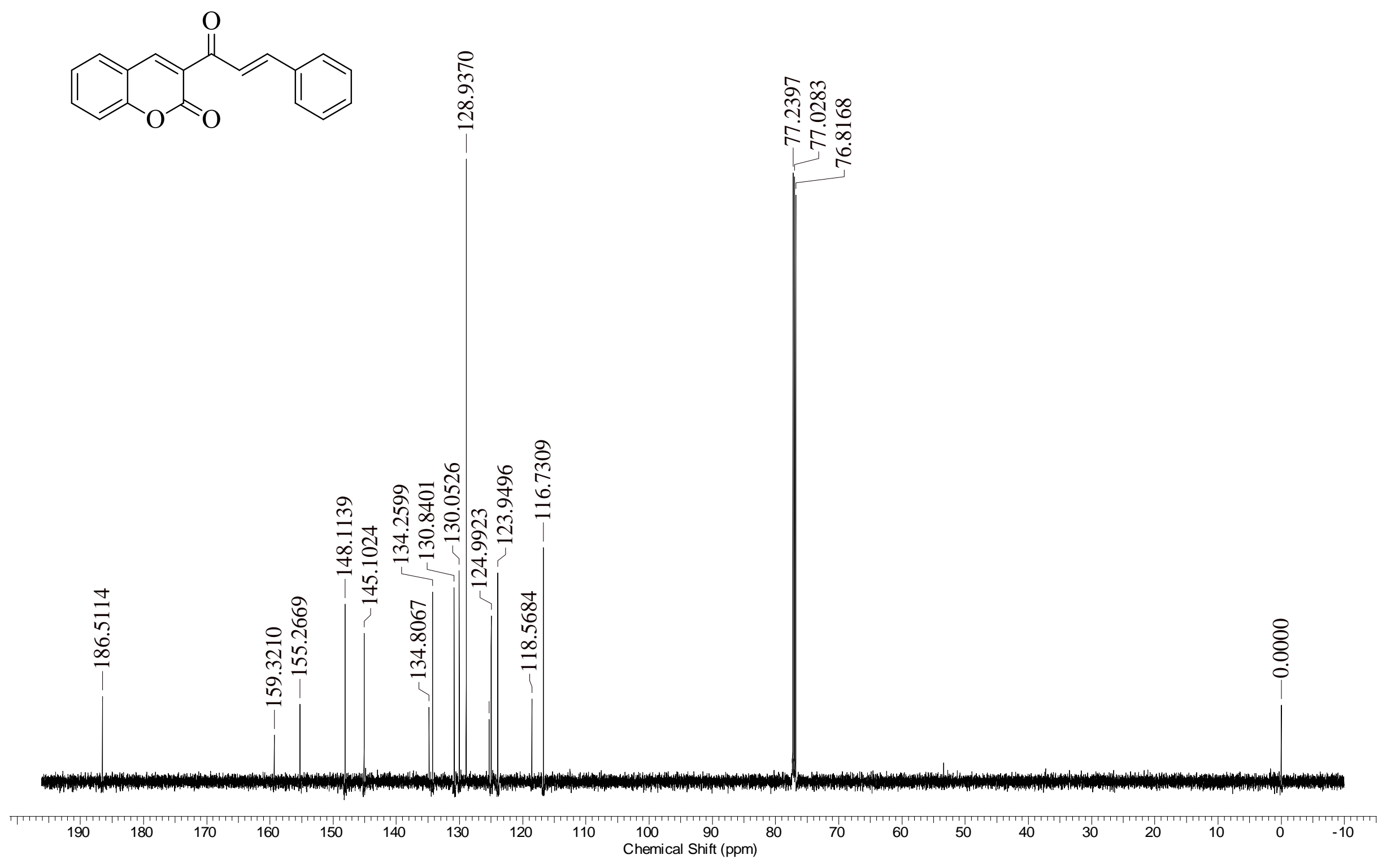

Espectro 8: Espectro de $\mathrm{RMN}^{13} \mathrm{C}\left(150 \mathrm{MHz}, \mathrm{CDCl}_{3}\right)$ da estrutura do híbrido 51B. 

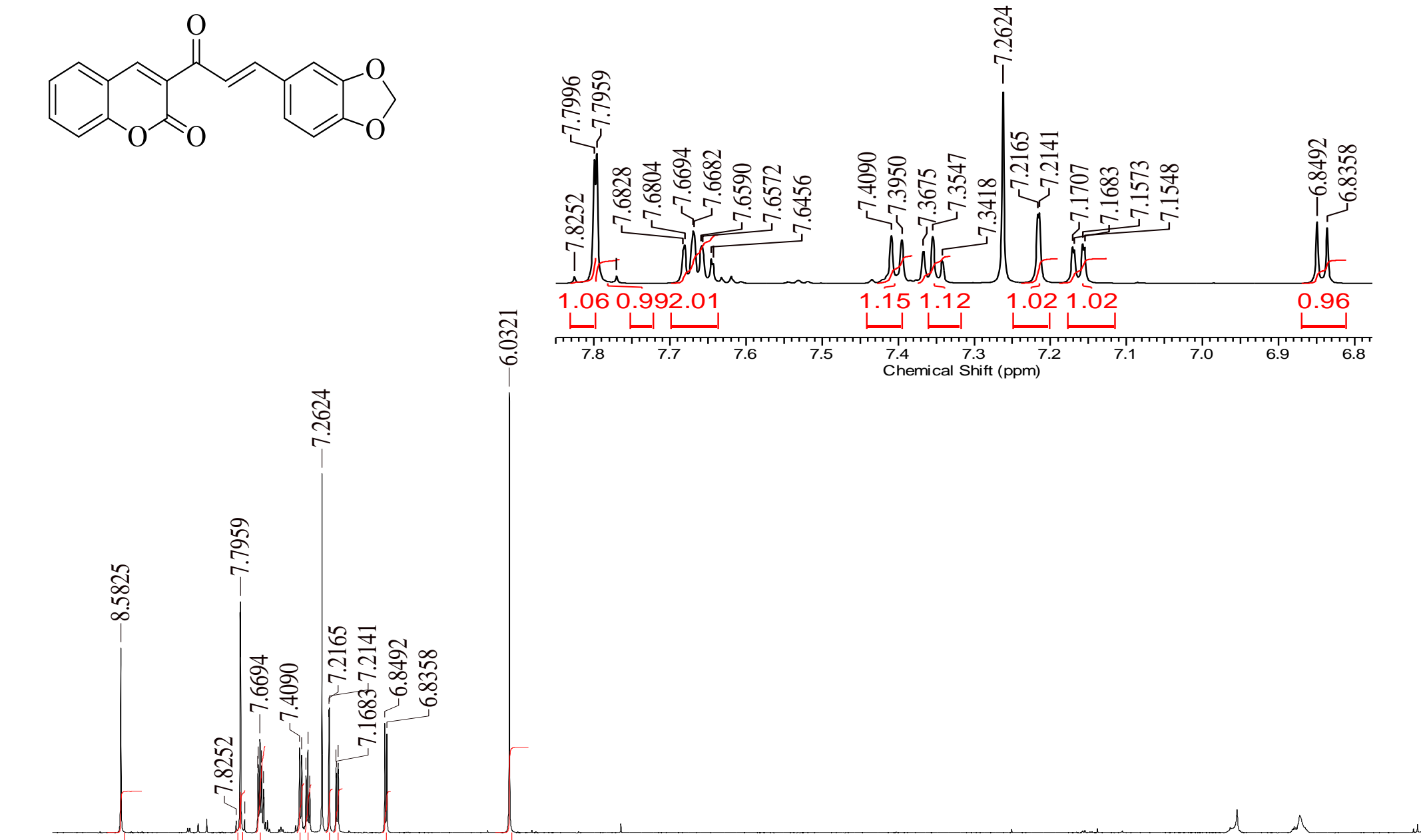

0.971 .060 .992 .011 .151 .121 .021 .020 .961 .99

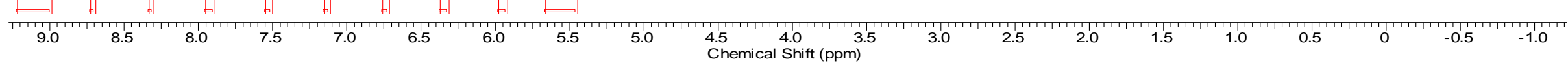

Espectro 9: Espectro de $\mathrm{RMN}{ }^{1} \mathrm{H}\left(600 \mathrm{MHz}, \mathrm{CDCl}_{3}\right)$ da estrutura do híbrido 52B. 


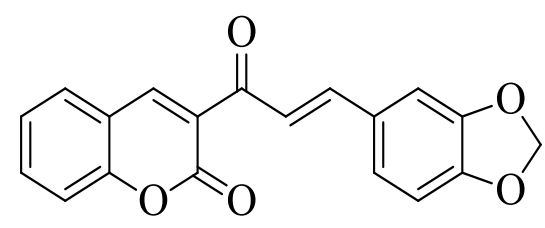

商

당요

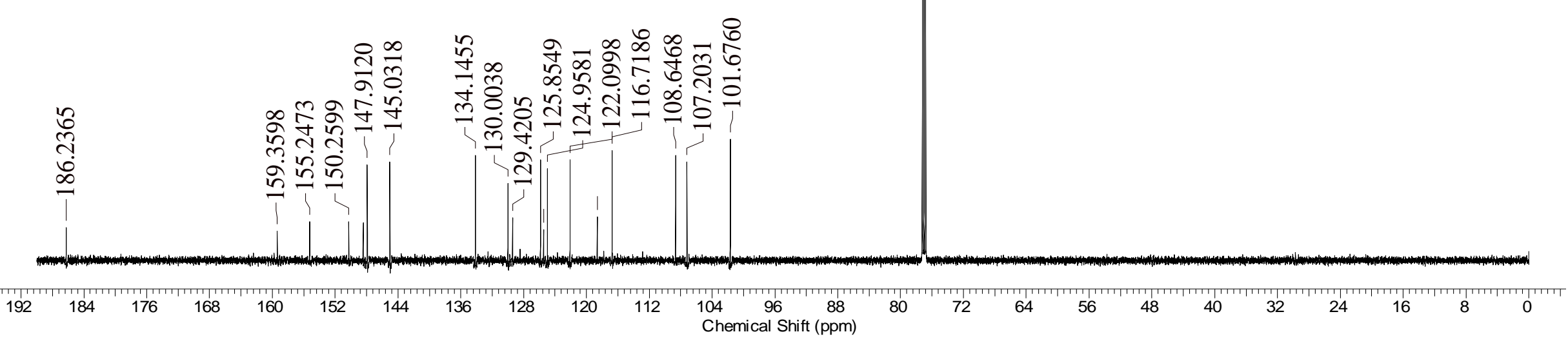

Espectro 10: Espectro de $\mathrm{RMN}^{13} \mathrm{C}\left(150 \mathrm{MHz}, \mathrm{CDCl}_{3}\right)$ do híbrido 52B. 


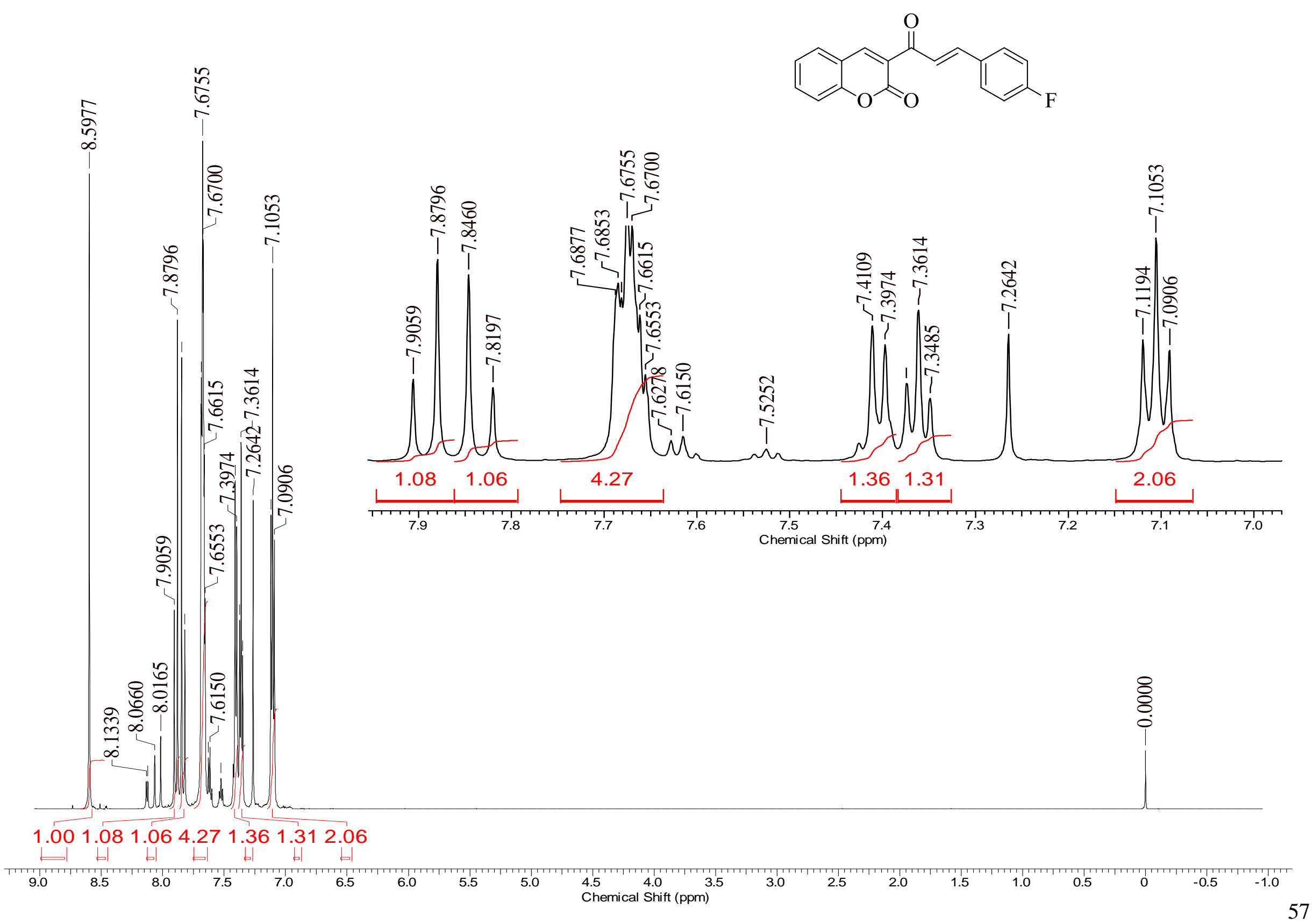

Espectro 11: Espectro de $\mathrm{RMN}{ }^{1} \mathrm{H}\left(600 \mathrm{MHz}, \mathrm{CDCl}_{3}\right)$ da estrutura do híbrido 53B. 


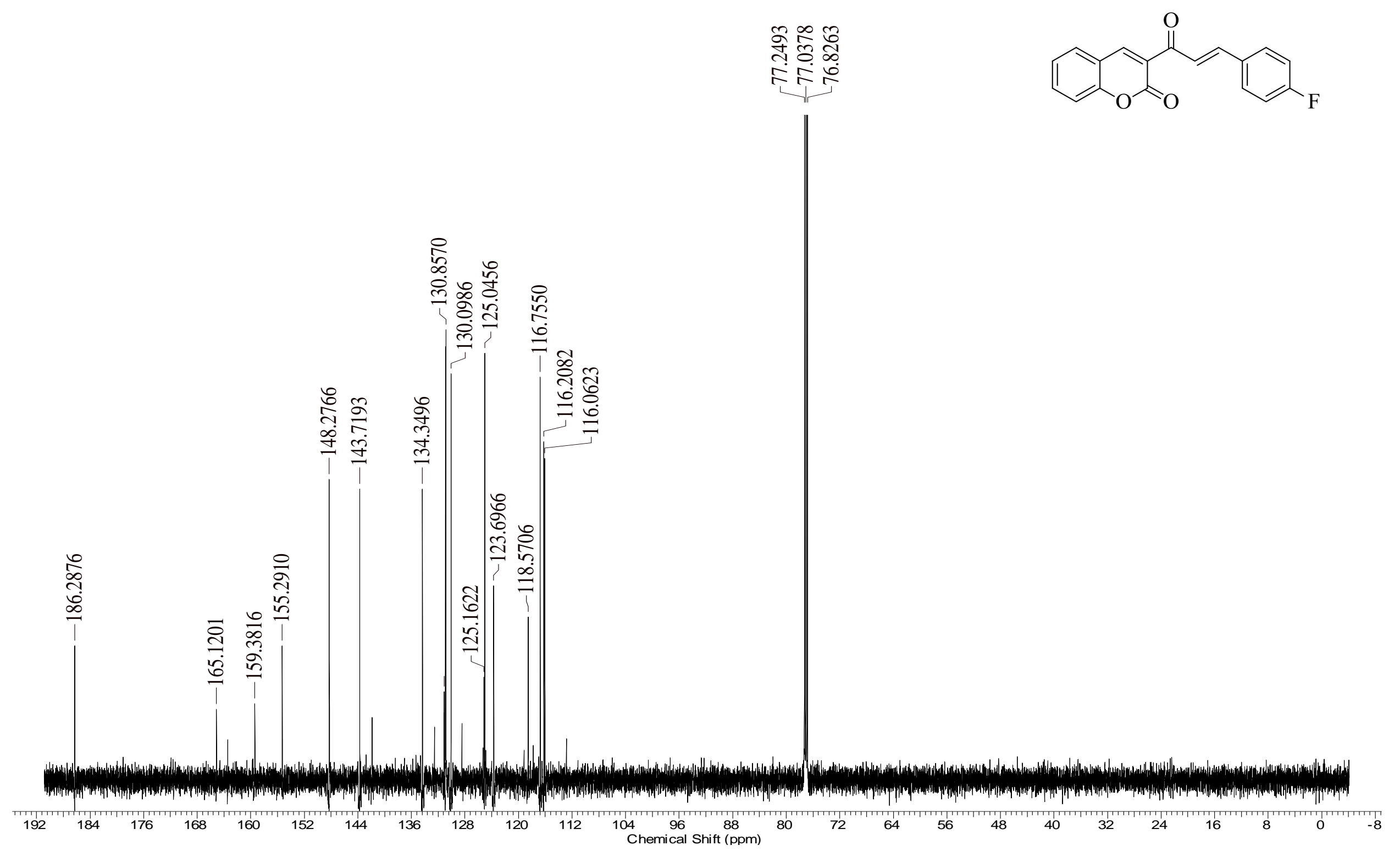

Espectro 12: Espectro de RMN ${ }^{13} \mathrm{C}\left(150 \mathrm{MHz}, \mathrm{CDCl}_{3}\right)$ do híbrido 53B. 


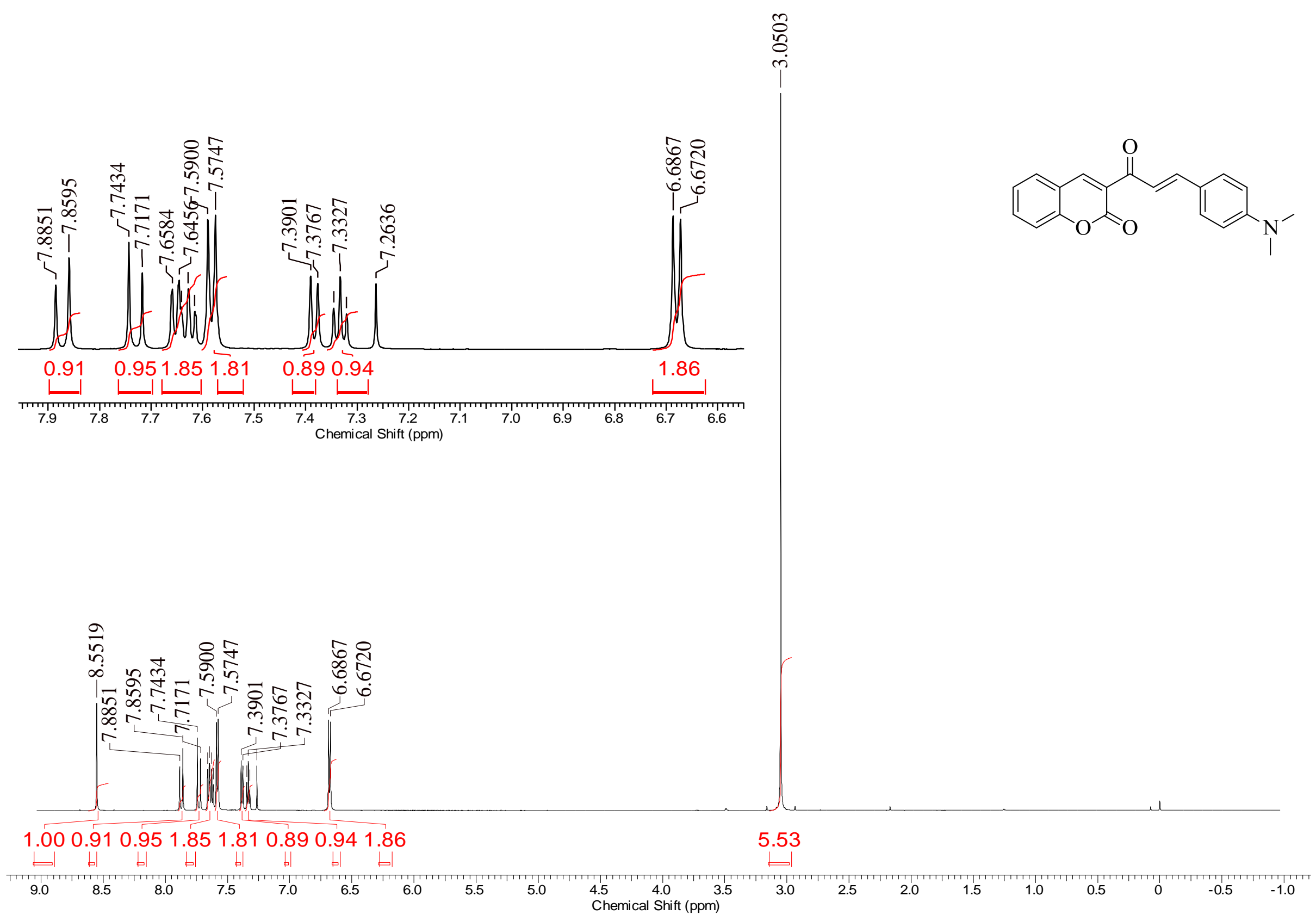

Espectro 13: Espectro de $\mathrm{RMN}{ }^{1} \mathrm{H}\left(600 \mathrm{MHz}, \mathrm{CDCl}_{3}\right)$ da estrutura do híbrido 54B. 


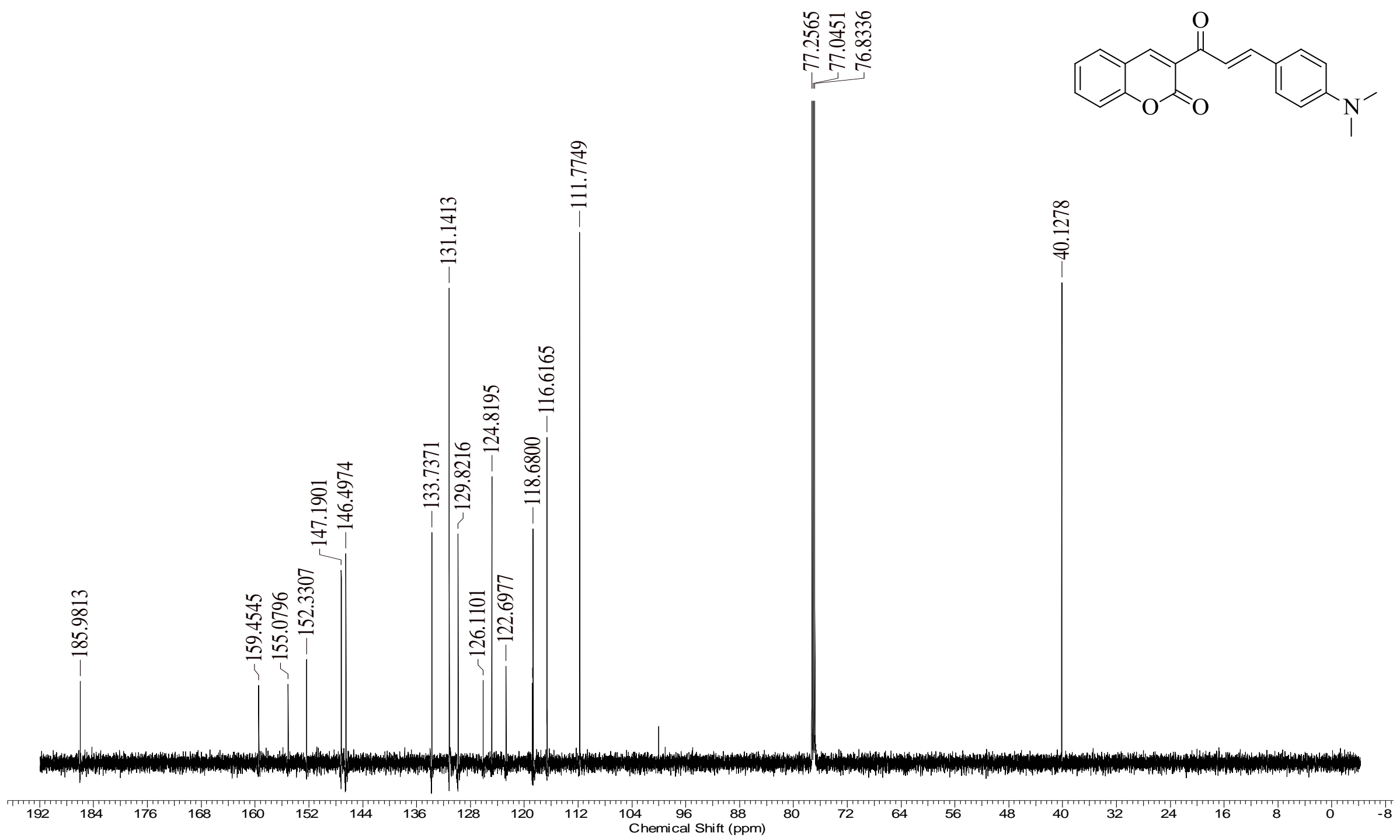

Espectro 14: Espectro de $\mathrm{RMN}{ }^{13} \mathrm{C}\left(150 \mathrm{MHz}, \mathrm{CDCl}_{3}\right)$ do híbrido 54B. 


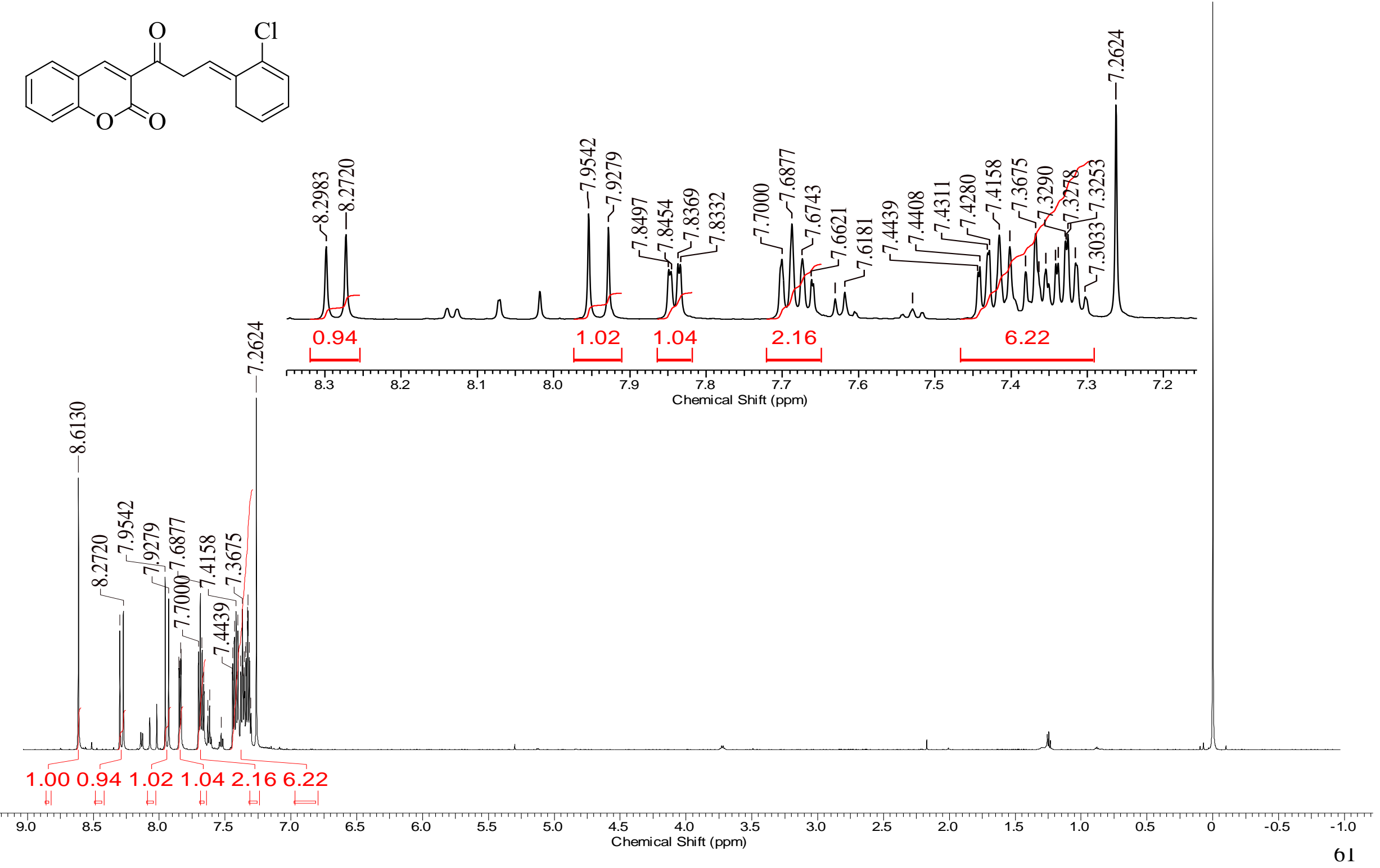

Espectro 15: Espectro de $\mathrm{RMN}{ }^{1} \mathrm{H}\left(600 \mathrm{MHz}, \mathrm{CDCl}_{3}\right)$ da estrutura do híbrido 55B. 

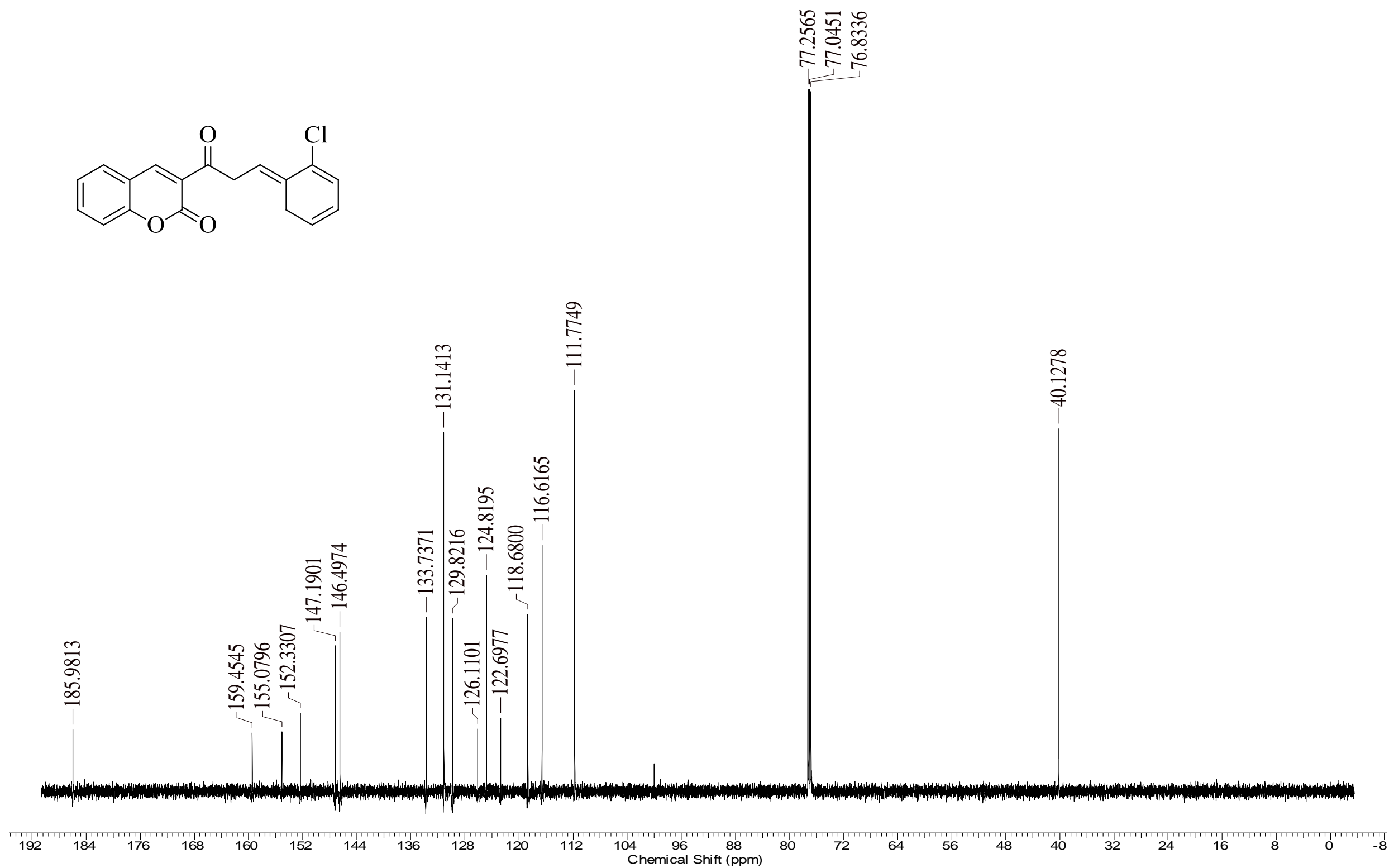

Espectro 16: Espectro de $\mathrm{RMN}{ }^{13} \mathrm{C}\left(150 \mathrm{MHz}, \mathrm{CDCl}_{3}\right)$ do híbrido 55B. 


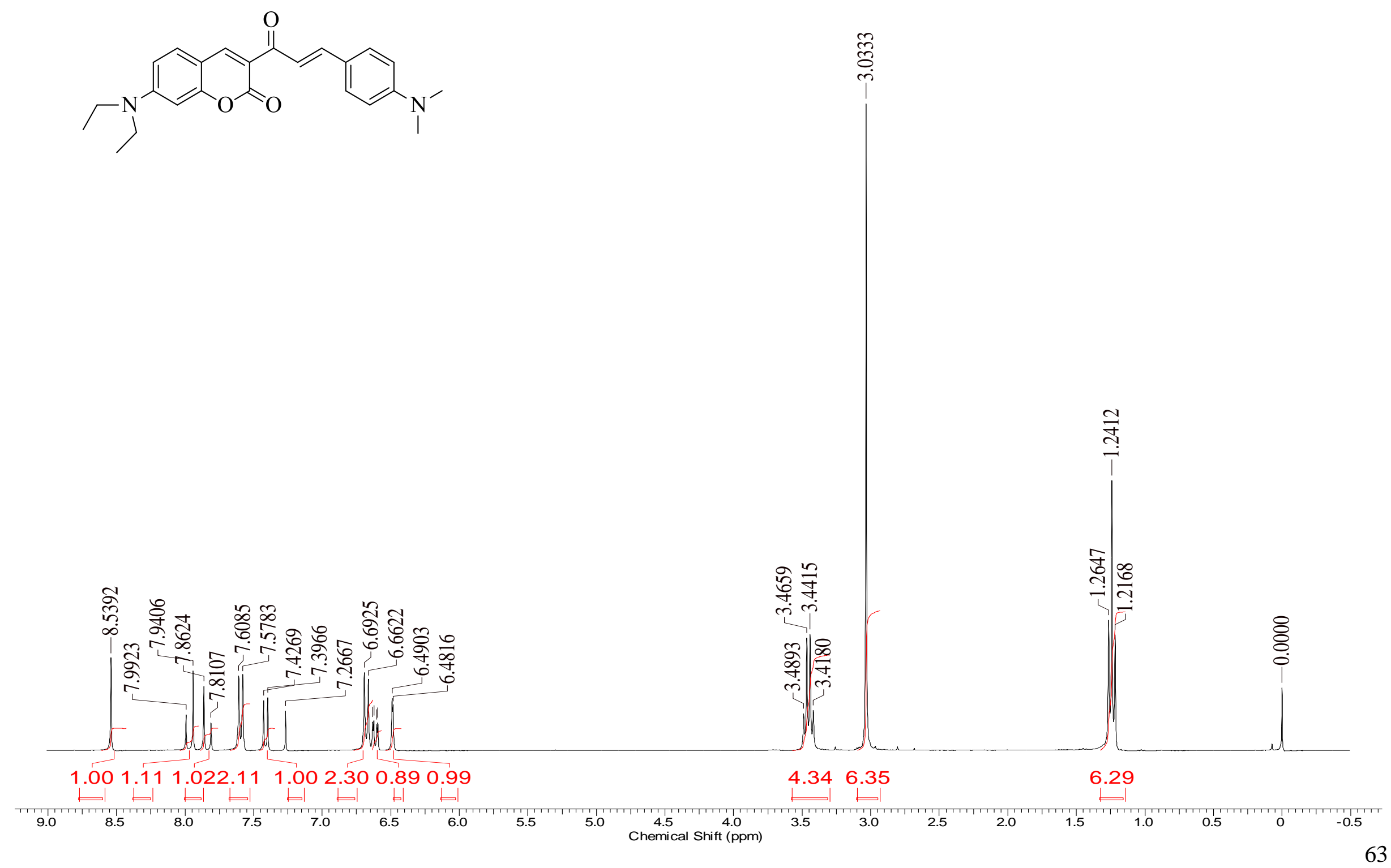

Espectro 17: Espectro de RMN ${ }^{1} \mathrm{H}\left(600 \mathrm{MHz}, \mathrm{CDCl}_{3}\right)$ do híbrido 56B. 

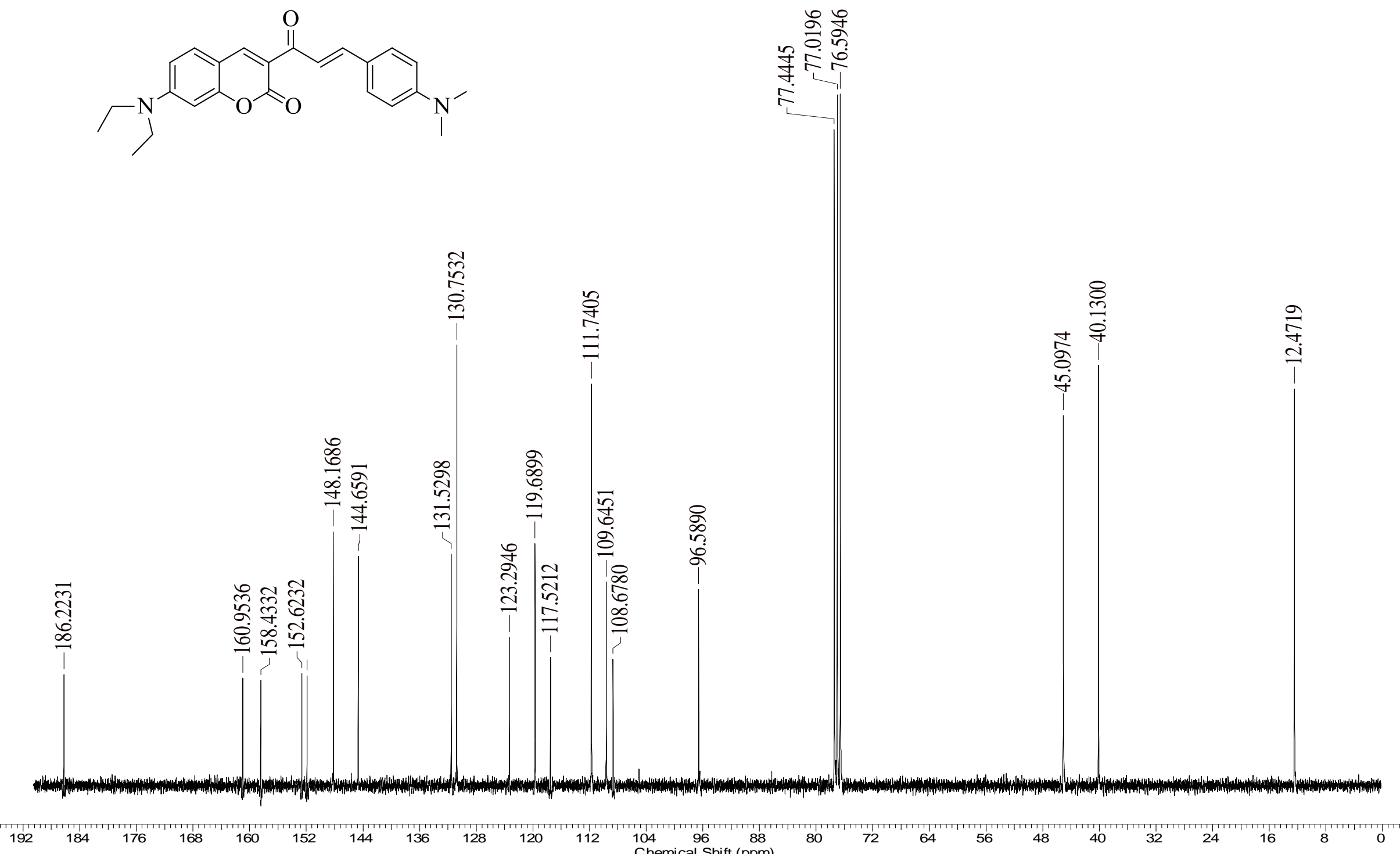

Espectro 18: Espectro de $\mathrm{RMN}^{13} \mathrm{C}\left(150 \mathrm{MHz}, \mathrm{CDCl}_{3}\right)$ do híbrido 56B. 


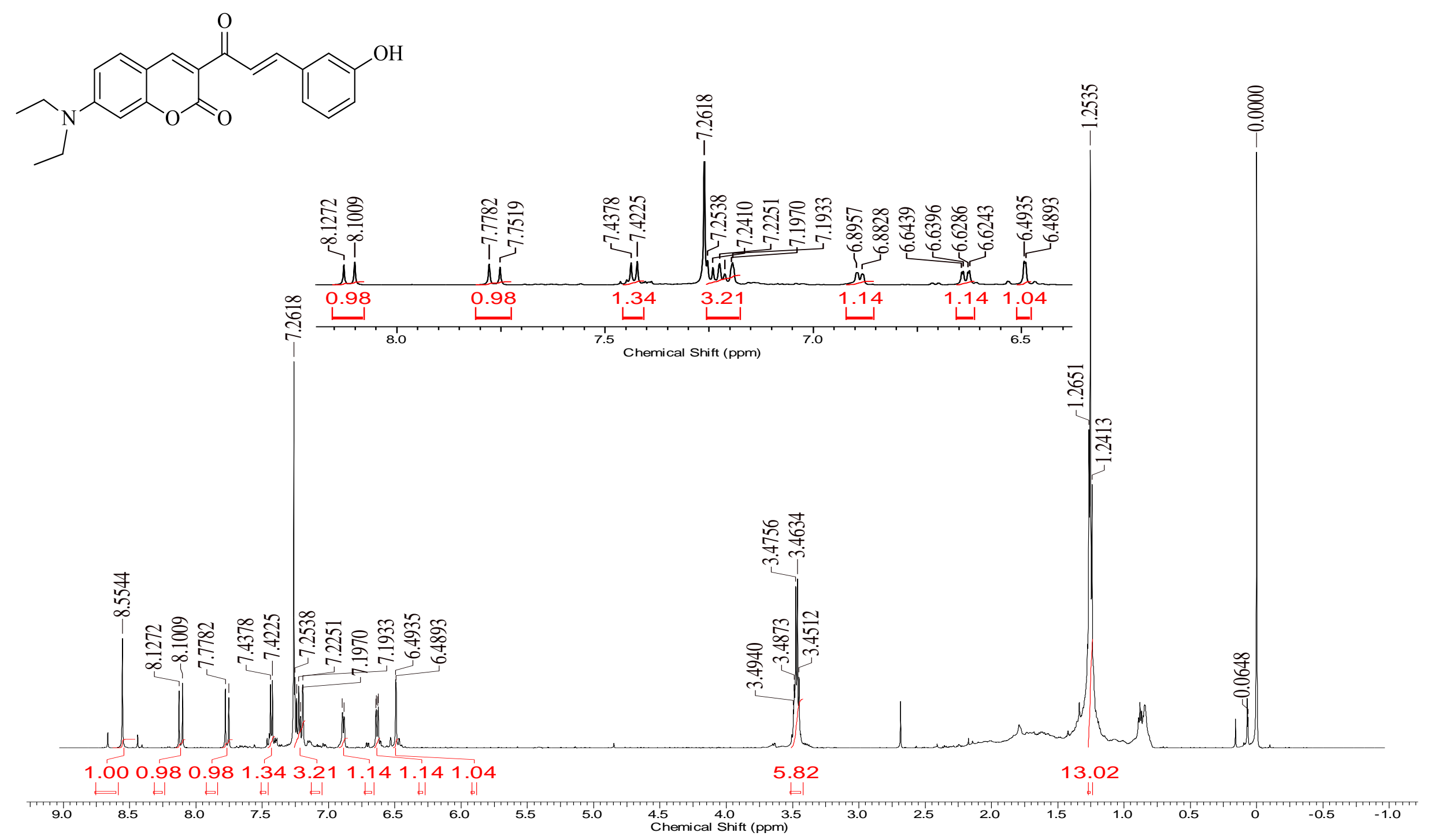

Espectro 19: Espectro de $\mathrm{RMN}{ }^{1} \mathrm{H}\left(600 \mathrm{MHz}, \mathrm{CDCl}_{3}\right)$ do híbrido 57B. 


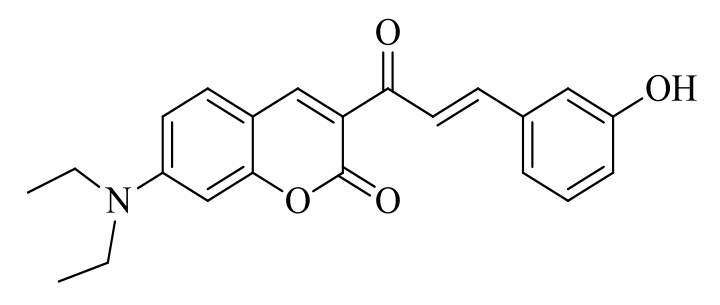

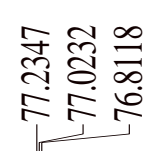

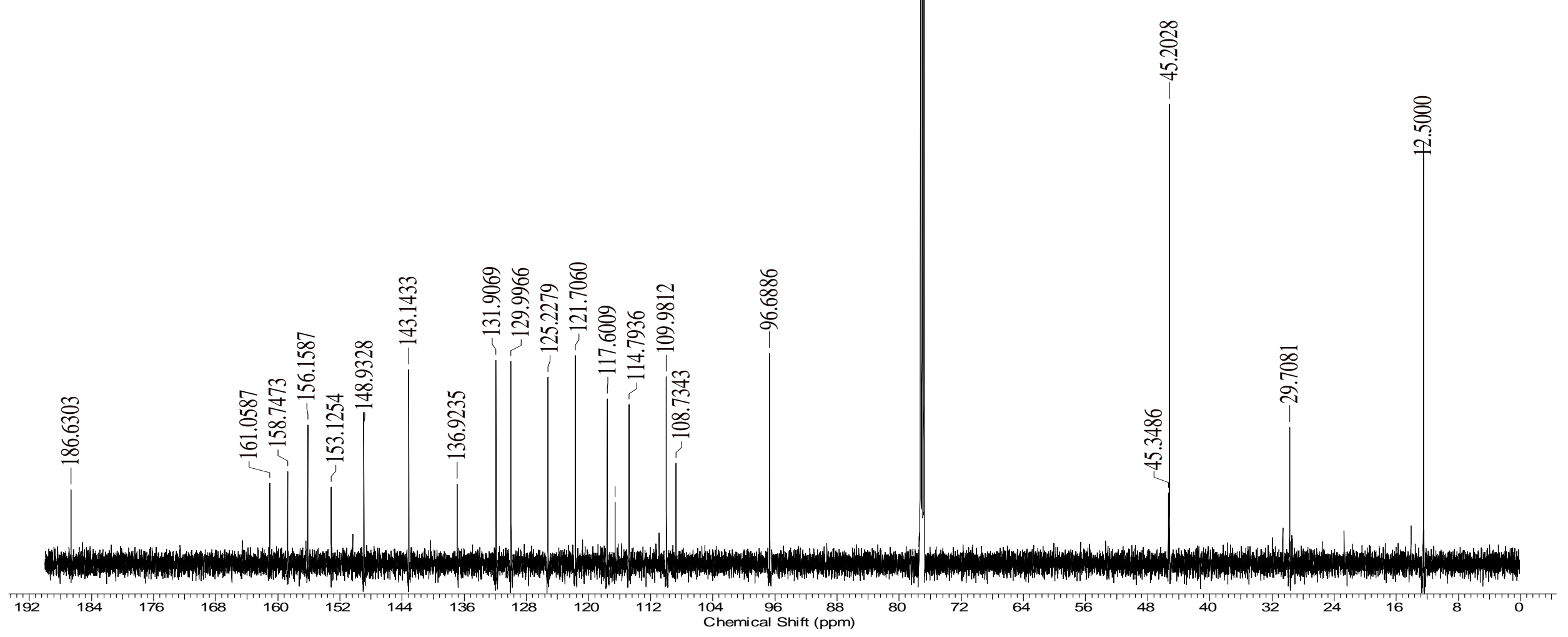

Espectro 20: Espectro de $\mathrm{RMN}{ }^{13} \mathrm{C}\left(150 \mathrm{MHz}, \mathrm{CDCl}_{3}\right)$ do híbrido 57B. 


\subsection{ESPECTROS DE ABSORÇÃO E EMISSÃO}

8.2.1. Espectros das Cumarinas 31 e 32
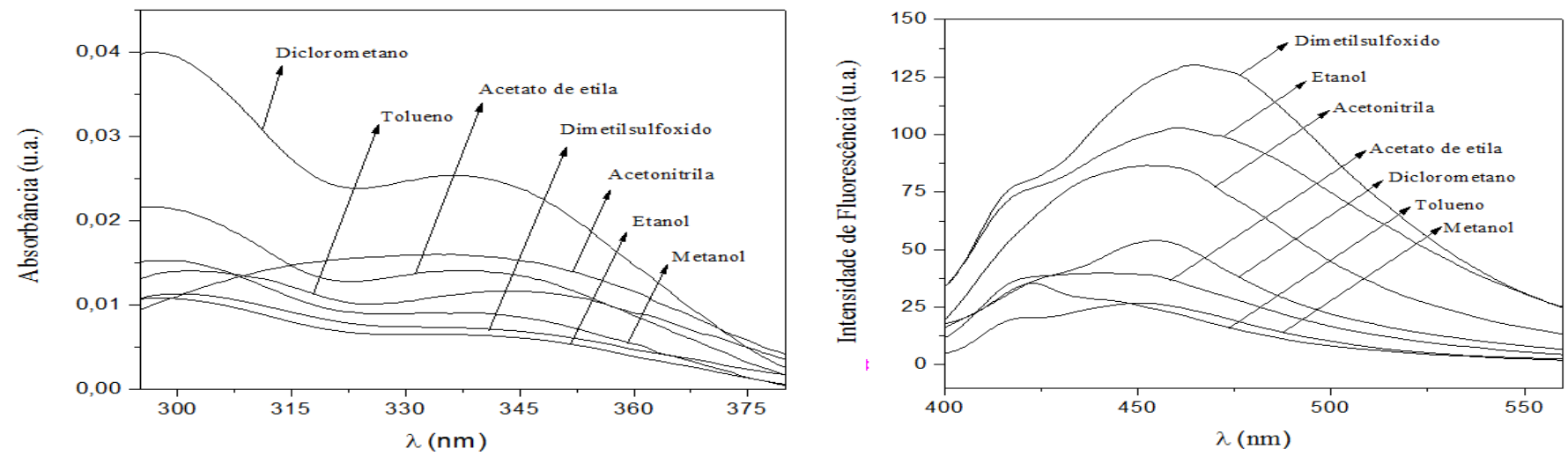

Espectro 21. Espectros de absorção (direita) e emissão (esquerda) da cumarina 31.
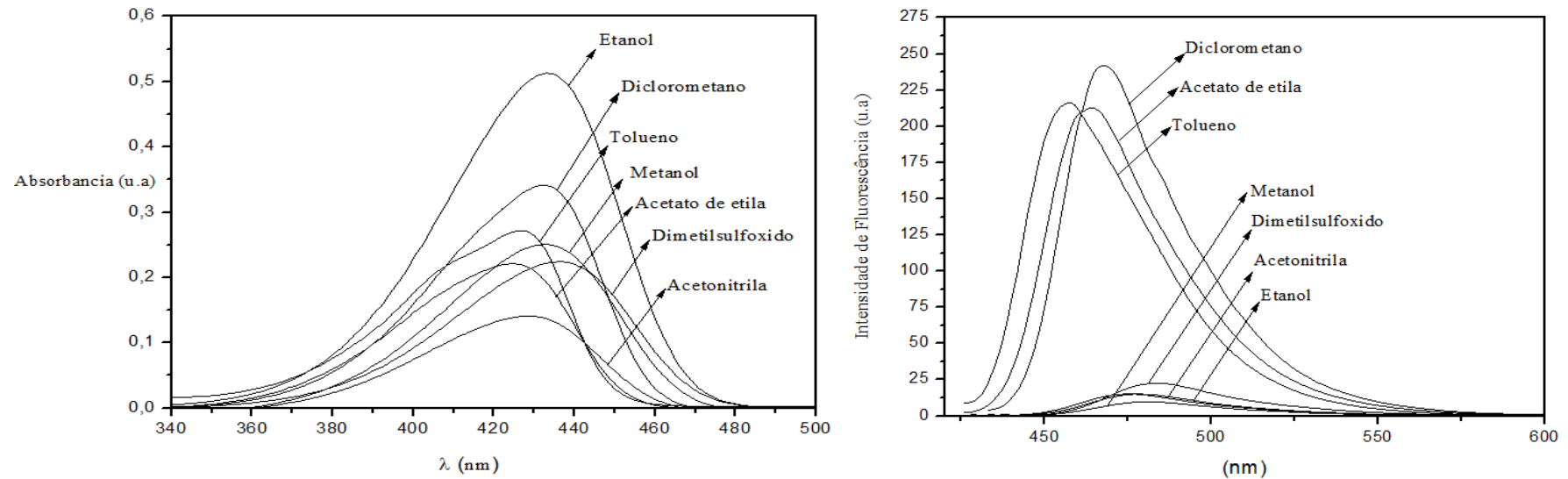

Espectro 22. Espectros de absorção (direita) e emissão (esquerda) da cumarina 32. 
8.2.2 Espectros dos híbridos de cumarinas-chalconas 51B-57B
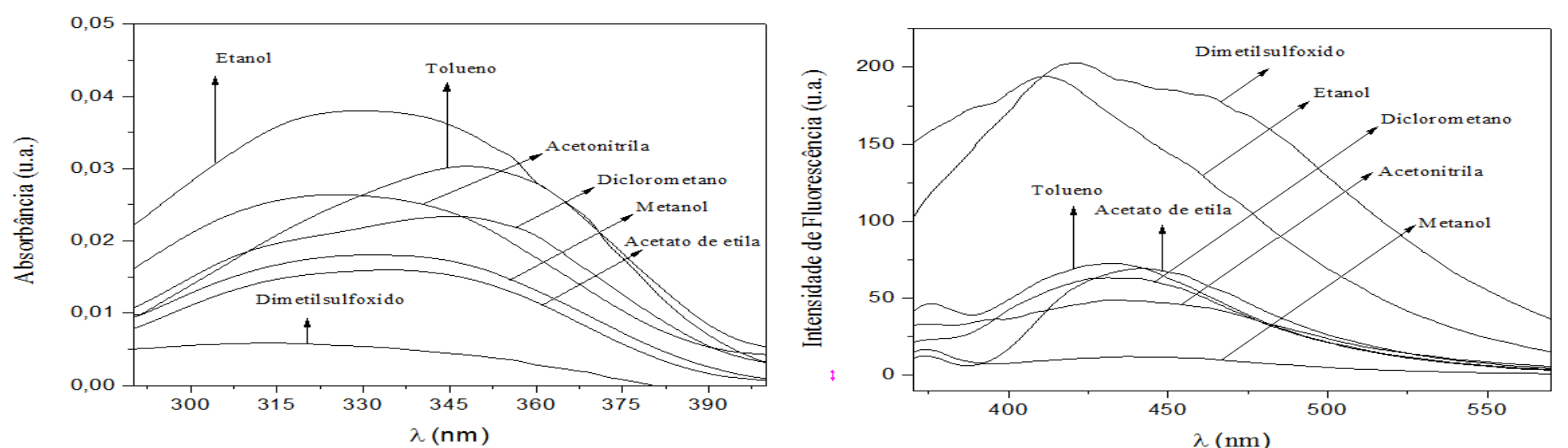

Espectro 23. Espectros de absorção (direita) e emissão (esquerda) do híbrido 51B.
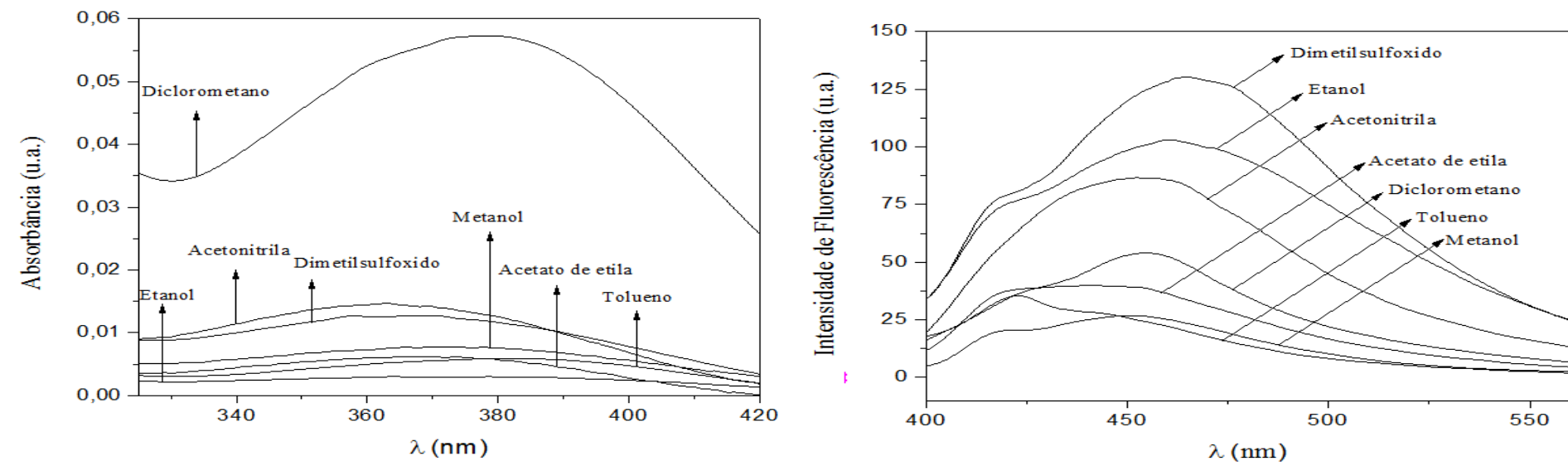

Espectro 24. Espectros de absorção (direita) e emissão (esquerda) do híbrido 52B. 

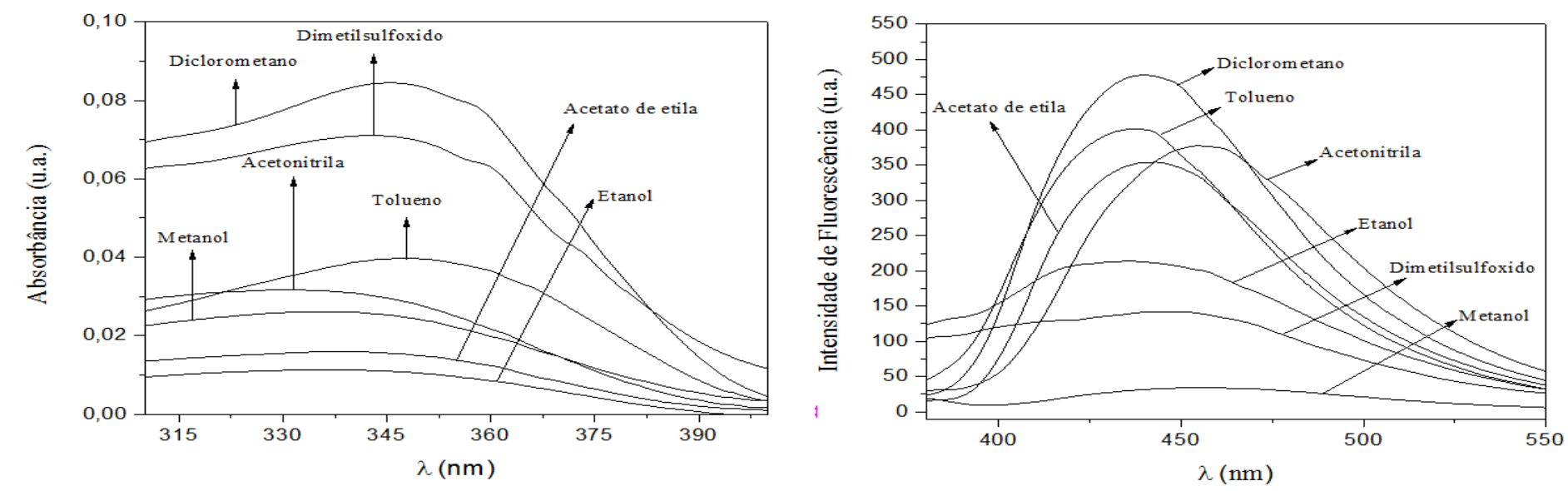

Espectro 25. Espectros de absorção (direita) e emissão (esquerda) do híbrido 53B.
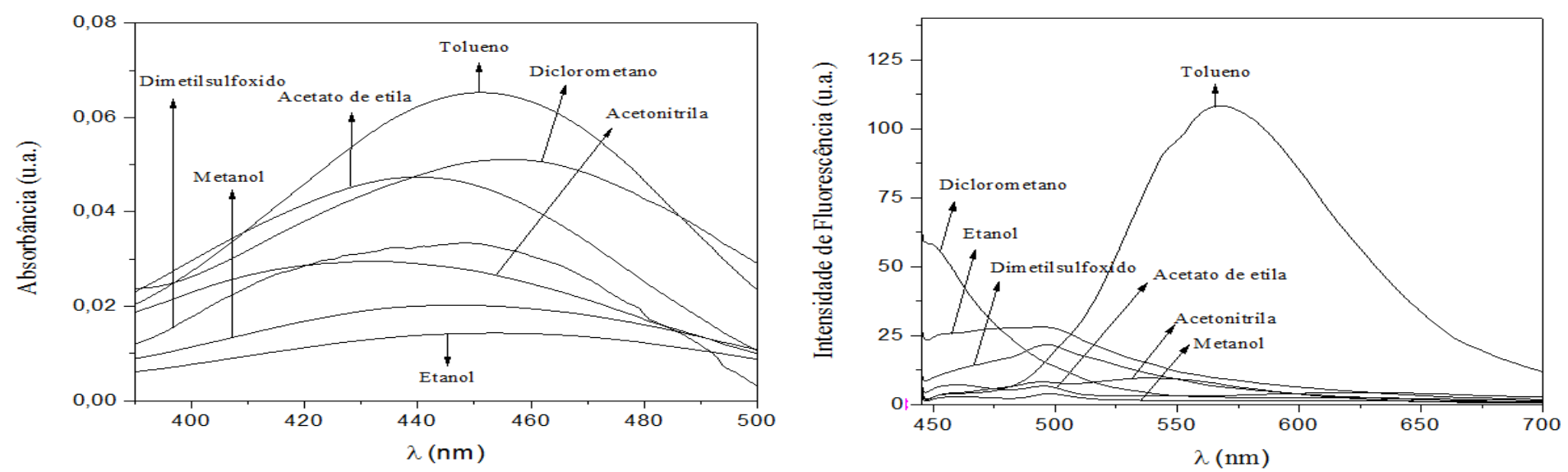

Espectro 26. Espectros de absorção (direita) e emissão (esquerda) do híbrido 54B. 

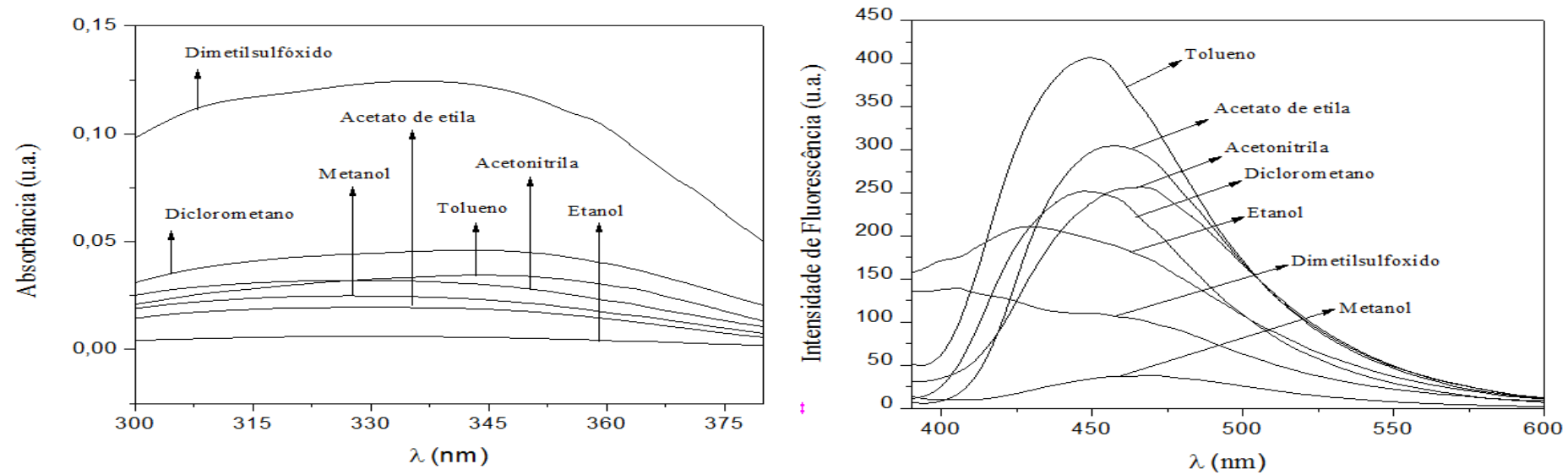

Espectro 27. Espectros de absorção (direita) e emissão (esquerda) do híbrido 55B.
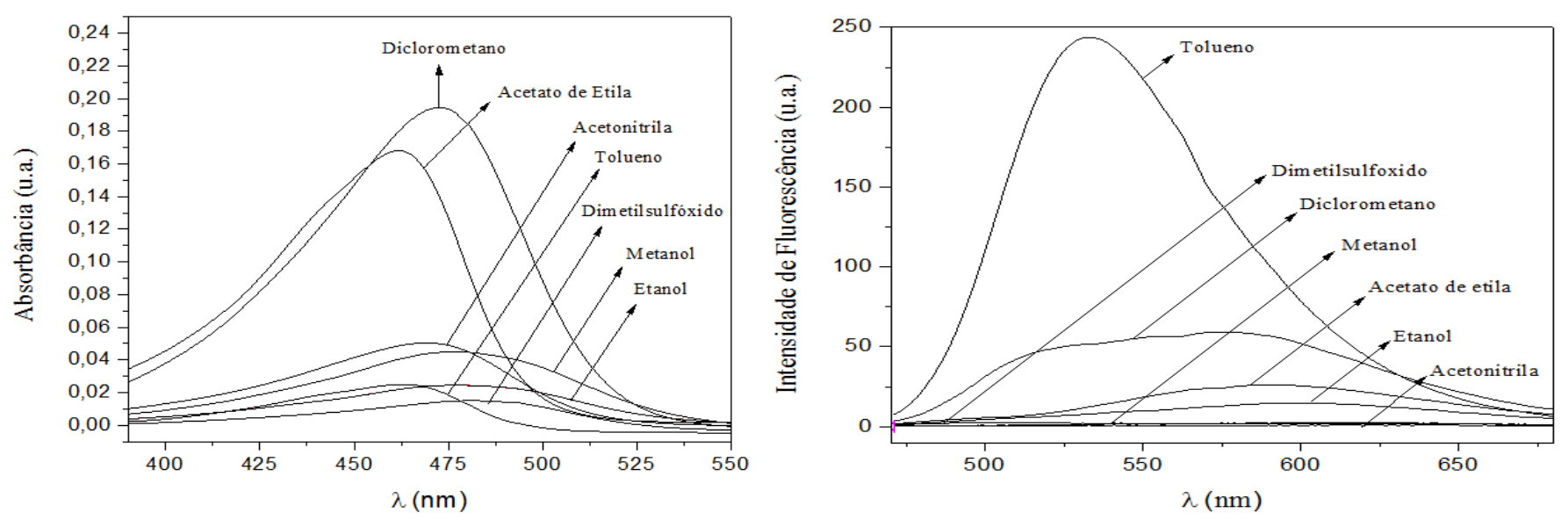

Espectro 28. Espectros de absorção (direita) e emissão (esquerda) do híbrido 56B. 

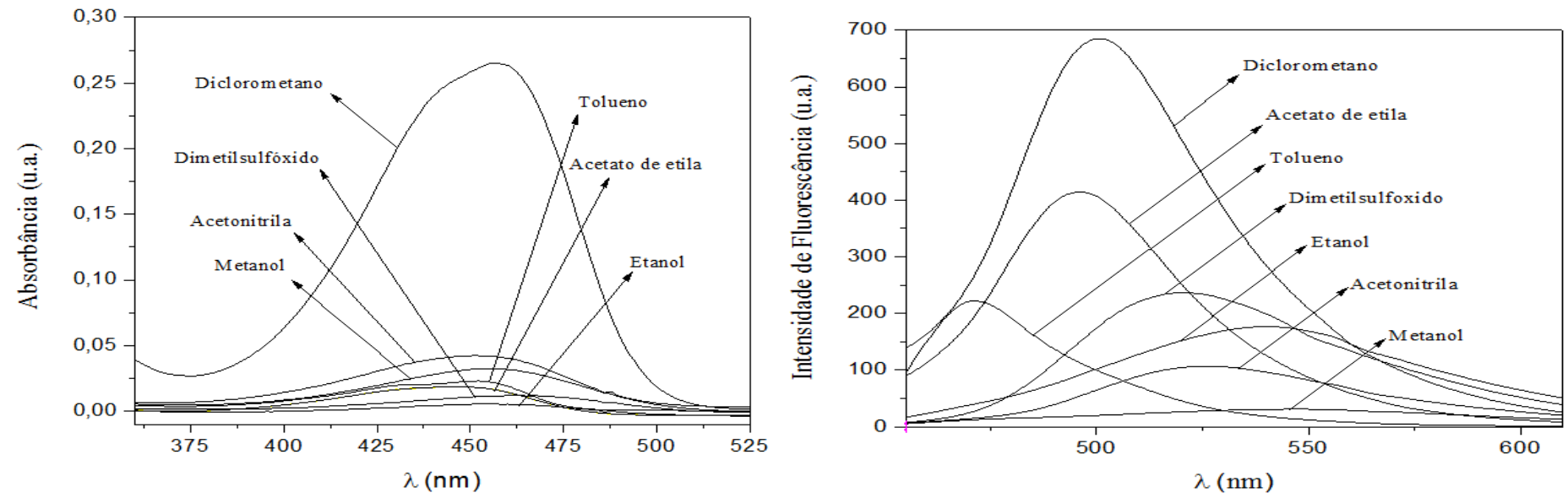

Espectro 29. Espectros de absorção (direita) e emissão (esquerda) do híbrido 57B. 
8.3 GRÁFICOS DE LIPERT-MATAGA

8.3.1. Gráficos das cumarinas 31 e 32

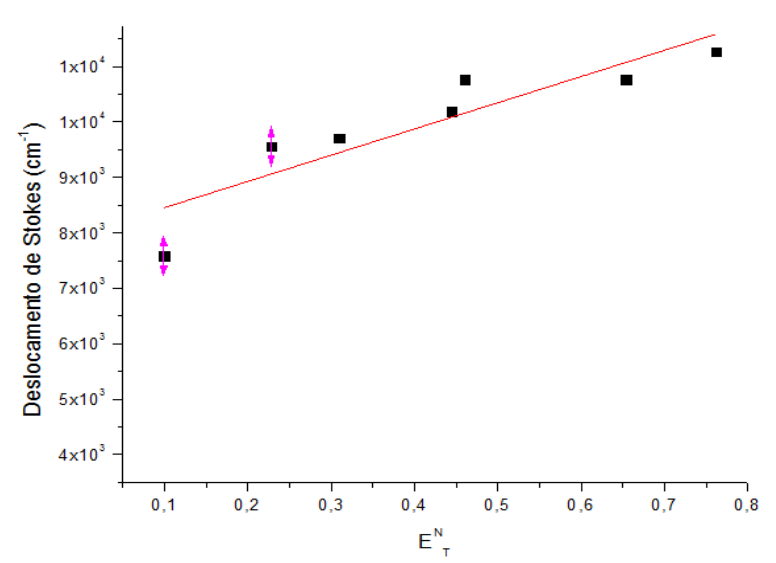

Gráfico 1. Lippert-Mataga da cumarina 31. 


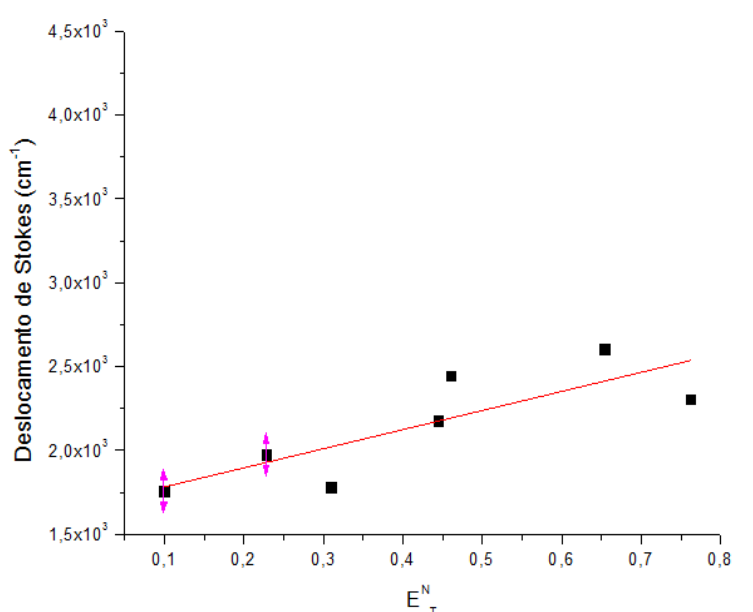

Gráfico 2. Lippert-Mataga da cumarina 32. 
8.3.2. Gráficos dos híbridos de cumarinas-chalconas 51B a 57B

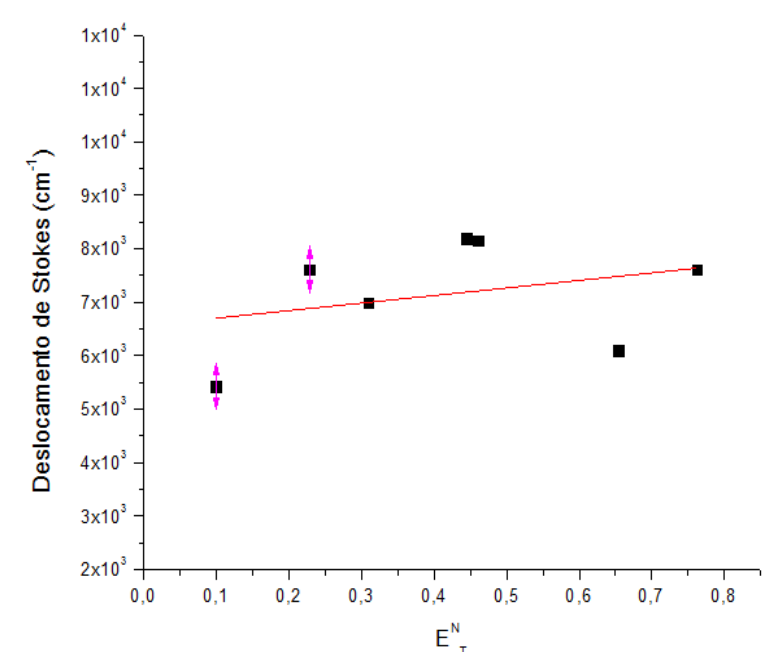

Gráfico 3. Lippert-Mataga do híbrido de 51B.

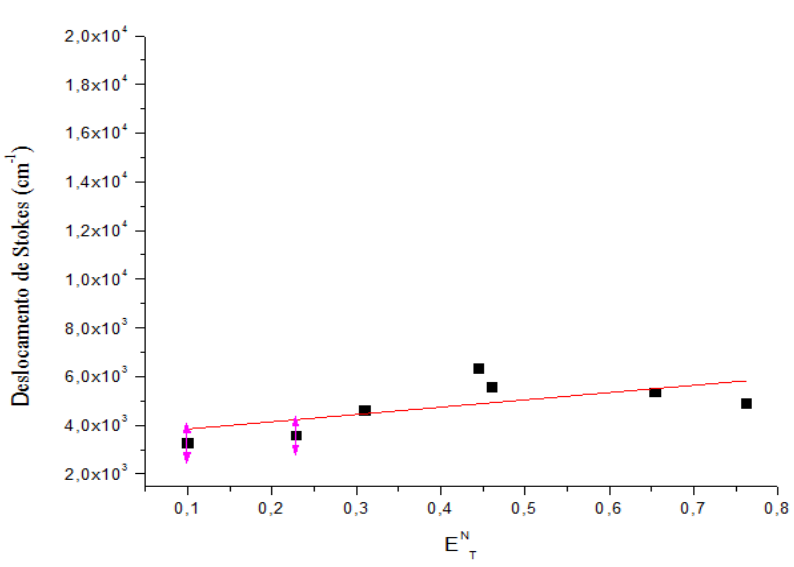


Gráfico 4. Lippert-Mataga do híbrido de 52B.

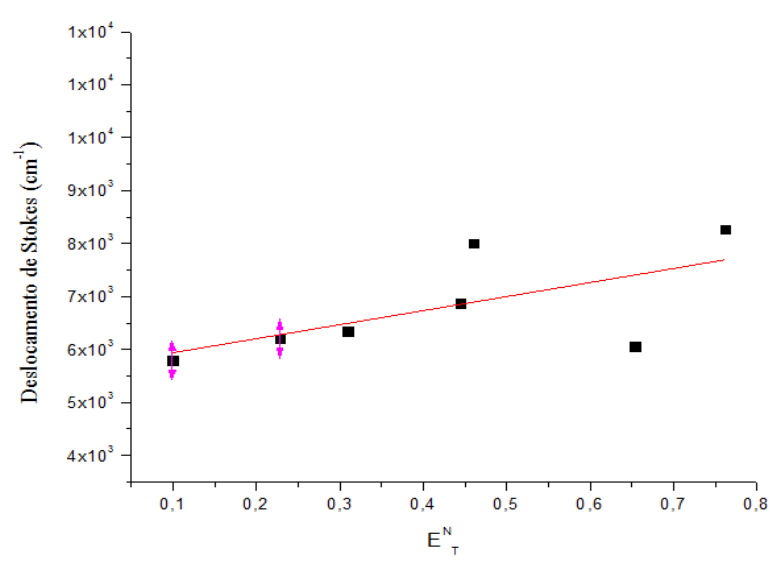

Gráfico 5. Lippert-Mataga do híbrido de 53B.

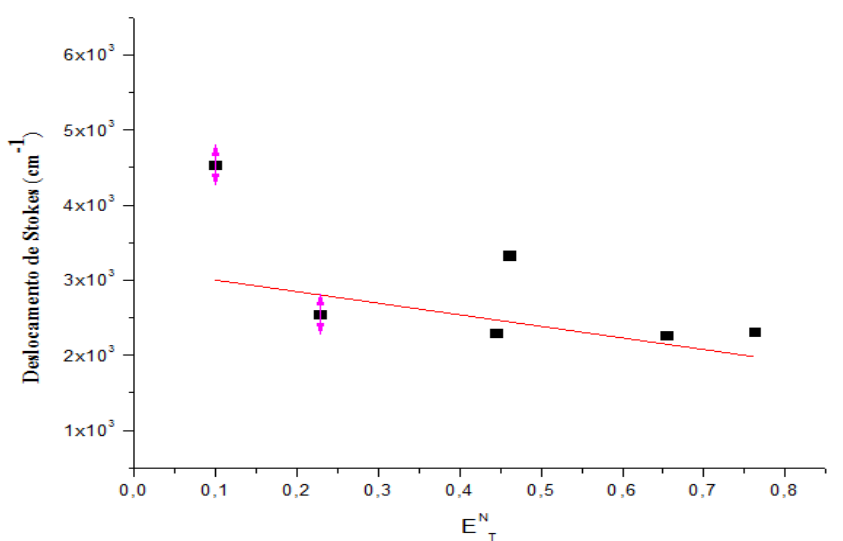

Gráfico 6. Lippert-Mataga do híbrido de 54B. 


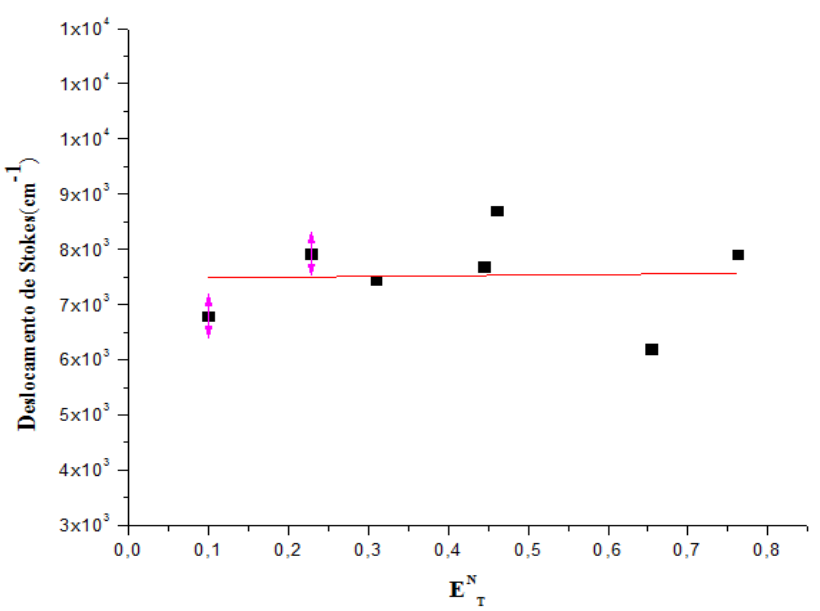

Gráfico 7. Lippert-Mataga do híbrido de 55B.

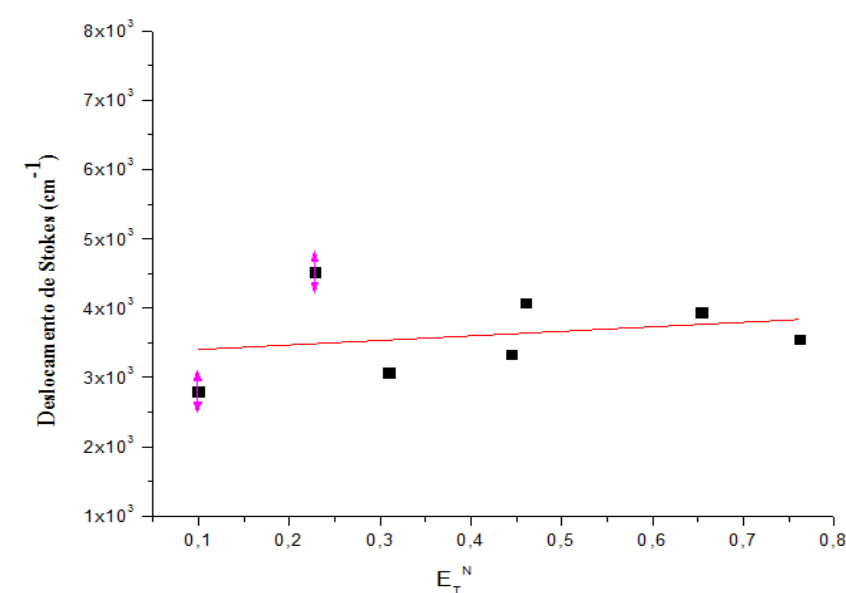

Gráfico 8. Lippert-Mataga do híbrido de 56B. 


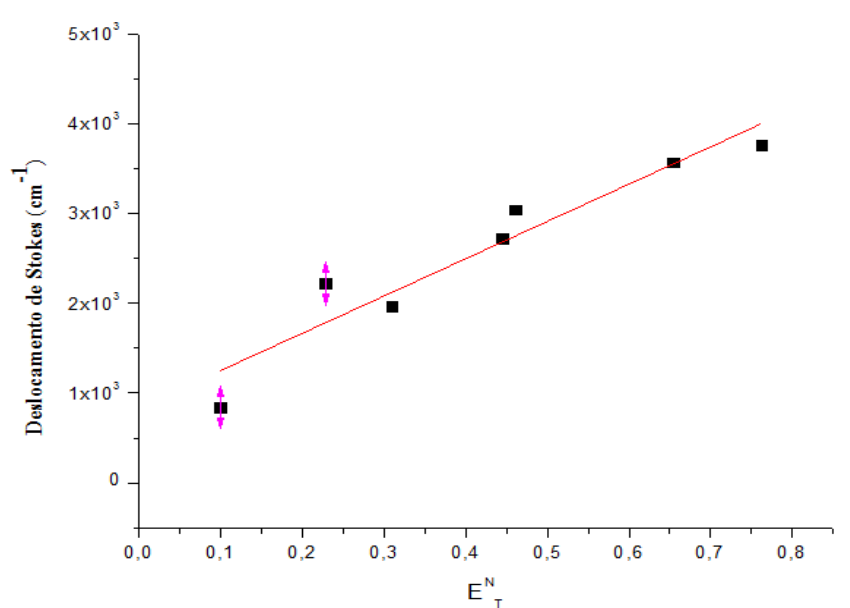

Gráfico 9. Lippert-Mataga do híbrido de 57B. 